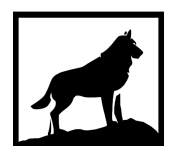

Michigan Technological

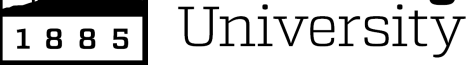

Michigan Technological University Digital Commons @ Michigan Tech

\title{
CAPILLARY-ASSISTED ENHANCED CONDENSATION HEAT
}

TRANSFER FOR LOW SURFACE TENSION LIQUIDS

Gnana Vishnu Durgam

Michigan Technological University, gdurgam@mtu.edu

Copyright 2018 Gnana Vishnu Durgam

\section{Recommended Citation}

Durgam, Gnana Vishnu, "CAPILLARY-ASSISTED ENHANCED CONDENSATION HEAT TRANSFER FOR LOW SURFACE TENSION LIQUIDS", Open Access Master's Thesis, Michigan Technological University, 2018.

https://doi.org/10.37099/mtu.dc.etdr/574

Follow this and additional works at: https://digitalcommons.mtu.edu/etdr

Part of the Heat Transfer, Combustion Commons, and the Manufacturing Commons 


\title{
CAPILLARY-ASSISTED ENHANCED CONDENSATION HEAT TRANSFER FOR LOW SURFACE TENSION LIQUIDS
}

\author{
By \\ Gnana Vishnu Durgam

\begin{abstract}
A THESIS
Submitted in partial fulfillment of the requirements for the degree of MASTER OF SCIENCE

In Mechanical Engineering
\end{abstract}

MICHIGAN TECHNOLOGICAL UNIVERSITY

2018

(C) 2018 Gnana Vishnu Durgam 
This thesis has been approved in partial fulfillment of the requirements for the Degree of MASTER OF SCIENCE in Mechanical Engineering.

Department of Mechanical Engineering - Engineering Mechanics

\author{
Thesis Advisor: $\quad$ Dr. Sajjad Bigham
}

Committee Member: Dr. Amitabh Narain

Committee Member: Dr. Kazuya Tajiri

Committee Member: $\quad$ Dr. Susanta Ghosh

Department Chair: $\quad$ Dr. William W. Predebon 


\section{Table of Contents}

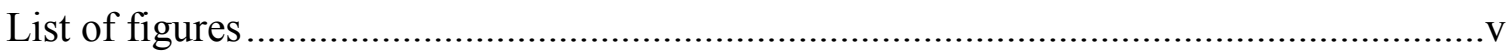

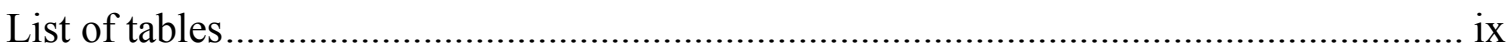

Preface

Acknowledgements .................................................................................................. xi

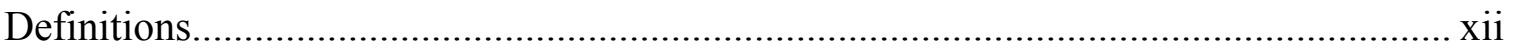

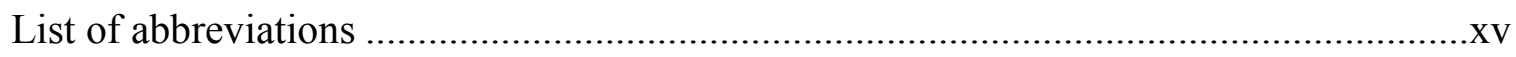

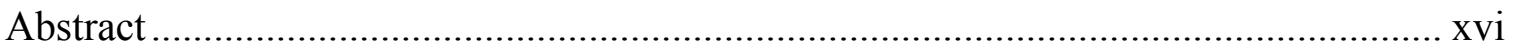

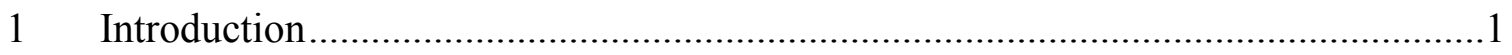

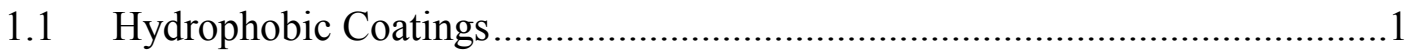

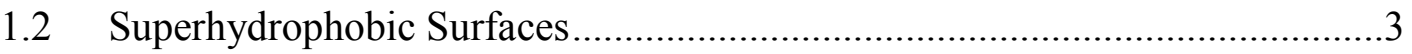

1.3 Jumping Droplet Effect …………………………....................................10

1.4 Low Surface Tension Liquids and Condensation............................................17

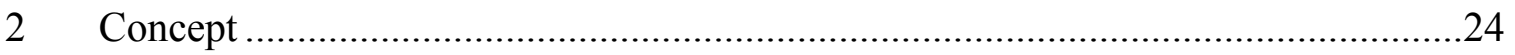

2.1 Capillary Assisted Condensate Removal ....................................................25

2.2 Capillary Assisted Condensate Removal with a Covering Mesh Layer .........31

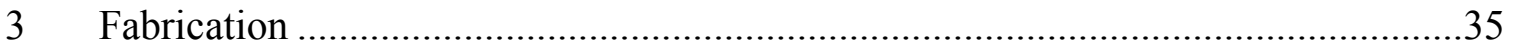

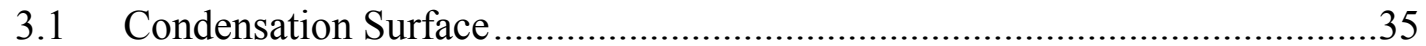

3.1.1 Preparation of the Individual Parts ...................................................35

3.1.2 $\mathrm{Cu}-\mathrm{Cu}$ Diffusion Bonding.................................................................

3.1.3 Machining of Channels on the Copper Mesh Surface ........................38

3.2 Condensation Surface with Cover Mesh ........................................................39

3.3 Heat Exchanger .......................................................................................

3.3.1 Machining of Individual Parts ........................................................ 41

3.3.2 Assembly of Heat Exchanger.................................................................

3.3.3 Fixing the Heat Exchanger to the Liquid Feedthrough.......................47

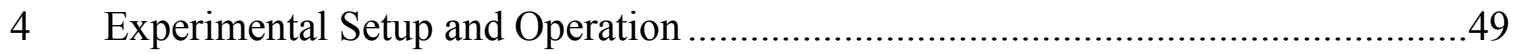

4.1 Condensation Test Setup Components......................................................51

4.1.1 Vacuum Chamber …………............................................................

4.1.2 Thermocouples and Data Acquisition System ...................................52 
4.1.3 Pressure Transducer, DC Power Source, and Multimeter ...............53

4.1.4 Heating Block and Cooling Water ...............................................54

4.1.5 Novec 7100 Dielectric Fluid ......................................................55

4.2 Assembly of the Experimental Setup .......................................................56

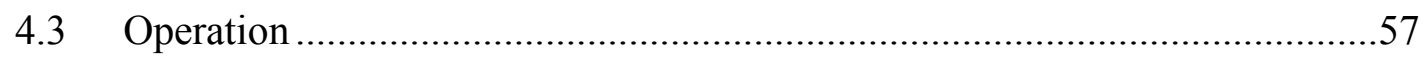

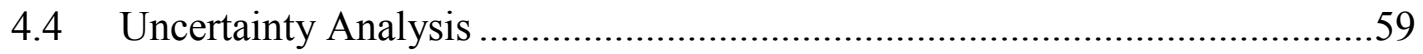

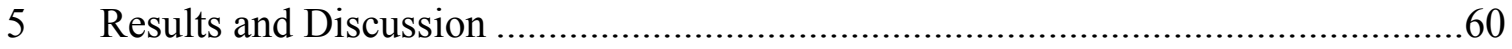

5.1 Performance Comparison of Water.........................................................61

5.2 Performance Comparison of Novec 7100 Fluid..........................................67

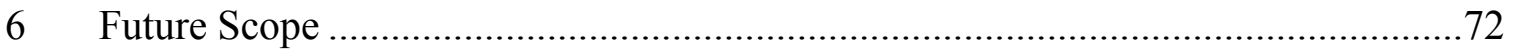

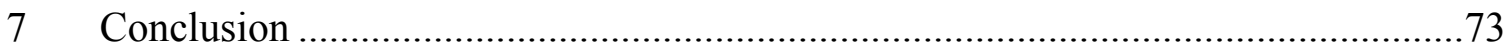

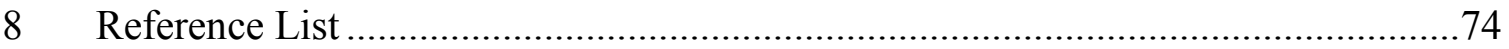

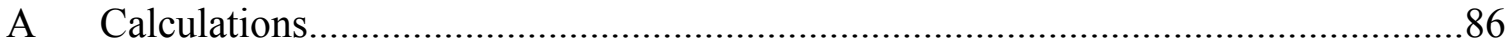

A.1 Calculation of Capillary Length for Novec 7100 .....................................86

A.2 Calculation of Meniscus Profile for Novec 7100 ........................................86

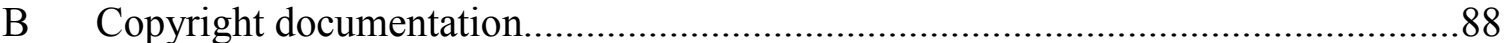




\section{List of figures}

Figure 1.1: Transition from suspended Cassie-Baxter state to pinned Wenzel state as condensation proceeds (Copyright of Narhe et al. [76]) .....................................4

Figure 1.2: Two-tier textures: micropillars are etched in silicon, and CNT nanopillars are subsequently deposited (Copyright of Chen et al. [80])

Figure 1.3: Coalescence of condensate drops on parylene-coated textures (Copyright of Chen et al. [80])) ...........................................................................................

Figure 1.4: Hydrophobic nanowires (Copyright of Wen et al. [81]) . ...............................6

Figure 1.5: Condensation rates on hydrophobic nanowires (Copyright of Wen et al. [81]).6

Figure 1.6: Nanocone structures and their performance (Copyright of Mouterde et al. [82]).....

Figure 1.7: Chemically homogeneous micropillar array (left) and microdroplets controlled on the tips of these pillars (right) Copyright of Mandsberg et al. [83])..7

Figure 1.8: $(\mathrm{a}, \mathrm{b})$ Mesh screen and magnified image of screen showing the 4 regions, and (c-f) magnified images showing the microstructures of the regions 1 (copper substrate), 2 (warp wire), 3 (weft wire with nanograss) and 4 (weft wire with micropits) (Copyright of Xie et al. [84])....................................................... 8

Figure 1.9: Growth of microdroplets on oxidized mesh screen (Copyright of Xie et al. [84])

Figure 1.10: Physical model of the mesh structure, droplet growth and thermal analysis (Copyright of Xie et al. [84]).

Figure 1.11: Comparison of microdroplet nucleation and growth between an array of hybrid micropillars of hydrophobic walls and hydrophilic tips, and an array of only hydrophobic micropillars (Copyright of Varanasi et al. [86]).

Figure 1.12: Demonstration of droplet jumping by electrowetting for different electrode configurations (Copyright of Lee et al. [87]).

Figure 1.13: Mechanism of droplet jumping (Copyright of Boreyko et al. [88])

Figure 1.14: Stages of droplet growth and subsequent removal of droplet by out-of-plane jumping (Copyright of Boreyko et al. [88]). 
Figure 1.15: Copper nanostructures produced through surface oxidation Copyright of Miljkovic et al. [92]).

Figure 1.16: Droplet growth dynamics and subsequent coalesce jumping during condensation (Copyright of Miljkovic et al. [92]).

Figure 1.17: Comparison of heat flux and heat transfer coefficient for various modes of condensation (Copyright of Miljkovic et al. [92]).

Figure 1.18: Comparison of heat flux for partially wetting, flat surface and suspended morphologies (Copyright of Miljkovic et al. [93]).

Figure 1.19: Variation of contact angle of droplets on copper surfaces with increasing levels of oxidation from. (a) to (g) (Copyright of Feng et al. [95]).

Figure 1.20: Condensation on nanostructures with varying levels of oxidation (density of nanostructures) (Copyright of Feng et al. [95]).

Figure 1.21: Demonstration of microscale glass particle removal, floating in the droplet (Copyright of Wisdom et al. [96]).

Figure 1.22: Demonstration of microscale glass particle by aggregation of condensing liquid (Copyright of Wisdom et al. [96]).

Figure 1.23: Hierarchical micropyramidal structures (Copyright of Chen et al. [97])......15

Figure 1.24: Droplet nucleation and growth on the hierarchical micropyramids (Copyright of Chen et al. [97]). .16

Figure 1.25: Droplet coalesce and out-of-plane jumping of condensed droplets (Copyright of Chen et al. [97]). .16

Figure 1.26: Schematic of jumping droplet assisted thermal diode (Copyright of Boreyko et al. [100])

Figure 1.27: Comparison of onset of frost formation between a hydrophobic surface and a superhydrophobic surface characteristic of jumping droplet (Copyright of Boreyko et al. [101]).

Figure 1.28: Comparison of freezing wave propagation between a hydrophobic surface, SHS with nano structures and SHS with hierarchical structures (Copyright of Chen et al. [102]).

Figure 1.29: SLIPS fabricated for condensation of low surface tension fluids (Copyright of Rykaczewski et al. [115]). 
Figure 1.30: Immiscibility tests conducted by Sett et al. [116] to determine working combination of lubricant and condensate (Copyright of Sett et al. [116])....

Figure 1.31: Conditions for selection of lubricant and working fluid combinations (Copyright of Sett et al. [116])......

Figure 2.1: Meniscus profile of Novec 7100 dielectric as calculated from Young-Laplace equation (Appendix A.2).

Figure 2.2: Condensation surface geometry.

Figure 2.3: Schematic of the condensation process from the cross-sectional top view of the surface.

Figure 2.4: Schematic of the condensation process from the cross-sectional side view of the surface.

Figure 2.5: Schematic of the cover mesh bonded condensation surface with dimensions.33

Figure 2.6: Schematic of the condensation process for the cover mesh bonded surface observed from the cross-sectional top view.

Figure 2.7: Schematic of the condensation process for the cover mesh bonded condensation surface as observed from the cross-sectional side view.

Figure 3.1: Image of the precisely machined and cleaned copper substrate (left), and the inter-woven copper mesh pieces cut to the required dimensions (right).

Figure 3.2: Progress of the experimental trials to arrive at a functional bonding of the copper meshes to the substrate.

Figure 3.3: Diffusion bonded copper substrate-mesh surface

Figure 3.4: Final condensation surface

Figure 3.5: Final condensation surface with cover mesh.

Figure 3.6: CAD model of the main body of the heat exchanger

Figure 3.7: CAD model of the cover plate (left) and the 1D column (right).

Figure 3.8: CAD model of the designed heat exchanger assembly.

Figure 3.9: Schematic of the assembled heat exchanger module with dimensions .46

Figure 3.10: Fabricated, brazed, and assembled heat exchanger module. 
Figure 4.1: Vacuum chamber with the viewport and KF40 T-junction.

Figure 4.2: Thermocouples (left), and the data acquisition system (right) used in the

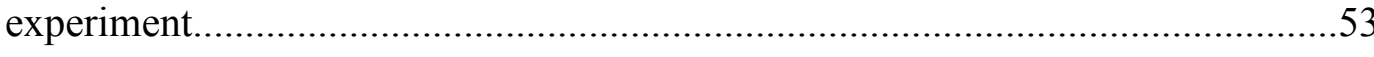

Figure 4.3: Pressure transducer - PX309-015AV model (left) with the DC power source (mid) and the Keithley 2700 multimeter (right). ................................................54

Figure 4.4: Schematic of Condensation Experimental Setup. ....................................57

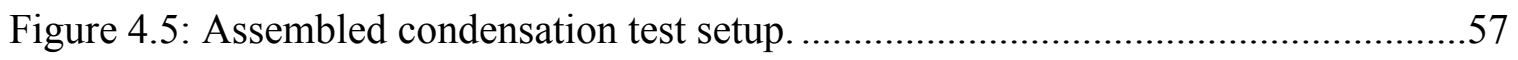

Figure 5.1: Heat flux of the plain surface and the capillary assisted condensation surface 1 at different subcooling temperatures for condensate water vapor. ....................63

Figure 5.2: Heat flux of the plain surface and the capillary assisted condensation surface land 2 at different subcooling temperatures for condensate water vapor.

Figure 5.3: Heat transfer coefficient comparison of plain surface with surface 1 and surface 2 (water).

Figure 5.4: Equivalent liquid film thickness for plain surface, surface 1, and surface 2 (water).

Figure 5.5: Heat flux of the plain surface and the capillary assisted condensation surface 1 at different subcooling temperatures for condensate Novec 7100 vapor. .68

Figure 5.6: Heat flux of the plain surface and the capillary assisted condensation surface 1and 2 at different subcooling temperatures for condensate Novec 7100 vapor...69

Figure 5.7: Heat transfer coefficient comparison of plain surface with surface 1 and surface 2 (Novec).

Figure 5.8: Equivalent film thickness for plain surface, surface 1, and surface 2 (Novec).71 


\section{List of tables}

Table 2.1: Specifications of the inter-woven copper meshes bonded to the copper substrate

Table 3.1: Specifications of the inter-woven copper meshes bonded to the copper substrate in the case of the surface with cover mesh layer.

Table 4.1: Specifications Properties of Novec 7100 Dielectric Fluid .55 


\section{Preface}

Introduction section consists of images from previously published journals. The images have been included to understand the research path that has been taken overtime to enhance the condensation performance of surfaces. The images are copyright of respective authors, are only provided to get better understanding of concepts and none of these have been reproduced in this thesis by any means. Appropriate citing has been included to credit the original papers and authors and official permission has been taken, for each image, to reference in this thesis. 


\section{Acknowledgements}

The entirety of this thesis has been carried out in the Multiphysics Energy Research Laboratory of Michigan Technological University in the years 2017-2018, under the guidance of Professor and Director of Multiphysics Energy Research Laboratory, Dr Sajjad Bigham.

I owe my deepest gratitude to my advisor, Dr. Sajjad Bigham, for being the cornerstone of this thesis and a constant source of encouragement and guidance throughout this thesis, right from the conceptual stages, to the fabrication stages, to the experimental stages and finally realizing the goal of this thesis.

I sincerely thank my lab partner, Mr. Mojtaba Hosseinnia, and the MEEM machine shop faculty, Mr. Martin Toth, Mr. Robert Kinney and Mr. Michael Goldsworthy for supporting me and helping me during the fabrication stages.

I thank Michigan Technological University and Multiphysics Energy Research Laboratory for giving me the opportunity to work on this thesis and successfully seeing it through. 


\section{Definitions}

The following are the definitions of the parameters used in this document. All the units are in SI systems.

$q^{\prime \prime}=$ Heat flux of the condensation surface $\left(\frac{\mathrm{kW}}{\mathrm{m}^{2}}\right)$

$\dot{m}=$ Mass flow rate of the cooling water $\left(\frac{\mathrm{kg}}{\mathrm{s}}\right)$

$C_{p}=$ Specific heat of water $\left(\frac{J}{k g-K}\right)=4184\left(\frac{J}{k g-K}\right)$

$T_{\text {out }}=$ Outlet temperature of the cooling water $\left({ }^{0} \mathrm{C}\right)$

$T_{\text {in }}=$ Inlet temperature of the cooling water $\left({ }^{0} \mathrm{C}\right)$

$T_{\text {sat }}=$ Saturation temperature of the working fluid $\left({ }^{0} \mathrm{C}\right)$

$T_{\text {surface }}=$ Surface temperature of the condensation surface $\left({ }^{0} \mathrm{C}\right)$

$A=$ Surface area of the condensation surface $\left(\mathrm{m}^{2}\right)=0.0004\left(\mathrm{~m}^{2}\right)$

$k_{c}=$ Thermal conductivity of copper $\left(\frac{W}{m-K}\right)=400\left(\frac{W}{m-K}\right)$

$k_{w}=$ Thermal conductivity of water $\left(\frac{W}{m-K}\right)=0.6\left(\frac{W}{m-K}\right)$

$k_{n}=$ Thermal conductivity of Novec $7100\left(\frac{W}{m-K}\right)=0.069\left(\frac{W}{m-K}\right)$ 


$$
\begin{aligned}
& \Delta T=T_{\text {sat }}-T_{\text {surface }}=\text { Subcooling }\left({ }^{0} \mathrm{C}\right) \\
& \Delta T_{c}=\text { Average temperature differenc between three holes in } 1 D \text { column }\left({ }^{0} \mathrm{C}\right) \\
& \text { Lor } t_{c}=\text { Average distance between three holes in } 1 D \text { column }(m) \\
& g=\text { Acceleration due to gravity }\left(\frac{m}{s^{2}}\right)=9.81\left(\frac{m}{s^{2}}\right)
\end{aligned}
$$$$
\text { Surface } 1=\text { Condensation surface without the cover mesh layer }
$$$$
\text { Surface } 2=\text { Condensation surface with the additional cover mesh layer }
$$$$
y=\text { Distance along the width of the channel }(m)
$$$$
z=\text { Height of the meniscus at } y(m)
$$$$
z_{0}=\text { Height of the meniscus at } y=0(m)
$$$$
h=\text { Heat transfer coefficient }\left(\frac{W}{m^{2}-K}\right)
$$$$
t_{f}=\text { Equivalent Film Thickness }(\mu m)
$$$$
\delta(\Delta T)=\text { Uncertainty in the subcooling temperature values }(K)
$$$$
\delta\left(\Delta T_{c}\right)=\text { Uncertainty in the } 1 D \text { column temperature difference values }(K)
$$$$
\delta t_{c}=\text { Accuracy of the machined holes in } 1 D \text { column }(\mathrm{m})
$$$$
\delta q^{\prime \prime}=\text { Uncertainty in the calculated heat flux values }\left(\frac{\mathrm{kW}}{\mathrm{m}^{2}}\right)
$$ 
$\delta h=$ Uncertainty in the calculated heat transfer coefficient values $\left(\frac{W}{m-K}\right)$

$\delta t_{f}=U n c e r t a i n t y$ in the calculated equivalent film thickness values $(\mu m)$ 


\section{List of abbreviations}

$\begin{array}{ll}\text { DC } & \text { - Direct Current } \\ \text { 1D } & \text { - One Dimensional column of the heat exchanger } \\ \mathrm{kPa} & - \text { kilo Pascal } \\ \text { MNPT } & \text { - Male National Pipe Thread } \\ \text { FNPT } & \text { - Female National Pipe Thread } \\ " & - \text { inches } \\ \text { mm } & - \text { millimeters } \\ \text { mV } & - \text { milli Volt } \\ \text { temp } & - \text { Temperature } \\ \text { HVAC } & - \text { Heating, Ventilation and Air Conditioning } \\ \text { hrs } & - \text { hours } \\ \text { SLIPS } & - \text { Slippery Liquid Infused Porous Surfaces }\end{array}$




\section{Abstract}

Extensive research has been carried out over the course of the last few decades to induce dropwise condensation as it offers 5 - 7 times better heat transfer performance compared to filmwise condensation process. A number of methods such as low surface energy hydrophobic coatings, surface modification of hydrophobic surfaces to fabricate micro, nano and hierarchical structures, and the recent incorporation of jumping droplet phenomenon have provided effective means to further enhance the condensation heat transfer. However, existing methods to enhance condensation heat transfer rate fail in the case of low surface tension, highly wetting liquids such as hydrocarbons, cryogens, and fluorinated dielectrics and refrigerants used in various industrial applications. Due to their extremely wetting behavior, such fluids almost always condense in a filmwise mode and the removal of the condensate other than by gravity has been a challenge. Here, we fabricate a novel capillary surface to decouple the removal of the condensate vapor from the condensing surface. The new surface consists of alternating capillary bridge and plain sections. The liquid condensing in the plain channels and the outer surfaces of the capillary bridge is wicked into the wick bridge, effectively decoupling the condensation surface and the condensate removal paths.

We have determined that the condensation performance of the fabricated surfaces is enhanced by a factor of 3 compared to a plain surface, and further enhanced by a factor of 4.5, compared to a plain surface, by bonding an additional cover mesh layer and decreasing the channels widths of the condensation surface. This proves that the concept 
of employing a capillary bridge greatly enhances the rate of condensation for low surface tension liquids such as dielectric fluids. Hence, the knowledge gained from this thesis will serve as basic guideline for designing new simple, cost effective, and scalable surface technologies with enhanced condensation heat transfer for widely used low surface tension liquids. 


\section{Introduction}

Condensation is a very common process occurring throughout in nature [1-5] and a very influential process, which plays significant role in a wide range of industrial applications [6-13]. Condensation heat transfer has been the subject of more than a century of research [14-24] undergoing numerous advances to augment the rate of heat transfer. Enhancement in the condensation heat transfer rate has huge ramifications in improving the efficiency of power generation, and thereby better utilization of world's energy resources [25-27]. Condensation also plays a significant role in many other applications such as water supply in regions of water scarcity through desalination technologies [2830], industrial heat exchangers, HVAC applications [31-34], fuel cells [35], thermal management of electronics [36], water harvesting [37, 38], nuclear reactors [1-3, 39, 40].

\subsection{Hydrophobic Coatings}

Most industrial clean metal surfaces provide reduced energy barrier for droplet nucleation during condensation process owing to their high surface energy [41]. Due to high wetting tendency of these surfaces, the condensate forms a liquid film on the surface. This liquid film acts as a thermal resistance reducing the condensation heat transfer. This mode of condensation is termed as filmwise condensation [14]. Schmidt et al. [14] first recognized the concept of dropwise condensation in 1930. They reported that the dropwise condensation improves the heat transfer rate by up to 7 times compared to the filmwise condensation [14]. There has been extensive research to understand mechanisms of nucleation and growth processes of condensing droplets [14, 52-67]. It has been identified that the major driving force for liquid transport off the condensing surface and 
replenishing the surface for further droplet nucleation is through gravity-induced droplet removal, when condensing droplets merge and reach a critical size close to their capillary length $(2.7 \mathrm{~mm}$ for water) [68-70]. Clean metals such as gold, silver, which were earlier believed to have filmwise condensation, were shown to promote dropwise condensation because of the adsorption of impurities and contaminants onto their surface thereby making the surface a low energy non-wetting surface with high contact angles [42-46]. Subsequently, industrial metals were coated with low energy non-wetting promoter materials such as long chain fatty acids, wax or gold or silver layers, which have the tendency to adsorb contaminants to ensure dropwise condensation. Marto et al. [47] showed that by coating polymer materials, gold, silver, dropwise condensation could be sustained for more than 12000 hrs with heat transfer coefficients of 6 times compared to the filmwise mode. Bonner et al. [48], Das et al. [51] and Vemuri et al. [49, 50] have shown the technique of self-assembled monolayers to form an ultra-thin coating of hydrophobic material, which provides negligible resistance to heat transfer and promotes dropwise condensation. Though the advantages of dropwise condensation heat transfer phenomenon was realized more than 80 years ago, a durable approach to sustain this mode in industrial conditions is yet to be realized. Low surface energy coatings although ensure effective dropwise condensation, the durability of these coatings for long term applications and in industrial conditions has been a roadblock for widespread implications of hydrophobic coating approaches [71, 72]. The hunt for robust coatings is still an ongoing research interest. 


\subsection{Superhydrophobic Surfaces}

With recent understanding of the superhydrophobic nature of the lotus leaf, a new approach of surface structuring to induce superhydrophobicity has been the topic of the last two decades of research. A hydrophobic surface when roughened results in air being filled in the pores created by roughening, thereby leading to a superhydrophobic surface. Condensation on these surfaces, termed Cassie-Baxter state [73], promotes highly mobile droplets resulting in easy removal of condensed liquid. Narhe et al. [74-76] experimentally investigated the nucleation and growth of droplets on roughened superhydrophobic surfaces. The spatial control of microstructuring and its effect on droplet condensation has been shown by Varanasi et al. [77]. They showed, as the condensation process proceeds, there is a transition from the Cassie-Baxter state to a highly pinned Wenzel state [74-78], where the liquid partially penetrates into the pores thereby increasing contact pinning. Figure 1.1 shows time-lapsed images of the transition from suspended Cassie-Baxter state to pinned Wenzel state with the growth of droplets during condensation, as investigated by Narhe et al. [76] 
(a)

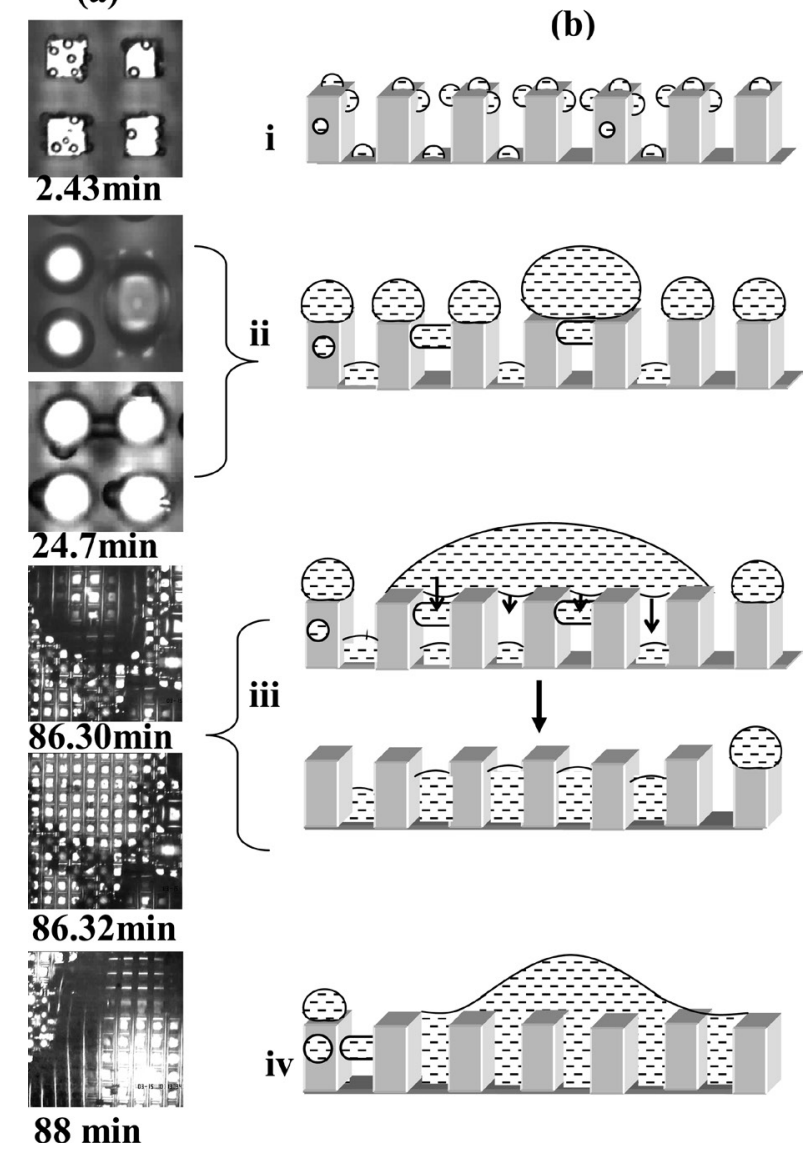

Figure 1.1: Transition from suspended Cassie-Baxter state to pinned Wenzel state as condensation proceeds (Copyright of Narhe et al. [76]).

Doerrer et al. [79] have studied this transition in detail where the micro-structured posts were coated with fluoropolymer. To achieve a sustained Cassie-Baxter state, Chen et al. [80] experimented with a two-tier hierarchical roughness, similar to a lotus leaf structure. A Silicon substrate was etched by deep reactive ion etching to create squared micropillars on top of which Carbon nanotubes were deposited by plasma enhanced vapor deposition. The substrate was then coated by a thin layer of parylene $\mathrm{C}$ or gold further coated by a monolayer of 1-hexadecanethiol. The resulting structure is as shown in Figure 1.2 [80]. 


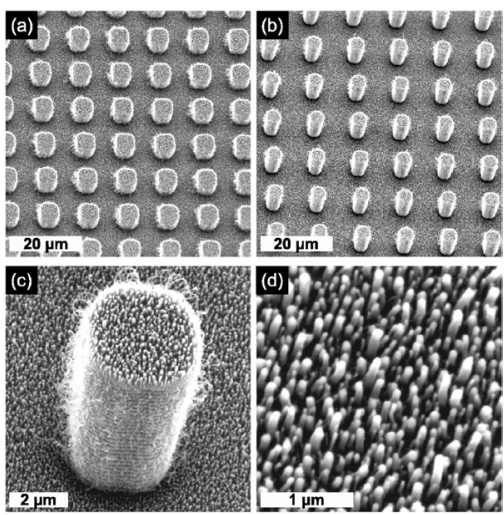

Figure 1.2: Two-tier textures: micropillars are etched in silicon, and CNT nanopillars are subsequently deposited. $(a, b)$ microstructures with two varying sets of dimensions, (c) single micropillar with carbon nanotubes, and (d) deposited carbon nanotubes (Copyright of Chen et al. [80]).
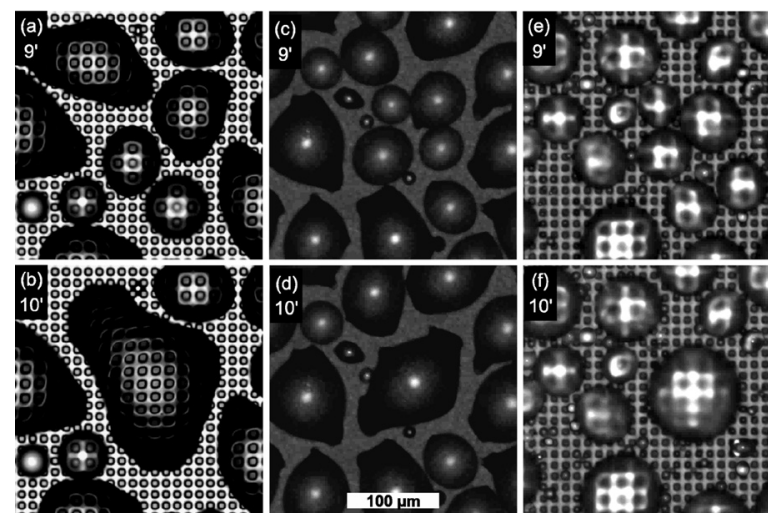

Figure 1.3: Coalescence of condensate drops on parylenecoated textures. $(a, b)$ condensate drops on only one-tier micropillars, (c, d) condensate drops on only one-tier nanopillars, and (e, f) condensate drops on two-tier micropillars deposited with nanopillars (Copyright of Chen et al. [80])).

It can be observed from Figure 1.3 that by using a combination of hierarchical micropillars with nanopillars ((e), (f)), spherical droplets typical of Cassie-Baxter state can be obtained before and after condensation as shown by Chen et al. [80].

Wen et al. [81] showed enhanced condensation rates by structuring high aspect ratio nanowires and reducing the permeability of water vapor between copper nanowires. A copper substrate was cleaned to remove impurities and oxides and high aspect ratio nanowires were deposited by a two-step porous anodic alumina (PAA) template-assisted electro-deposition method. The structures were then immersed in an ethanol solution of n-octadecanethiol and n-octadecyl mercaptan to make them hydrophobic [81]. The resulting aspect ratio structures were shown in Figure 1.4 [81]. The high aspect ratio was responsible for reduced diffusion of vapor between the nanowires and condensation occurred at the tips of the nanowires. Wen et al. [81] were able to achieve high heat fluxes for surface subcooling greater than $5 \mathrm{~K}$ as shown in Figure 1.5 [81]. 

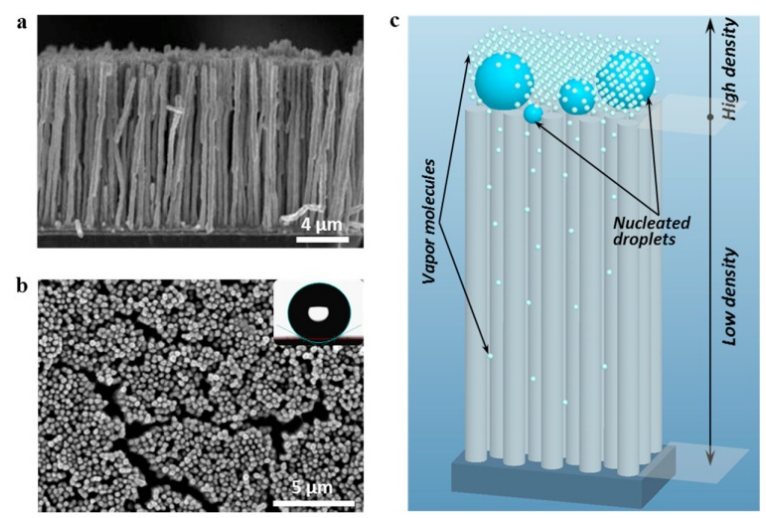

Figure 1.4: Hydrophobic nanowires (Copyright of Wen et al. [81]).

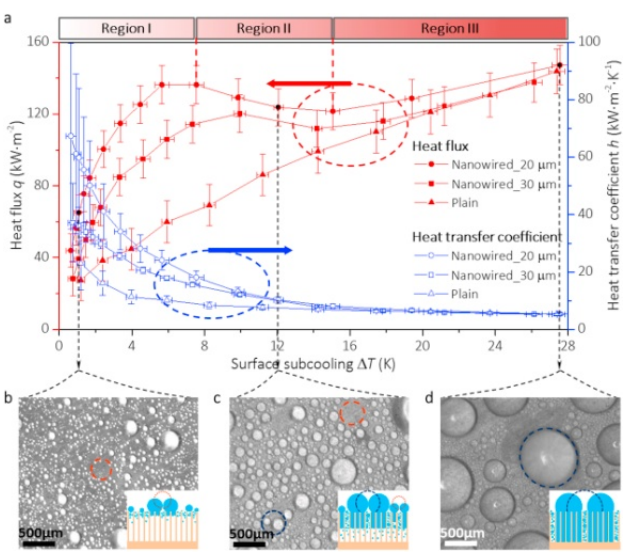

Figure 1.5: Condensation rates on hydrophobic nanowires. (a) heat transfer performance, (b) jumping condensation, (c) mixing condensation, and (d) dropwise condensation (Copyright of Wen et al. [81]).

Shaping the nanopillars, as cones, resulting in a nanocone array, similar to the nanostructures on cicada wings, seemed to have higher superhydrophobic performance and antifogging abilities even for microdroplets as investigated by Mouterde et al. [82].

Figure 1.6 shows the structure of nanocones and their effect on micro sized droplets.
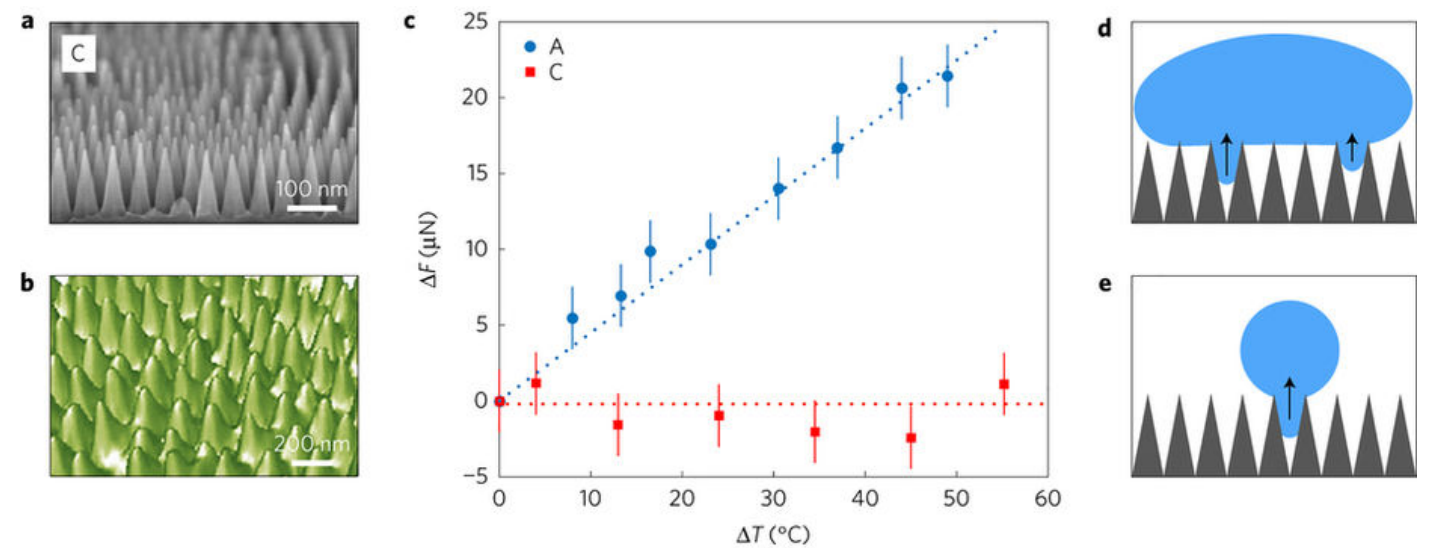

Figure 1.6: Nanocone structures and their performance. (a) nanocone array structured on the substrate, (b) structures on cicada wings, (c) adhesive force comparison between nanocylinder array (A-blue) and nanocone array (C-red) with temperature, and (d), (e) varying droplet sizes on nanocones (Copyright of Mouterde et al. [82]).

Mandsberg et al. [83] fabricated a chemically homogeneous micro pillar array by photolithography and treated to obtain a self-assembled monolayer of 
perfluorodecyltrichlorosilane to make it hydrophobic [83]. They showed that by having control over the micropillar dimensions and spacing, and also the way by which the vapor is introduced onto the surface, spatial control of condensing microdroplets is possible (cf. Figure 1.7) [83].

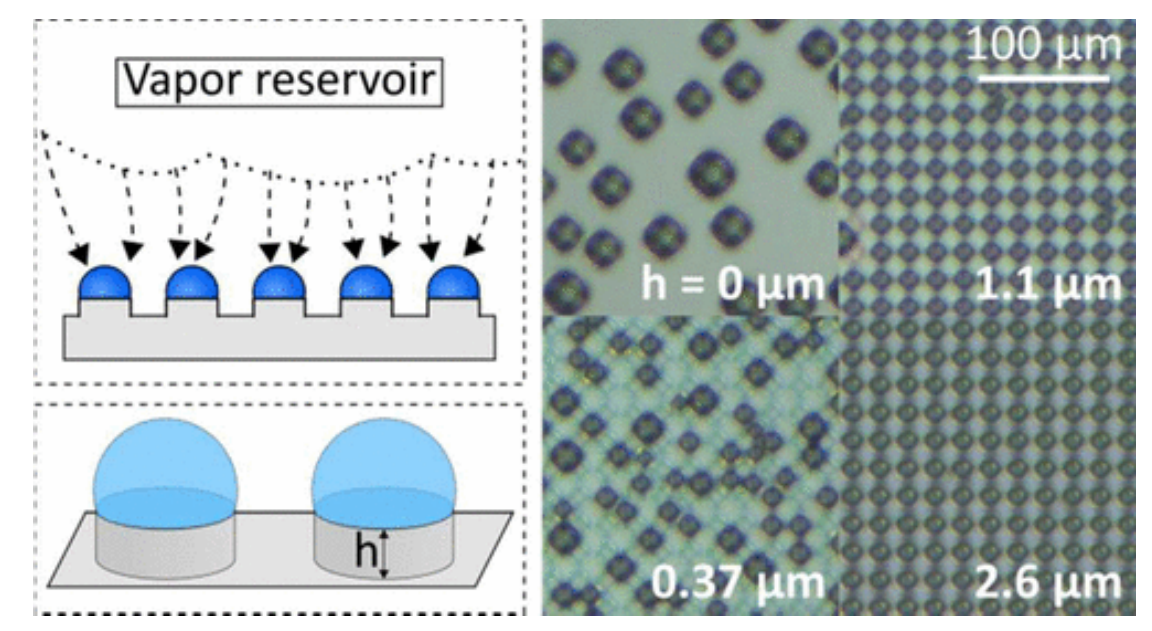

Figure 1.7: Chemically homogeneous micropillar array (left) and microdroplets controlled on the tips of these pillars (right) Copyright of Mandsberg et al. [83]).

A novel cost effective method to spatially control a condensing microdroplet array was experimented by Xie et al. [84]. They fabricated a surface by sintering a copper mesh on to a copper block. Commercially available mesh screens of varying pore sizes provided an easy and economical way to control the spacing and dimensions. After subjecting the meshed substrate to oxidization, they found that various parts of the mesh were subjected to varying levels of oxidization due to the non-uniform distribution of stresses in the mesh, as shown in Figure 1.8 [84]. On the same weft wires itself, region 3 (Figure 1.8 (b), (e)) achieved a dense population of nano-rods/grass making it hydrophobic whereas region 4 (Figure 1.8 - (b), (f)) was over-oxidized and resulted in micropits making it hydrophilic. This surface gradient resulted in the microdroplets condensing only on the 
region 4 areas, thereby creating a controlled microdroplet condensation array as shown in Figure 1.9 [84]. Nam et al. [85] also made a detailed comparative study to understand the effect of varying levels copper oxidation on their wettability behavior.
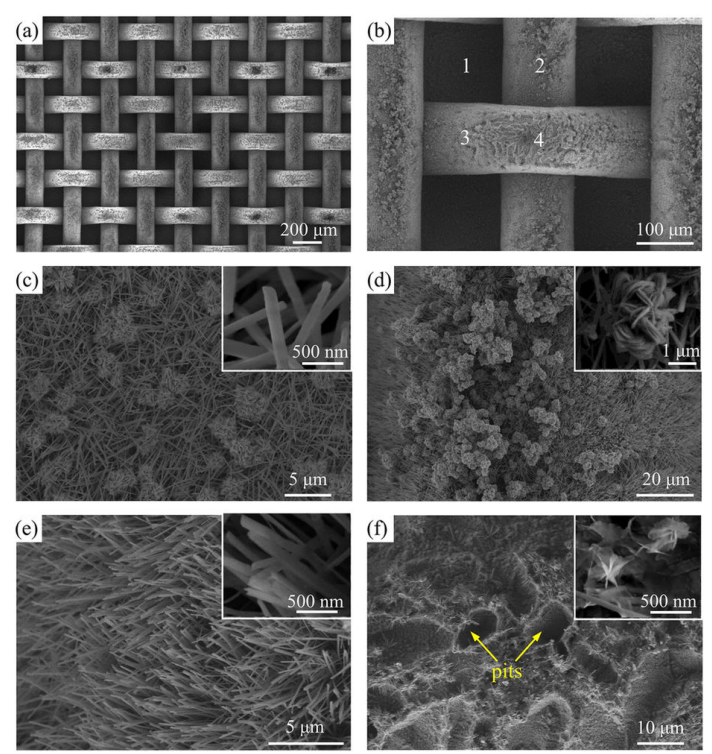

Figure 1.8: (a, b) Mesh screen and magnified image of screen showing the 4 regions, and (c-f) magnified images showing the microstructures of the regions 1 (copper substrate), 2 (warp wire), 3 (weft wire with nanograss) and 4 (weft wire with micropits) (Copyright of Xie et al. [84]).
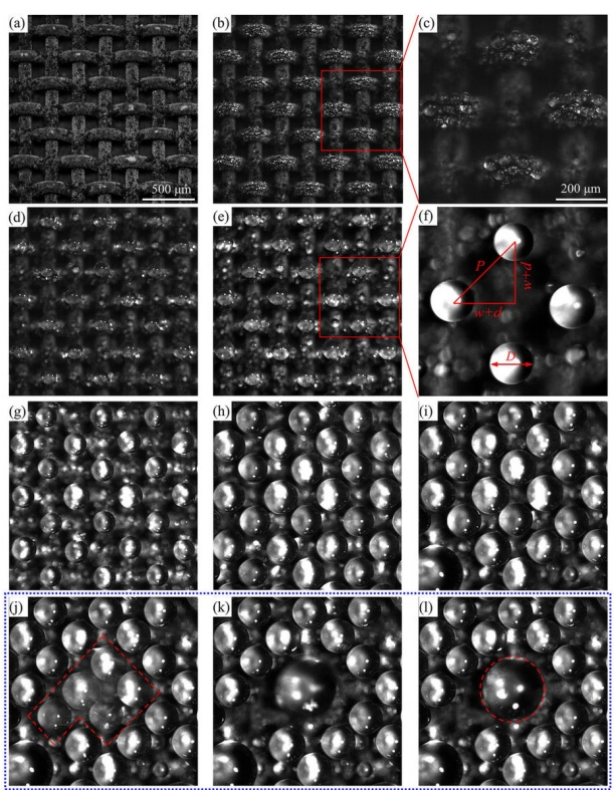

Figure 1.9: Growth of microdroplets on oxidized mesh screen (Copyright of Xie et al. [84]). 


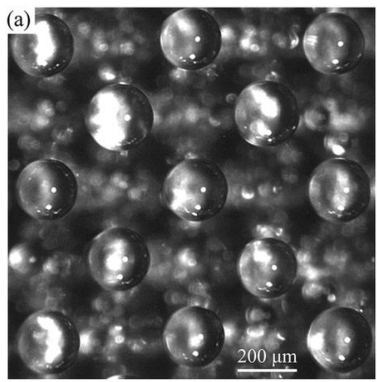

(c)

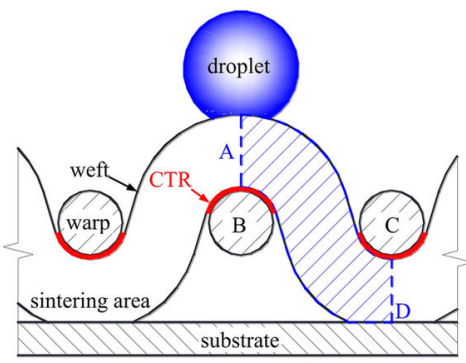

(d)

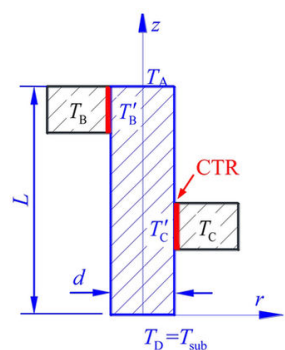

Figure 1.10: Physical model of the mesh structure, droplet growth and thermal analysis (Copyright of Xie et al. [84]).

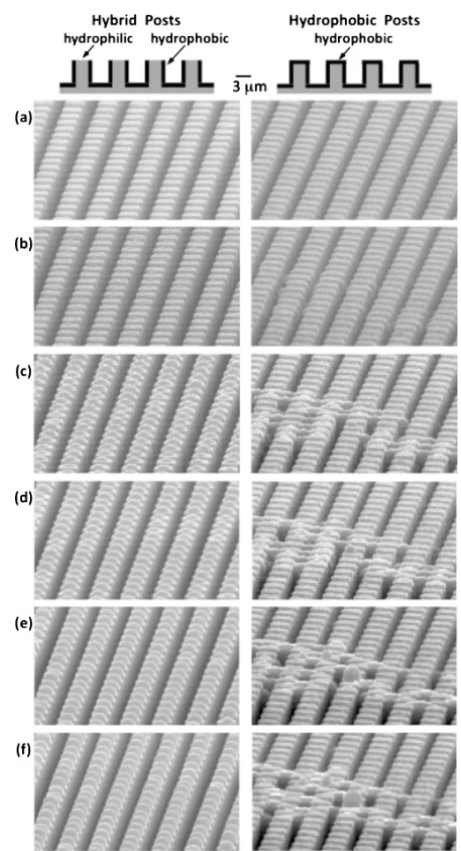

Figure 1.11: Comparison of microdroplet nucleation and growth between an array of hybrid micropillars of hydrophobic walls and hydrophilic tips, and an array of only hydrophobic micropillars (Copyright of Varanasi et al. [86]).

Taking inspiration from the Namib beetle, Varanasi et al. [86] fabricated a novel hybrid micropillar array consisting of hydrophobic posts and hydrophilic tips, and thus effectively creating a wettability gradient on the same micropillar. The microstructures were fabricated by a combination of lithography and a UV-assisted surface modification technique. The micropillar walls and substrate channels were made hydrophobic with fluorinated hydrocarbons while the pillar tips were made hydrophilic by a deposition of silicon dioxide. The condensation experiments showed that these hybrid micropillars promoted condensation preferentially on the tips compared to completely hydrophobic micropillars, which showed droplet nucleation and growth with any spatial preference as shown in Figure 1.11 [86]. 
Removal of condensed droplets from the surface for further condensation forms an integral part of any approach to enhance condensation heat transfer performance. Lee et al. [87] (Figure 1.12) investigated the concept of electrowetting of the condensation surface. In this method, an externally applied voltage stretches a sessile droplet due an axisymmetric balance of electrowetting forces. During the stretching, energy is stored in the droplet and when the voltage is cut off, the stored energy is released in the form of kinetic energy thus providing the extra energy to overcome the energy barrier and making the droplets jump off the surface as shown in Figure 1.12. This concept is a novel approach of applying an external force to remove droplets off a condensing surface, and thus enhancing condensation heat transfer rate.

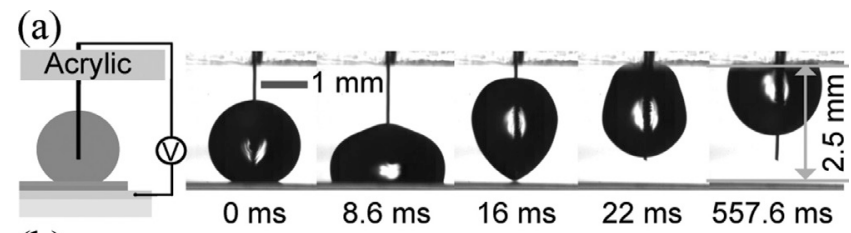

(b)

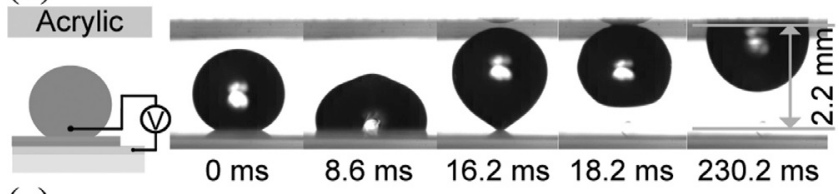

(c)

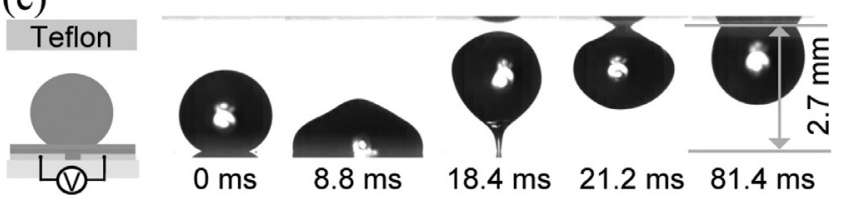

Figure 1.12: Demonstration of droplet jumping by electrowetting for different electrode configurations (Copyright of Lee et al. [87]).

\subsection{Jumping Droplet Effect}

Jumping droplet phenomenon is the recent advancement and state-of-the-art mechanism for easy removal of the condensing droplets off the surface for condensation heat transfer 
enhancement. This phenomenon occurs when the condensing droplets coalesce and release the extra surface energy in the form of kinetic energy, thereby resulting in out of plane jumping of the droplet, irrespective of gravity. Boreyko et al. [88], Dietz et al. [89], and Enright et al. [90, 91] explored thoroughly the mechanism of jumping droplet as shown in Figure 1.13 and Figure 1.14. The jumping drop mode is present when a superhydrophobic surface is precisely designed in an optimum range. This phenomenon has added a new dimension to effectively remove condensate from the surface and refresh the surface for re-nucleation. The jumping droplet effect has been extensively studied for a number of applications and still is an actively pursued research interest.

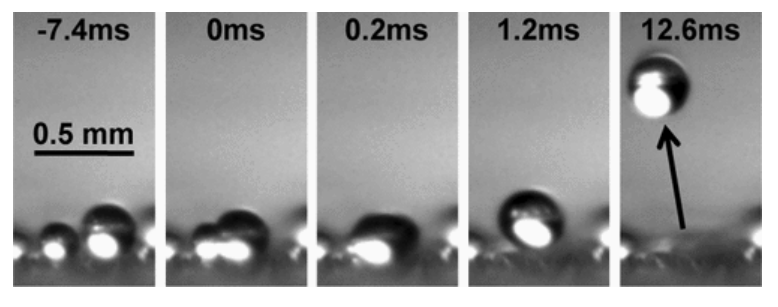

Figure 1.13: Mechanism of droplet jumping (Copyright of Boreyko et al. [88]).

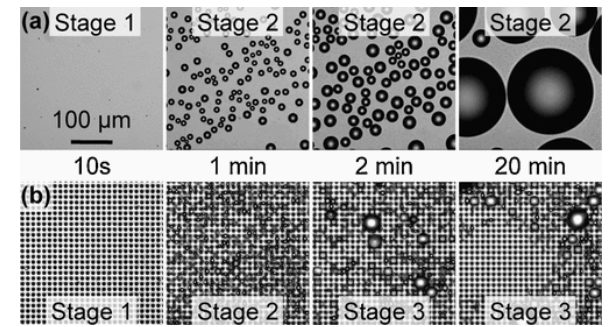

Figure 1.14: Stages of droplet growth and subsequent removal of droplet by out-of-plane jumping (Copyright of Boreyko et al. [88]).

Miljkovic et al. [92, 93] produced knife like copper oxide nanostructures of approximately $1 \mu \mathrm{m}$ characteristic length on copper tubes through a simple immersion of the substrate in an alkaline solution. This fabrication approach resulted in oxidation and deposition of a layer fluorinated silane, making substrate superhydrophobic, as shown in Figure 1.15. They studied the droplet growth dynamics as shown in Figure 1.16. Condensation experiments with various structures showed a $25 \%$ higher overall heat flux and $30 \%$ higher heat transfer coefficient on the copper nanostructures at low super saturations owing to the spontaneous out-of-plane jumping of droplets clearing the 
surface for re-nucleation (cf. Figure 1.17). Miljkovic et al. [93] also performed a detailed heat transfer analysis of various droplet morphologies such as partially wetting and suspended with respect to the jumping droplet effect shown in Figure 1.18.
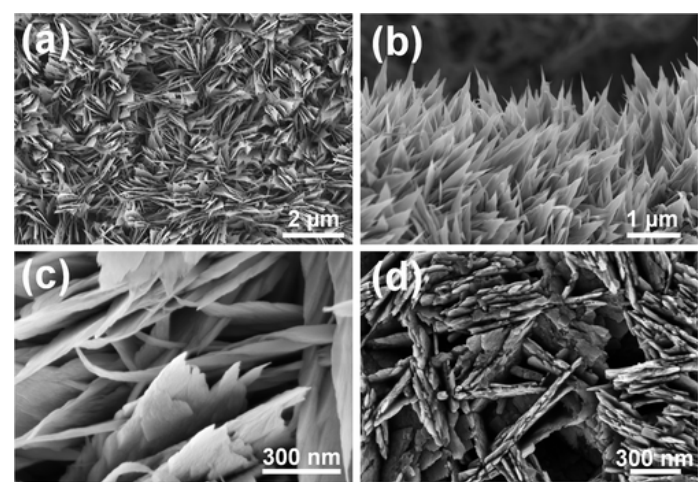

Figure 1.15: Copper nanostructures produced through surface oxidation. (a-c) and structures after silane deposition, and (d) Copyright of Miljkovic et al. [92]).

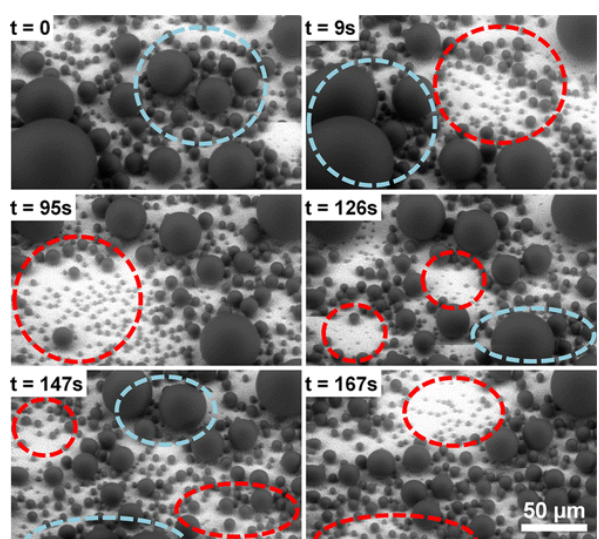

Figure 1.16: Droplet growth dynamics and subsequent coalesce jumping during condensation (Copyright of Miljkovic et al. [92]).
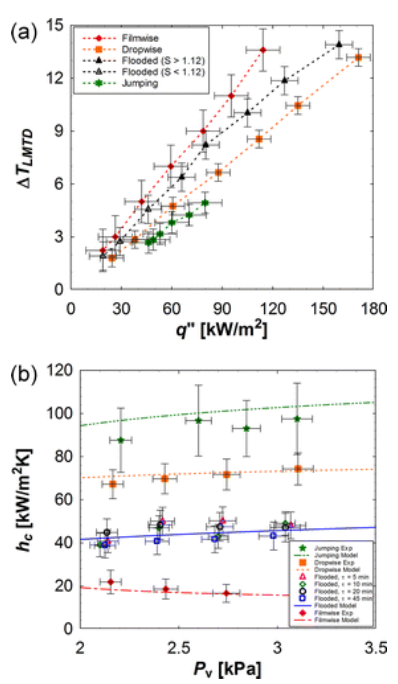

Figure 1.17: Comparison of heat flux and heat transfer coefficient for various modes of condensation (Copyright of Miljkovic et al. [92]).

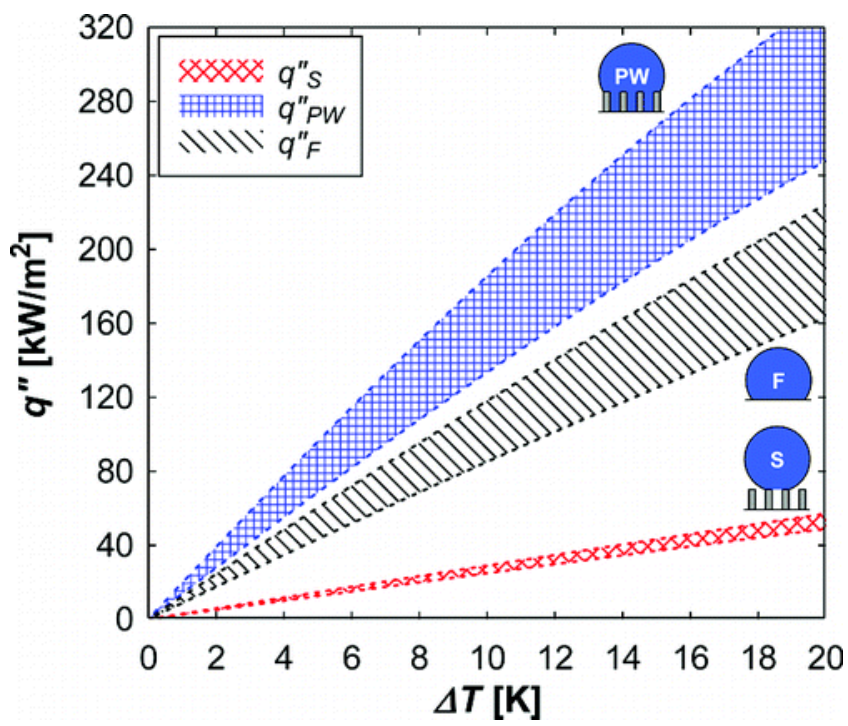

Figure 1.18: Comparison of heat flux for partially wetting, flat surface and suspended morphologies (Copyright of Miljkovic et al. [93]). 
Rykaczewski et al. [94] also explored the effect of micro topology of superhydrophobic surfaces on wetting states and droplet coalescence dynamics during condensation by fabricating varying dimensions of superhydrophobic surfaces with truncated microcones. Feng et al. [95] also investigated the various factors influencing the jumping droplet condensation. They fabricated a series of copper substrates with varying levels of oxidation to produce nanostructures and varying levels of fluorization and showed that these factors play a significant role in the coalescence jumping droplet performance (cf.

Figure 1.19 and Figure 1.20).

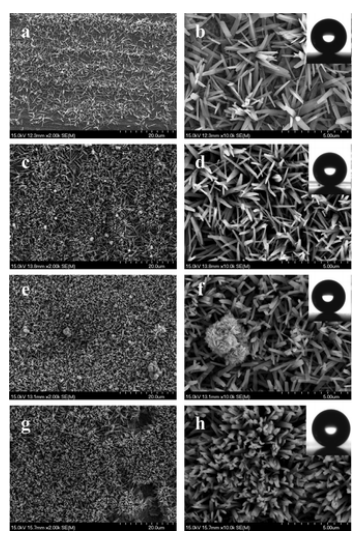

Figure 1.19: Variation of contact angle of droplets on copper surfaces with increasing levels of oxidation from (a) to (g) (Copyright of Feng et al. [95]).

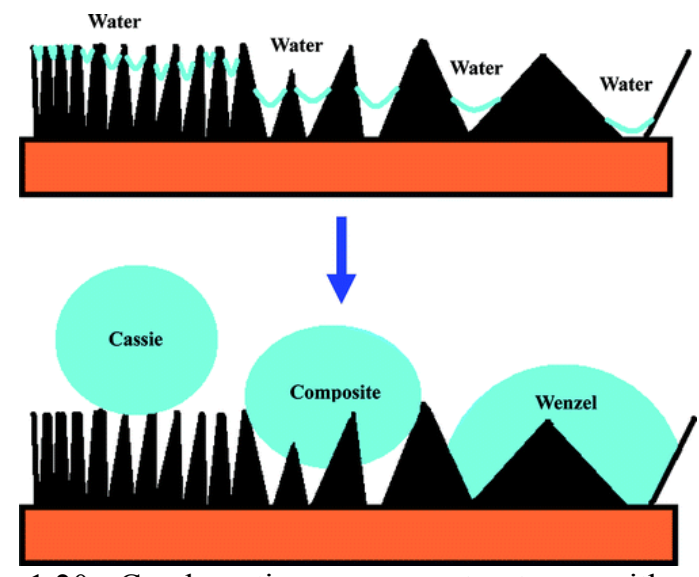

Figure 1.20: Condensation on nanostructures with varying levels of oxidation (density of nanostructures) (Copyright of Feng et al. [95]).

Wisdom et al. [96] demonstrated that the self-propelled jumping droplet effect can be used as an effective means for self-cleaning of contaminants from surfaces, as inspired from the cicada wings. They showed that when a contaminated superhydrophobic surface typical of a cicada wing is subjected to atmospheric condensation, the contaminants either attach to the air-liquid interface or detach into the bulk liquid, of the droplet. When these microscale droplets containing the liquid coalesce, the surface energy released propels the droplets along with contaminants out of the condensing surface, there 
removing the contaminants from the surface. Figure 1.21 and Figure 1.22 show the process of contaminant removal when the contaminant is floating in the bulk liquid or when the contaminants are collected by the aggregating liquid respectively. They also showed that this method of removing the contaminants is highly effective when compared with other natural cleaning processes such as wind shear or mechanical vibration approaches.

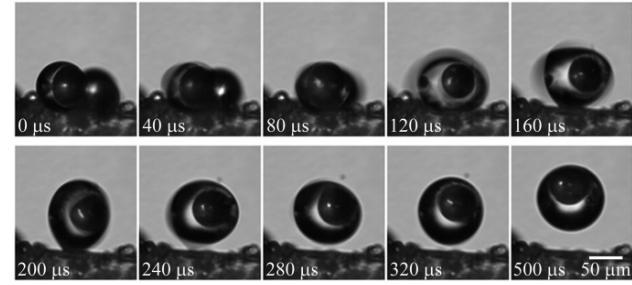

Figure 1.21: Demonstration of microscale glass particle removal, floating in the droplet (Copyright of Wisdom et al. [96]).

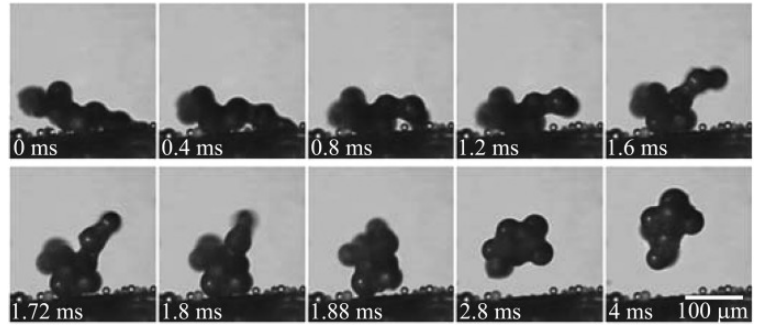

Figure 1.22: Demonstration of microscale glass particle by aggregation of condensing liquid (Copyright of Wisdom et al. [96]).

Overall condensation heat transfer can be enhanced if the rate of droplet growth can be enhanced. This requires a hydrophilic surface though. At the same time, the rate of droplet removal from the surface should be enhanced to sustain dropwise condensation and enable faster re-nucleation. This typically is favored by hydrophobic surfaces. Chen et al. [97] engineered a hierarchical micropyramidal surface and showed that these two conflicting effects, that is, both the hydrophilic and hydrophobic effects can be achieved and droplets can be made to coalesce and be removed from the surface by the out-ofplane jumping phenomenon. The fabricated hierarchical micropyramidal structures are as shown in Figure 1.23 [97]. 
(a)

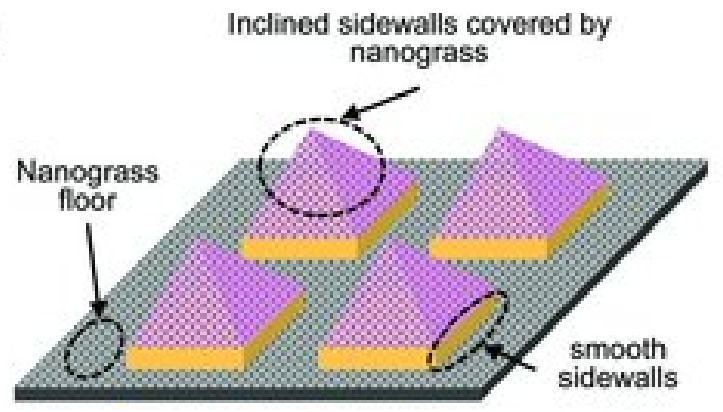

(b)

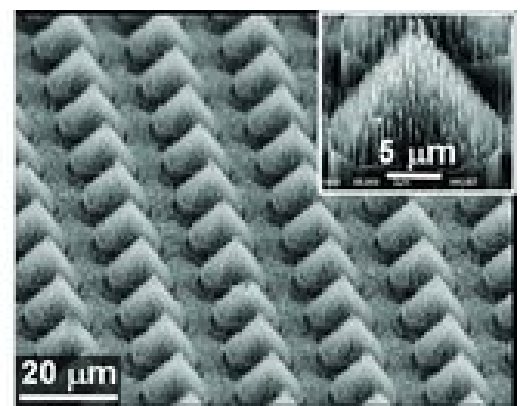

Figure 1.23: Hierarchical micropyramidal structures (Copyright of Chen et al. [97]).

The micropyramids were fabricated by standard photolithography, anisotrophic etching of silicon, and controlling the etching time. A deep reactive ion etching (DRIE) process was used to produce the nanopillars. The base walls of the micropyramids were made smooth by over-etching and the height of the nanopillars was reduced. The structures were further treated to make them hydrophobic. As a result, the smooth sidewalls of the micropyramids were hydrophilic whereas the inclined walls of the pyramids and the space between the pyramids comprising of nanopillars were hydrophobic. During condensation, the droplet nucleation occurred at the smooth sidewalls and as the droplets increased in size over the nanopillars and coalesced, the droplets jumped off the surface. Hence, they showed an enhanced droplet growth rate and droplet removal rate could be achieved. Figure 1.24 and Figure 1.25 show the droplet growth and removal respectively on this surface.

Jumping droplets due to their interaction with the hydrophobic surfaces were found to attain a positive charge. In addition to the advantage of easy droplet removal, this charge could also be harvested to generate low levels of electric power by making the droplet jump from hydrophobic surfaces to hydrophilic surfaces as discovered by Miljkovic et al. [98]. They also found that by subjecting the condensing surface to an electric field, any 
possibility of return of the positively charged jumping droplets back to the condensation surface could be eliminated [99].
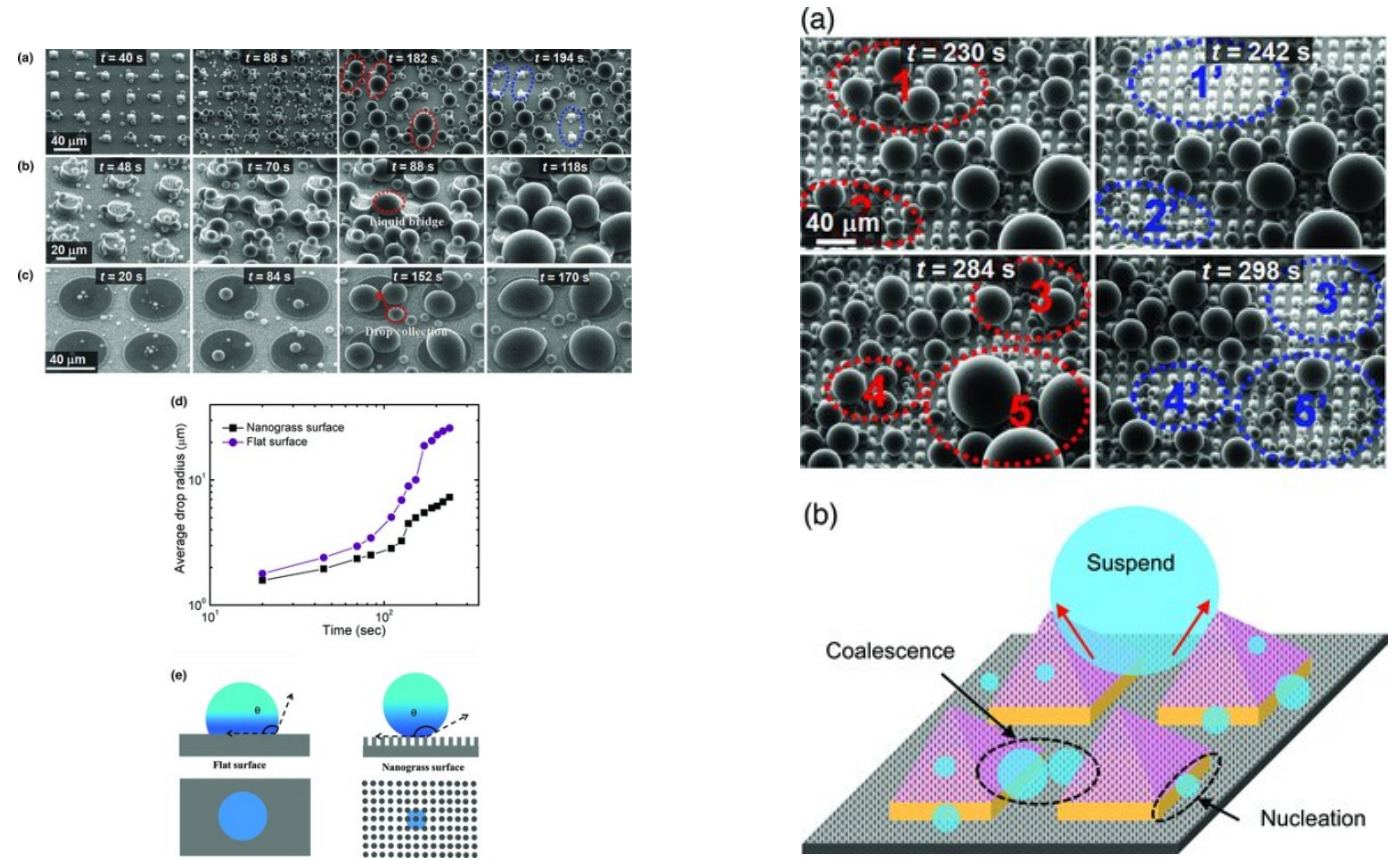

Figure 1.24: Droplet nucleation and growth on the hierarchical micropyramids (Copyright of Chen et al. [97]).

Phase-change thermal diodes also make use of the jumping droplet effect to provide an effective means of heat transfer between the cooling surface and the surface to be cooled. By placing both the surfaces close to each other, the vapor condenses on the cooler superhydrophobic surface and due to the jumping droplet effect, the condensed droplets jump, attach to the hot superhydrophilic surface, and hence are evaporated. The vapor produced further condenses on the cold surface and the cycle continues, thereby effectively transferring the heat from the hot surface to the cold surface without an external means as shown in Figure 1.26. 

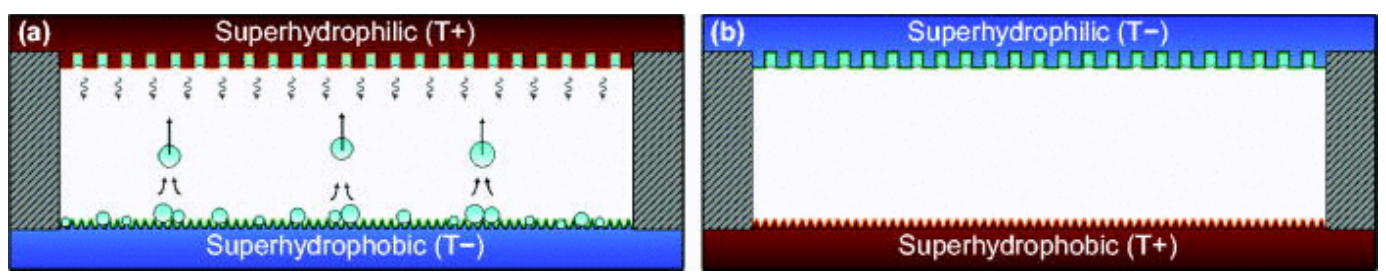

Figure 1.26: Schematic of jumping droplet assisted thermal diode (Copyright of Boreyko et al. [100]).

Jumping droplet phenomenon was discovered to suppress frost formation and also enabled easy defrosting as shown by Boreyko et al. [101], Chen et al. [102], and Zhang et al. [103] (cf. Figure 1.27 and Figure 1.28).
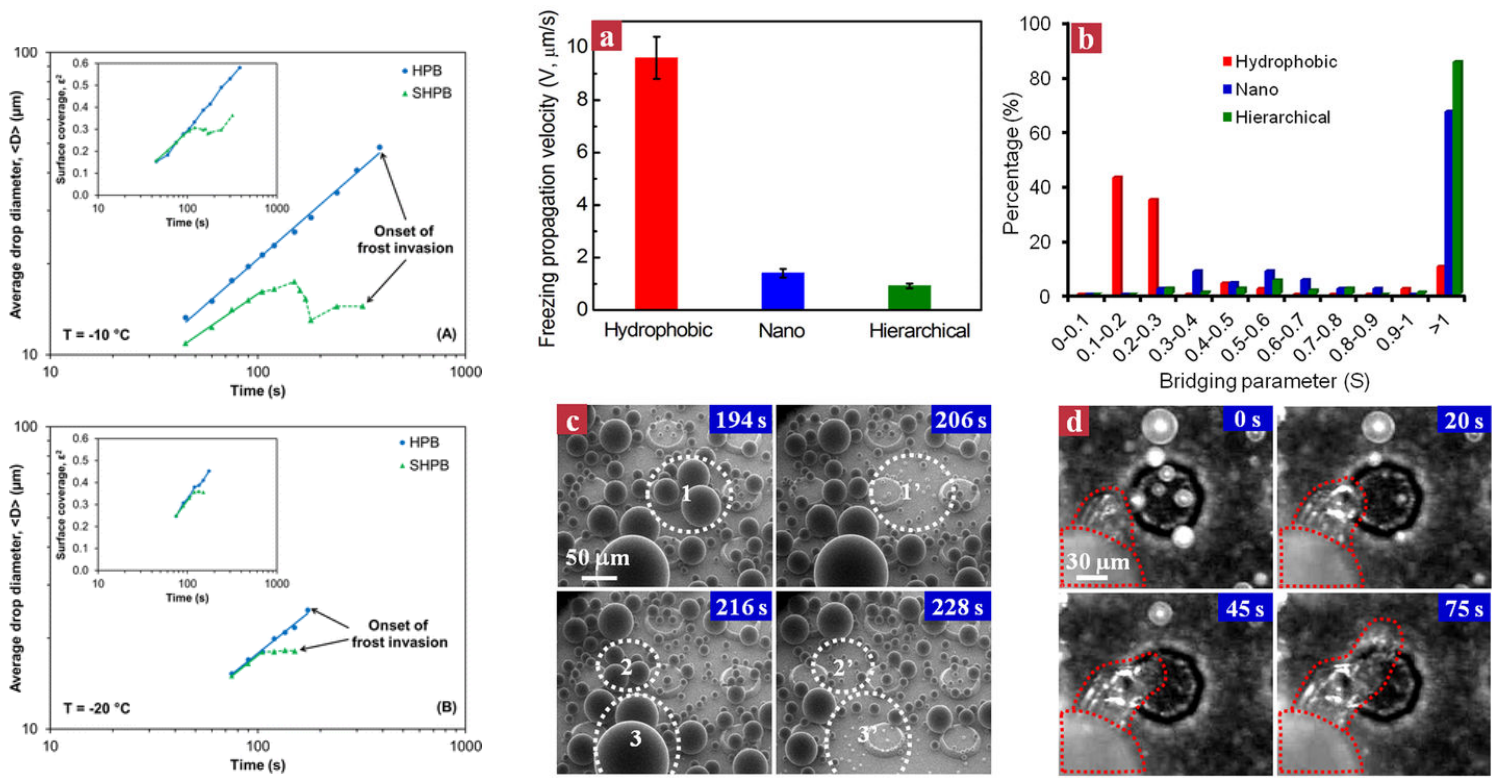

Figure 1.27: Comparison of onset of frost formation between a hydrophobic surface and a superhydrophobic surface

Figure 1.28: Comparison of freezing wave propagation between a hydrophobic surface, SHS with nano structures and SHS with hierarchical structures (Copyright of Chen et al. [102]). characteristic of jumping droplet (Copyright of Boreyko et al. [101]).

\subsection{Low Surface Tension Liquids and Condensation}

Although active pursuit of enhancing the condensation heat transfer performance has been carried out over the past century from the industrial and academic fronts, most of the research has been concentrated with water as the working fluid. There has been little 
motivation to do the same for low surface tension fluids. However, low surface tension fluids such as hydrocarbons, refrigerants, alcohols are widely present in many industrial applications, and there is an ever-increasing need to enhance the condensation of these low surface tension liquids. Such fluids have been a significant part of industries such as chemical plants [105], food industry as low temperature storage medium [106], natural gas production and biomass combustion applications [107, 106] and increasingly in HVAC applications [108, 109].

Low surface tension liquids owing to their extreme wetting behavior typically end up in a filmwise condensation mode, and the only means for condensate removal is through gravity. The filmwise mode demonstrates a significant thermal barrier for condensation reducing the condensation heat transfer rate. All conventional approaches described in the previous sections to promote dropwise condensation fail in the case of low surface tension liquids. Although recent attempts were made to induce dropwise condensation and enhance condensation performance of the completely wetting liquids, the results have not been as significant as expected and also presented their own set of new challenges. Realizing the importance of this domain, research has picked up a good interest in this regard and is quickly becoming a hot topic in the condensation research community. Recent investigations in employing Slippery Liquid Infused Porous Surfaces (SLIPS) to promote dropwise condensation for water proved to be highly effective in enhancing condensation performance $[20,110-114]$, although there were unique challenges to be further investigated. Rykaczewski et al. [115] explored the concept of employing these SLIPS surfaces for low surface tension liquids and performed experimental investigations 
with a number of surfaces and working fluids. The surfaces fabricated and tested are shown in Figure 1.29. They showed that the three surfaces fabricated in the nano to micro scales, before impregnating with the lubricant, resulted in complete wetting by the low surface tension fluids over time and always resulted in filmwise condensation mode. Only the re-entrant superomniphobic surfaces showed signs of Cassie-Baxter state for few of the working fluids but even then finally resulted in a filmwise condensation. Only after impregnation of condensing surface with a suitable lubricant, there was continuous formation and shedding of droplets. For a few of the working fluids, dropwise mode was observed, but ultimately even these surfaces resulted in filmwise condensation mode for fluids such as perfluorohexane, ethanol and isopropanaol, although with better heat transfer performances due to continuous shedding and hence a lower thickness condensate film on the surface. The nanostructured surface with the lubricant infused showed better performance of the three and promoted dropwise condensation for a better range of fluids.
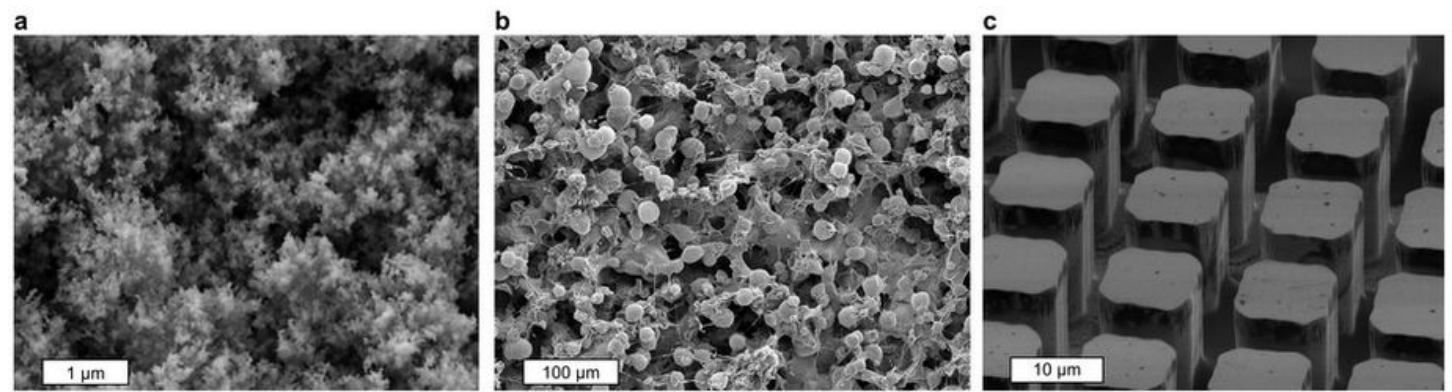

d
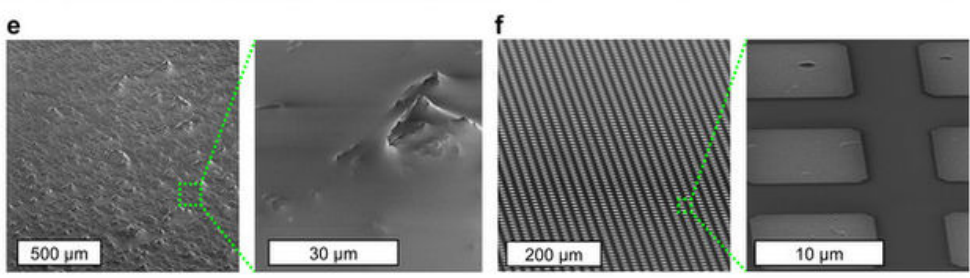
Figure 1.29: SLIPS fabricated for condensation of low surface tension fluids: (a) alumin-silica nanostructures, (b) re-entrant superomniphobic surface, (c) microposts fabricated via photolithography, and (d-f) surfaces impregnated with lubricants (Copyright of Rykaczewski et al. [115]).

SLIPS, although have shown to provide a better condensation performance for low surface tension fluids, compared to conventional approaches, these surfaces are faced with a variety of new challenges making them a less viable approach to be extensively used in wide ranges, scales, or applications. As reported by Rykaczewski et al. [115], there should be a very careful consideration while selecting the lubricant and working fluid combination. The reason that SLIPS have performed well with water is due to the large differences in the interfacial surface energies of the lubricant and water, which result in very high contact angles and low contact angle hysteresis, thus resulting in a very easy droplet removal from condensing surfaces. However, for low surface tension fluids, this difference in the interfacial energies is significantly lower, and only select number of combinations of lubricants and fluids exist which can potentially make the SLIPS work as expected. Hence, this concept, at the present stage, cannot be readily employed with any lubricant and working fluid and the choices are currently limited. Secondly, the lubricants should have low vapor pressure so that the lubricant does not evaporate during the condensation process. It should have a vapor pressure at least less the saturation pressure of the working fluid at all times. This further limits the availability of appropriate lubricants. In addition, during the actual removal of the condensate during the shedding process, there are chances that the lubricant shears off with the shedding condensate. Thus, the lubricant might be depleted over time, and the surfaces are plagued by the similar wetting problems by the condensate. Since, there are no active methods to 
replenish the lubricant while in process, the durability of the SLIPS is a major challenge with employing these surfaces, even for water, and yet to be addressed.

Sett et al. [116] further investigated the concept of SLIPS with low surface tension fluids, particularly, the issues associated with SLIPS in this regard. They mentioned another challenge that limits the choice of SLIPS is the miscibility of the lubricant with the working fluid. Sett et al. [116] conducted a number of test with various lubricant and working fluid combinations to determine their immiscibility as shown in Figure 1.30. They determined that there is only a narrow range of lubricant and working fluid combinations that result in effective utilization of SLIPS for condensation of low surface tension liquids.

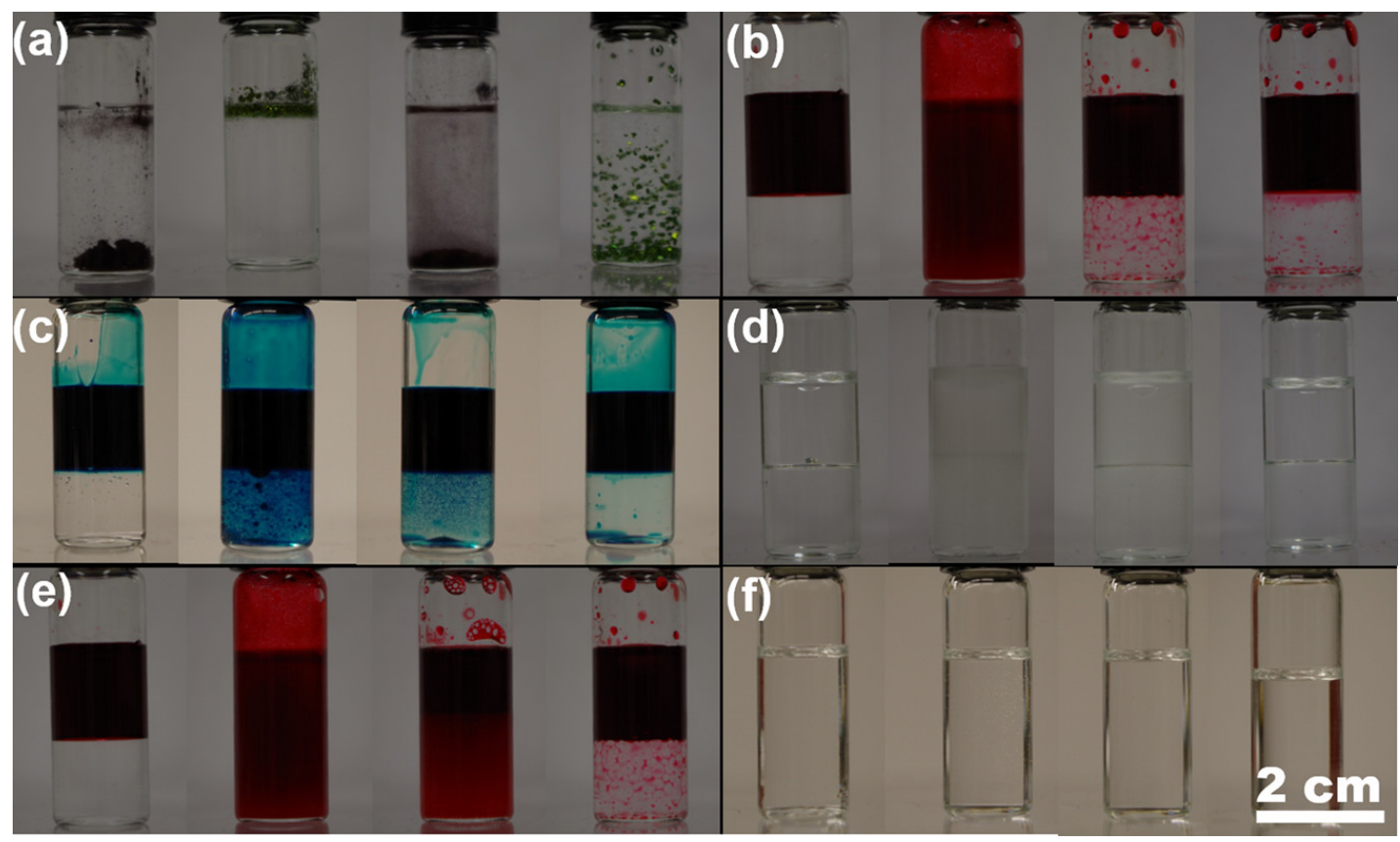

Figure 1.30: Immiscibility tests conducted by Sett et al. [116] to determine working combination of lubricant and condensate: (a) insoluble dyes in lubricant, (b-d), immiscibility of Krytox 1525 lubricant with water, ethanol and hexane respectively, (e) delayed separation of ethylene glycol with lubricant, and (f) completely miscible hexane with lubricant (Copyright of Sett et al. [116]). 
Sett et al. [116] also investigated another major issue associated with SLIPS, that is, the encapsulation of the condensate with the lubricant known as cloaking. Due to low interfacial energy differences between viable lubricant and low surface tension fluids, as the condensate forms, the lubricant gradually forms a thin layer around the condensate in the form of a spherical shell. This cloaked layer offers significant resistance to vapor diffusion, thus reduces the droplet growth rate, and hence results in overall poor performance of the surface. Figure 1.31 shows the issues associated with SLIPS surface, particularly the cloaking issue, as investigated by Sett et al. [116].

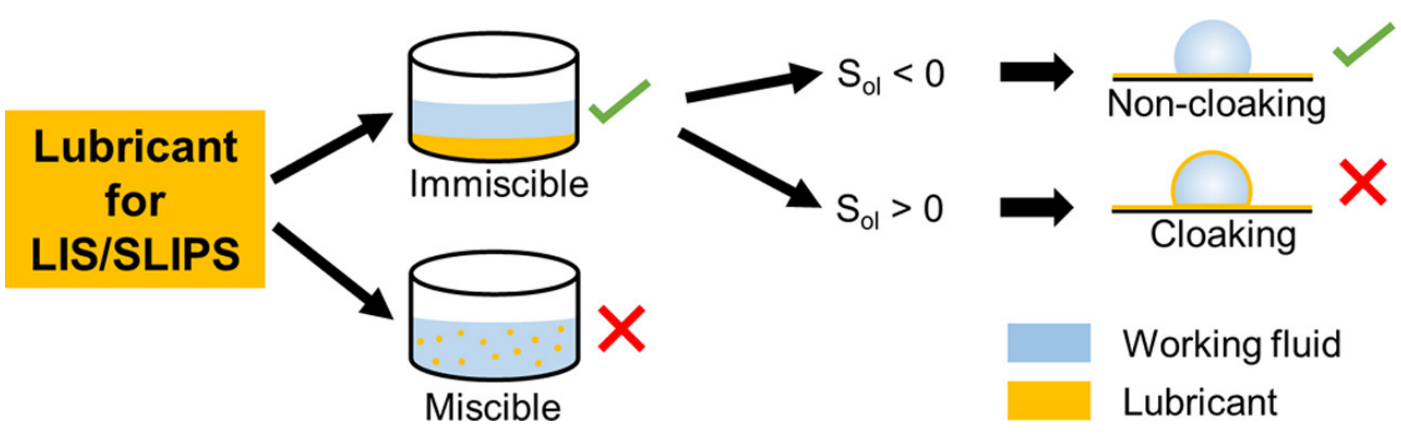

Figure 1.31: Conditions for selection of lubricant and working fluid combinations (Copyright of Sett et al. [116]).

Thus, SLIPS, although appear to be a promising approach, have their own challenges and further research is need to optimize the utilization of these surfaces.

Summarizing all the discussions so far, we conclude that there are no effective means yet to solve the challenges of enhancing the condensation performances specifically for low surface tension liquids. In this thesis, we are attempting to attack this problem from a different venue so as to mitigate the issues with SLIPS surfaces and external power supplies, and devise a novel, passive method to improve the condensation performance of low surface tension liquids. We are looking at utilizing the capillary effect to assist in the 
condensate removal from the surface along with gravity. The designed surface decouples the condensing surface and condensate removal path, and thus significantly enhance the condensation heat transfer of low surface tension liquids. This proposed approach completely mitigates all the issues faced by SLIPS, can be used for any low surface tension liquid if appropriately designed. 


\section{Concept}

As mentioned in the previous chapter, the enhancement in condensation heat transfer has been the subject of numerous evolutions over past decades in terms of surface coatings, surface modification in the microscale and nanoscale, employment of hierarchical structures, and recently the utilization of the jumping droplet effect. However, as mentioned previously, all these approaches typically fail with completely wetting low surface tension liquids. Although SLIPS has provided a way to improve the condensation performance of low surface tension liquids, a new set of limitations and challenges associated with SLIPS have hindered the immediate utilization of this approach in industry. Therefore, more research is needed before employing SLIPS or other alternate approaches for low surface tension liquids.

In this thesis, we attempt to utilize a capillary assisted condensation surface by fabricating novel, porous, 3D structures, on a surface to enhance the rate of condensation. The new concept in fact decouples the condensing surface and condensate removal paths. We are looking at utilizing the capillary effect to collect the liquid condensed on the vapor-exposed surfaces, and then use gravity for assist in the condensate removal. The

designed surface induces a capillary gradient in the out of plane direction to pull out the condensing liquid continuously, and thus significantly reduce the thickness of the condensate film on the condensing surface. The new surface consists of alternating capillary bridge and plain sections. The liquid condensing in the plain channels and the outer surfaces of the capillary bridge is wicked into capillary bridge, effectively decoupling the condensation surface and the condensate removal paths. Hence, the 
knowledge gained from this thesis will serve as basic guideline for designing new simple, cost effective, and scalable surface technologies with enhanced condensation heat transfer for widely used low surface tension liquids.

\subsection{Capillary Assisted Condensate Removal}

The inspiration for our proposed condensation surfaces comes from the fact that there exists a relationship between capillary pressure and size of pores through which a fluid flows. Smaller pores induce higher capillary pressure. It is also known that viscous losses can overcome the induced capillary pressure at very small pore sizes. The viscous losses directly depend on the pore characteristics (i.e., size and length) and flow rate. Therefore, there is an optimum feature size at which the wickability effect is maximum. The core idea of the current thesis is to employ the wickability effect to enhance the condensation rate of low surface tension liquids.

If a surface is preferentially patterned by porous metallic copper layers, a net out-of-plane capillary pressure can be created. This represents an effective and passive means of transporting the condensate vapor away from the cooler bottom surface and the side and top surfaces of the capillary bridge. We fabricated a capillary-assisted condensation surface consisting of alternating plain channels and porous capillary bridges. Due to menisci created at the top porous layer and associated capillary pressure, liquid condensing on the plain channels and the exposed surfaces of the capillary bridge is wicked into the capillary bridges. The liquid wicked into the capillary bridge then flows downward due to gravity. The capillary bridges are designed such that the pores in the 
bridge have a decreasing pore size from the base layer to the tip layer along their height. This reduces viscous losses associated with the liquid flow maximizing the wickability effect. Due to a steady wicking of the condensing liquid into the capillary bridge, the condensate vapor is continuously removed and the vapor-exposed surfaces are fresh for further condensation. The entire process thus decouples the condensing surface and the condensate removal paths, thereby enhancing the overall condensation heat transfer performance.

The specific design of this surface has been carried out with a focus on improving the condensation heat transfer performance of extremely wetting liquids such as Novec 7100 dielectric fluid with a surface tension of $13.6 \mathrm{mN} / \mathrm{m}$. Such low surface tension liquids easily spread throughout a condensing surface, thus leading to the filmwise condensation mode. The liquid film whose thickness increases as it flows due to gravity acts as a thermal barrier reducing the condensation heat transfer performance. Conventional methods of promoting the dropwise condensation mode such as low surface energy coatings, surface modification of superhydrophobic surfaces with microstructures, nano structures or hierarchical structures, enforcing conditions for jumping droplet effect typically fail for liquids with low surface tensions such as Novec 7100 dielectric. The state-of-the-art approach for low surface tension liquids consists of using lubricantinfused surfaces to induce the dropwise condensation mode. However, the presence of the additional lubricant fluid introduces several unexplored issues such as cloaking and lubricant depletion with time, and are yet to be explored. In addition, longevity and performance of these more complex approaches in harsh industrial conditions over an 
extended period need to be examined. Here, we utilize a simple and robust concept of capillary-assisted condensation surface to enhance the condensation heat transfer rate of completely wetting liquids.

The capillary length of Novec 7100 fluid is calculated to be $0.962 \mathrm{~mm}$ (Appendix A.1). The meniscus profile for the liquid is calculated using Young-Laplace equations (Appendix A.2) and shown in Figure 2.1. The channel widths of 1 and $2.5 \mathrm{~mm}$ were chosen during fabrication of condensation surfaces.

\section{Novec 7100 Profile}

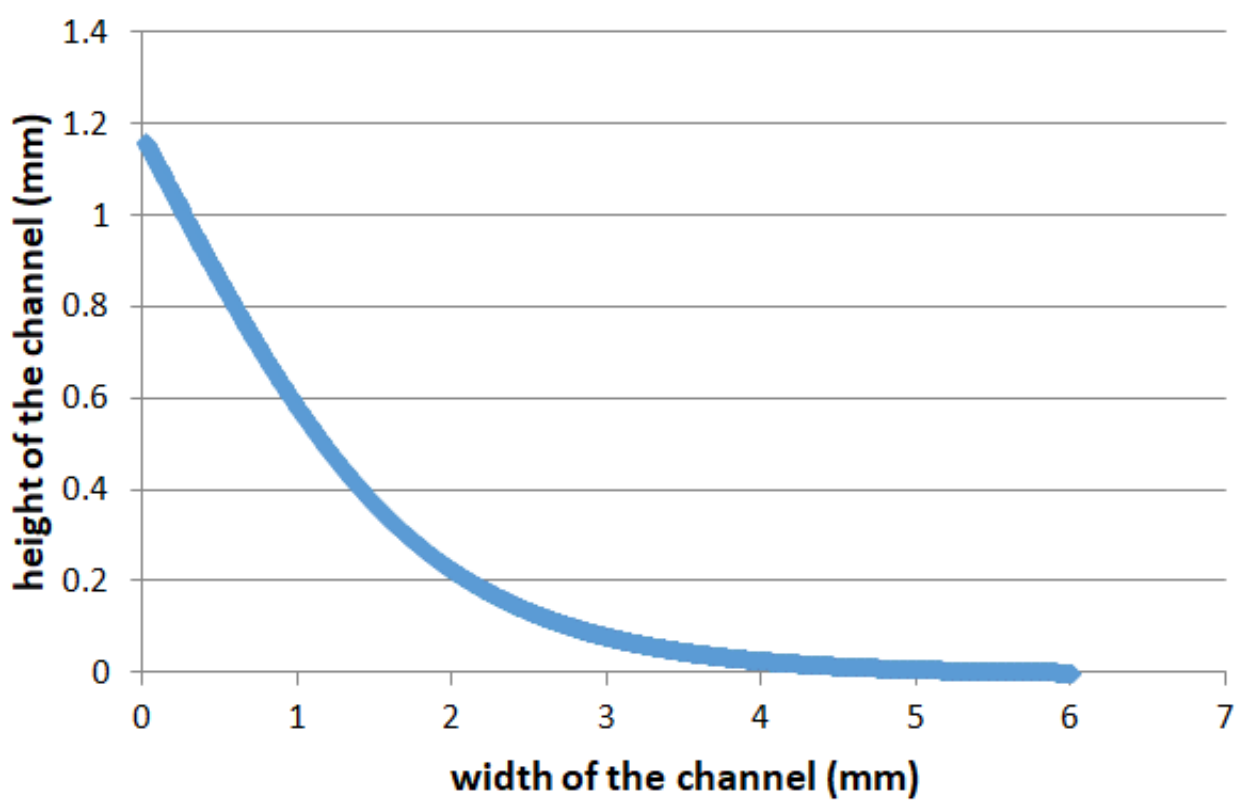

Figure 2.1: Meniscus profile of Novec 7100 dielectric as calculated from Young-Laplace equation (Appendix A.2).

The schematic of the condensation surface is shown in Figure 2.2. The condensation surface consists of a copper substrate that is $6.25 \mathrm{~mm}$ in thickness with a length and width of $20 \mathrm{~mm}$ each. From the base of the substrate, protruded are five capillary bridges with porous layers of varying pore sizes. Each of the bridges are $1.95 \mathrm{~mm}$ in height and 2 
$\mathrm{mm}$ in width. The bridges run along the length of the substrate and hence are $20 \mathrm{~mm}$ in length. The channels in between the bridges are $2.5 \mathrm{~mm}$ in width and run along the entire length of the substrate. From the schematic, it can be observed that, two porous layers immediately bonded to the substrate are of the largest pore size with a pore size of 0.5334 $\mathrm{mm}$. Following vertically up, bonded to the large pore layers, are two medium pore layers with a pore/opening size of $0.2794 \mathrm{~mm}$. Bonded to these medium pore layers are three layers of smallest pore size of $0.1778 \mathrm{~mm}$. Finally, one layer with a pore size of 0.1778 $\mathrm{mm}$ is the topmost layer of the surface, which is bonded to the small pore layers. This layer is bonded to ease the gravitational removal of the collected droplets. The bridges are therefore totally composed of eight porous layers of decreasing diameter from the bottom to the top with specifications as provided in Table 2.1.

Table 2.1: Specifications of the inter-woven copper meshes bonded to the copper substrate

\begin{tabular}{|c|c|c|c|c|}
\hline Layer & $\begin{array}{c}\text { Opening } \\
(\mathbf{m m})\end{array}$ & $\begin{array}{c}\text { Wire Dia } \\
(\mathbf{m m})\end{array}$ & $\begin{array}{l}\text { No. of } \\
\text { Layers }\end{array}$ & $\begin{array}{c}\text { Mesh Thickness } \\
(\mathbf{m m})\end{array}$ \\
\hline Base - Large Pore & 0.5334 & 0.3048 & 2 & 1.2192 \\
\hline Mid - Medium Pore & 0.2794 & 0.2286 & 2 & 0.9144 \\
\hline Top - Small Pore & 0.1778 & 0.1397 & 4 & 1.1176 \\
\hline \multicolumn{4}{|c|}{ Total Expected Mesh Thickness (Base + Mid + Top) } & 3.2512 \\
\hline \multicolumn{4}{|c|}{ Final Mesh Thickness Resulting from Bonding and Compression } & 1.95 \\
\hline
\end{tabular}



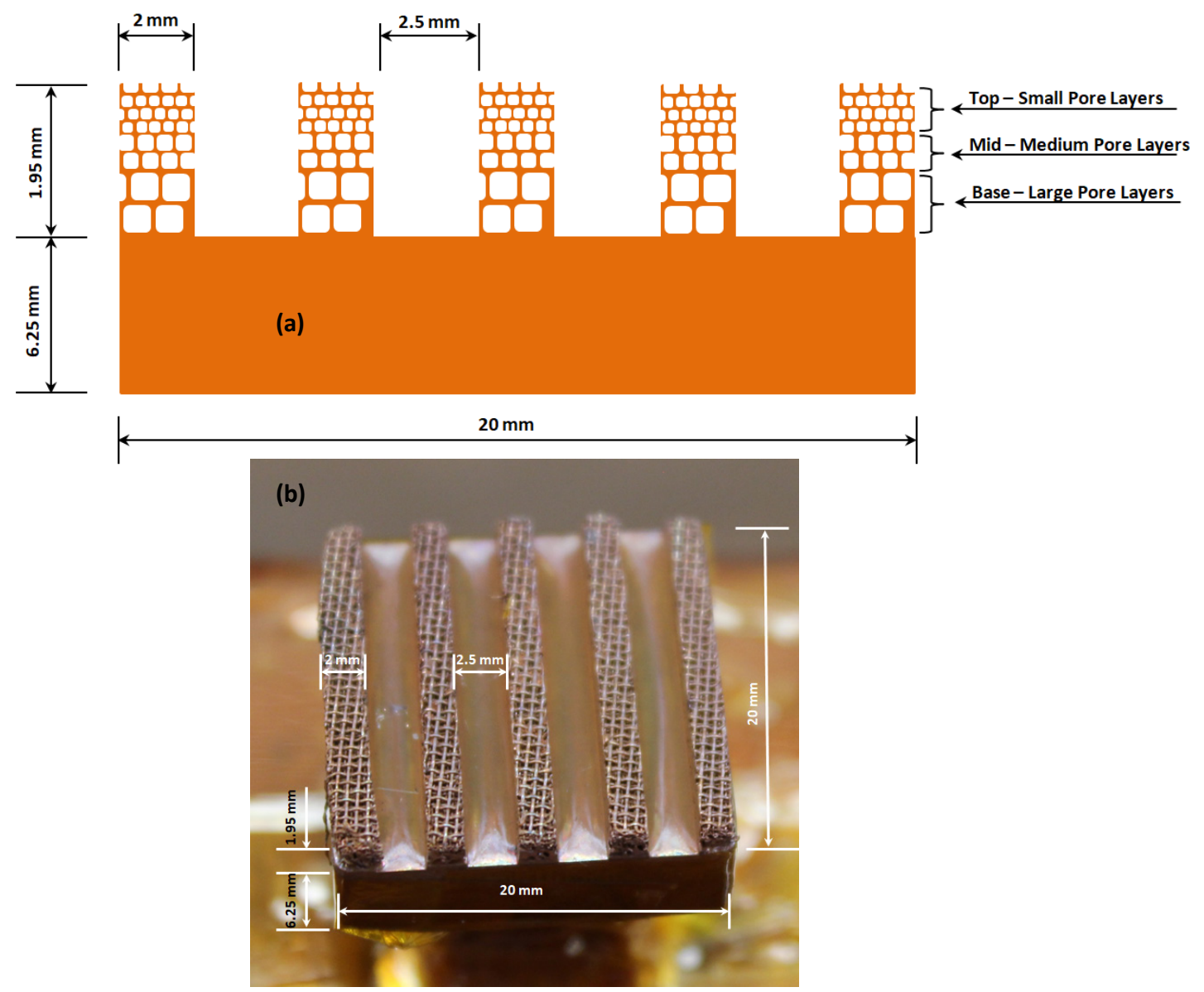

Figure 2.2: Condensation surface geometry: (a) schematic of the designed condensation surface geometry, and (b) image of the actual fabricated condensation surface geometry.

The schematic of the expected condensation process is as shown in Figure 2.3 and Figure 2.4, which represent cross-sectional top and side views of the condensation surface, respectively. 

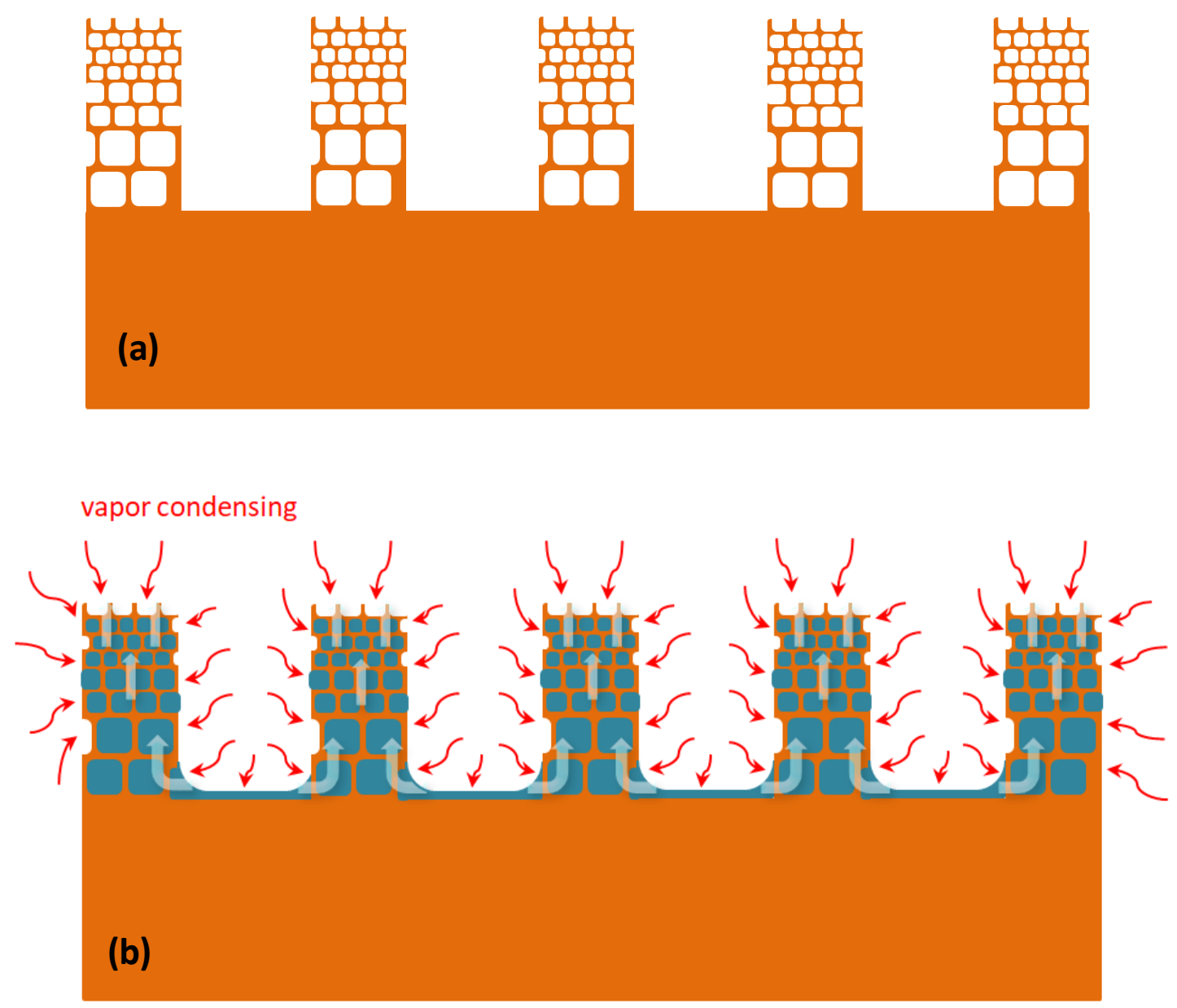

Figure 2.3: Schematic of the condensation process from the cross-sectional top view of the surface: (a) dry surface with the porous layers before subjecting to condensation, and (b) the condensate is wicked into the capillary bridge. 

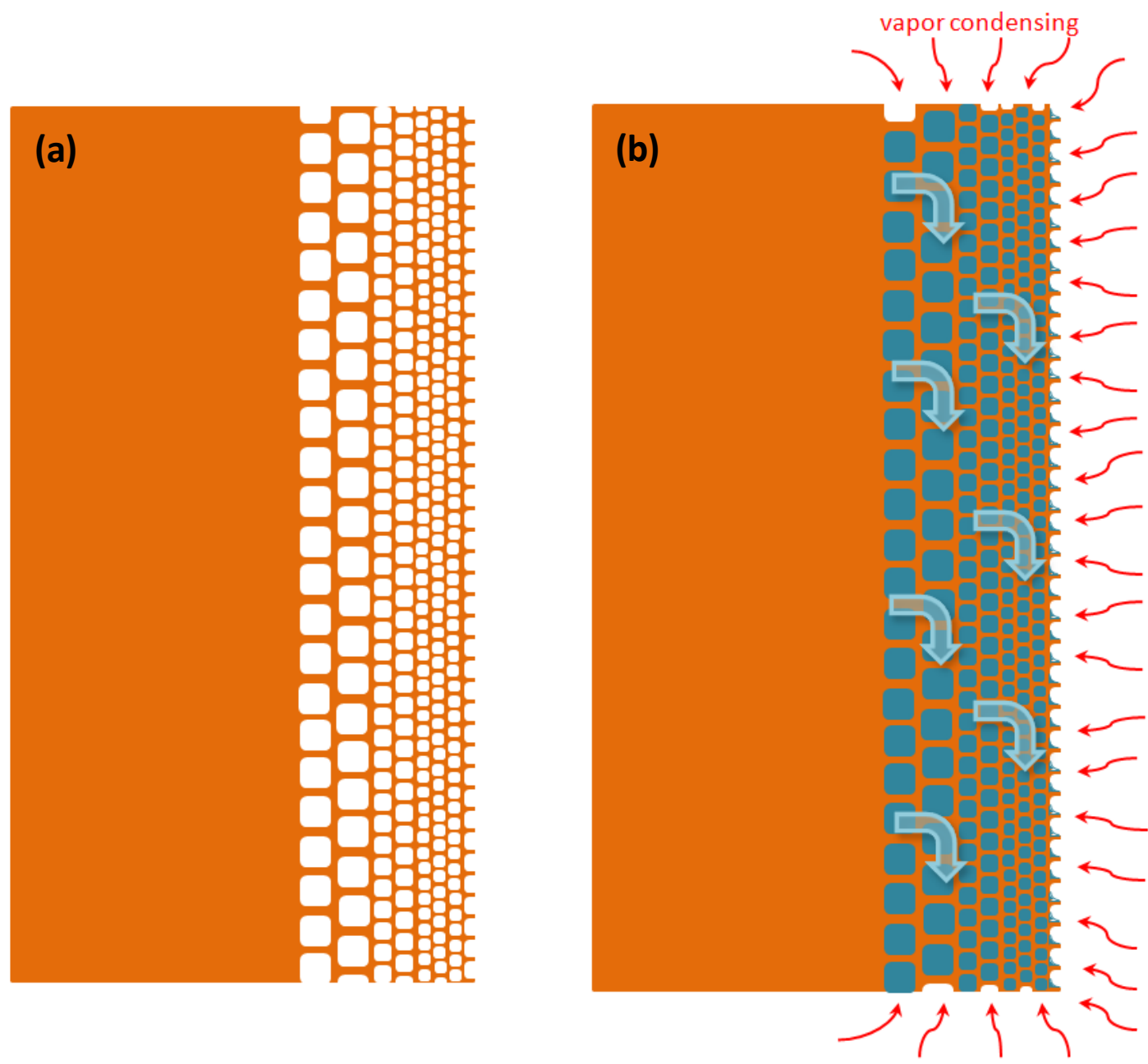

Figure 2.4: Schematic of the condensation process from the cross-sectional side view of the surface: (a) dry surface with the porous layers before subjecting to condensation, and (b) the condensate vapor being wicked into the capillary bridge, and the simultaneous liquid falling down due to gravity.

\subsection{Capillary Assisted Condensate Removal with a Covering Mesh Layer}

To further enhance the rate of condensation of this surface, a cover mesh layer with the small pore size is bonded to the tips of the capillary bridges. The top layer mesh provides a significantly greater surface area for condensation to take place. Since this cover layer will be of the same dimensions as the entire surface, it forms a cover over the entire surface. It is bonded to the tips of the capillary bridges and forms a porous cover for the 
channels as shown in Figure 2.5. Since the pores of this layer are of the same order of the capillary bridge, this layer does not cause any hindrance for the capillary assisted condensation process as described in the previous section. The schematic of the proposed cover mesh is shown in Figure 2.5. It is to be noted that the actual cover mesh bonded surface shown in Figure 2.5 is for a different condensation surface fabricated with different mesh layers and dimensions compared to the surface shown in Figure 2.2. It should be also noted that the surface in Figure 2.5 was initially intended to be fabricated with only different mesh configurations and channel widths. The added cover mesh layer was not expected to provide a significant increase in condensation, but in fact, it is later proved to be a major factor. The schematic of the expected condensation process is shown in Figure 2.6 and Figure 2.7.
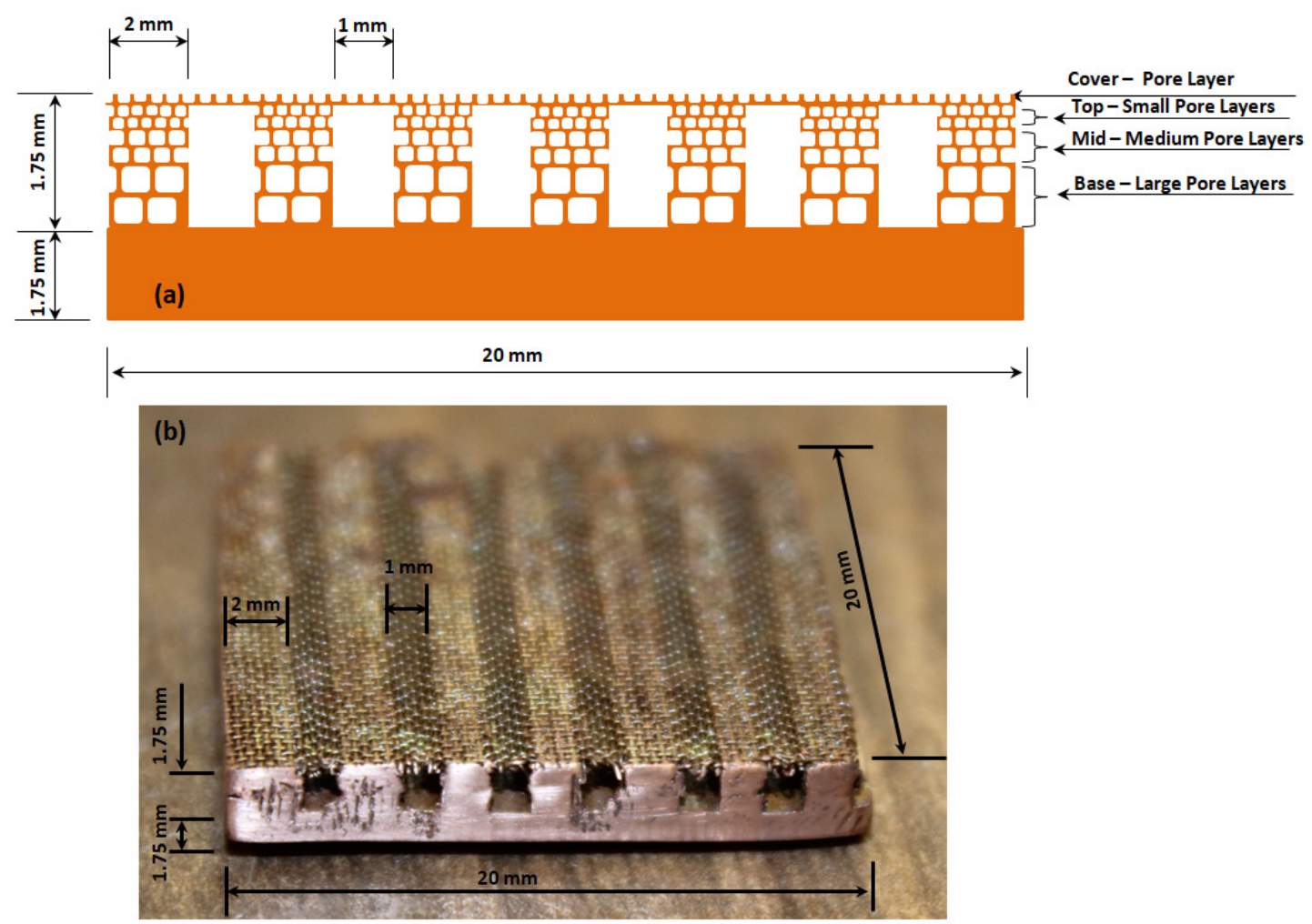
Figure 2.5: Schematic of the cover mesh bonded condensation surface with dimensions: (a) schematic of the designed condensation surface geometry, and (b) image of the actual fabricated condensation surface geometry.
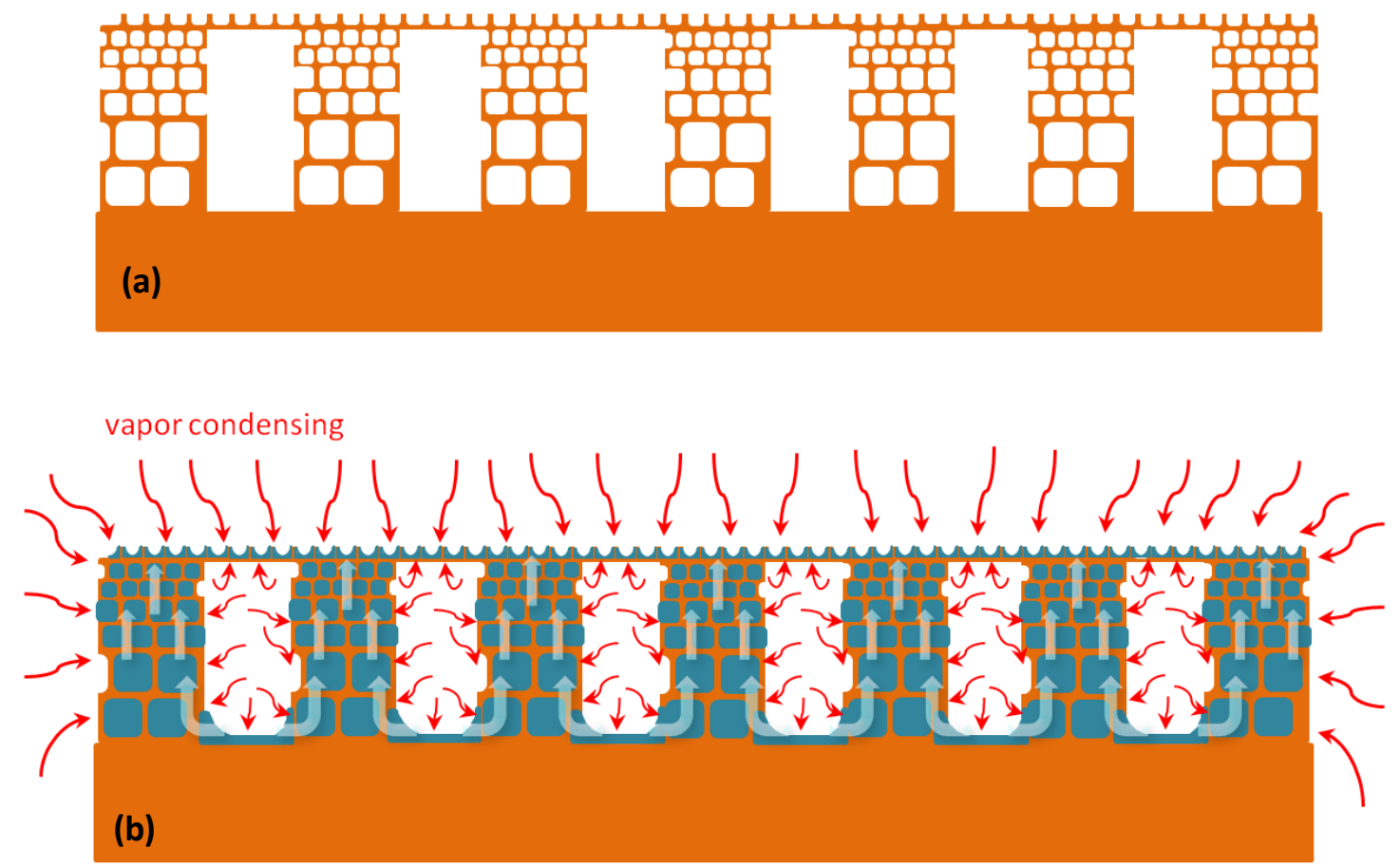

Figure 2.6: Schematic of the condensation process for the cover mesh bonded surface observed from the cross-sectional top view: (a) dry surface with the porous layers before subjecting to condensation, and (b) the condensate vapor being wicked into capillary bridge. 

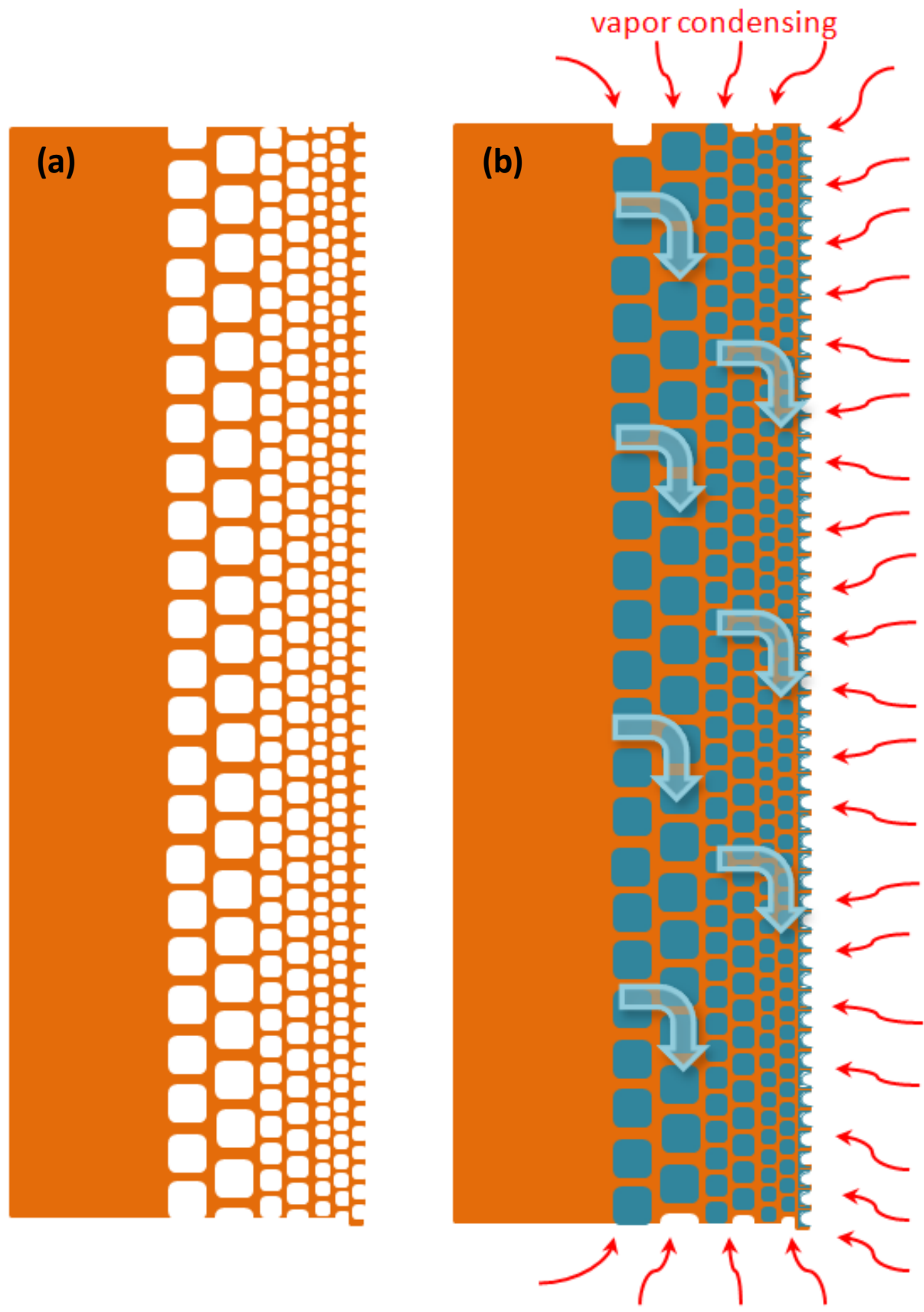

Figure 2.7: Schematic of the condensation process for the cover mesh bonded condensation surface as observed from the cross-sectional side view: (a) dry surface with the porous layers before subjecting to condensation, and (b) the condensate vapor being wicked into the capillary bridge, and the simultaneous liquid falling down due to gravity. 


\section{Fabrication}

The major fabrication work for this thesis involved the fabrication and assembly of the heat exchanger module used for the condensation experiment and finally the fabrication of the designed condensation surface.

\subsection{Condensation Surface}

The final condensation surface resulted from three manufacturing steps, where included the cutting/machining of the individual parts, diffusion bonding of the copper mesh layers to the copper substrate, and machining of channels in the copper mesh surface.

\subsubsection{Preparation of the Individual Parts}

The required copper substrate piece was cut from a 6" length, 3" wide, 1/4" thick commercially pure $(99.9 \%$ pure) stock copper block (Copper Plate, McMaster) using a band saw. The copper substrate piece was then machined using a milling machine to the dimensions of $20 \mathrm{~mm} \times 20 \mathrm{~mm} \times 6.25 \mathrm{~mm}$. Copper mesh pieces each of $25 \mathrm{~mm} \times 25 \mathrm{~mm}$ were cut from three different copper mesh swatches depending on their pore size. Two mesh pieces from the large pore mesh (30 Mesh Copper 0.012, TWP Inc.); three mesh pieces from the medium pore mesh (50 Mesh Copper 0.009, TWP Inc.) and three mesh pieces from the small pore mesh (80 Mesh Copper 0.0055 , TWP Inc.) were cut. The copper substrate was then made smooth by cleaning with a fine sand paper and washed with acetone to remove any surface oxide layer or impurities present on the surface. The eight copper mesh pieces were subjected to similar cleaning with acetone to obtain clean surface before placing them in the copper diffusion bonding setup. The image of the 20 
$\mathrm{mm} \times 20 \mathrm{~mm}$ copper substrate and the $25 \mathrm{~mm} \times 25 \mathrm{~mm}$ large pore copper mesh is shown in Figure 3.1.

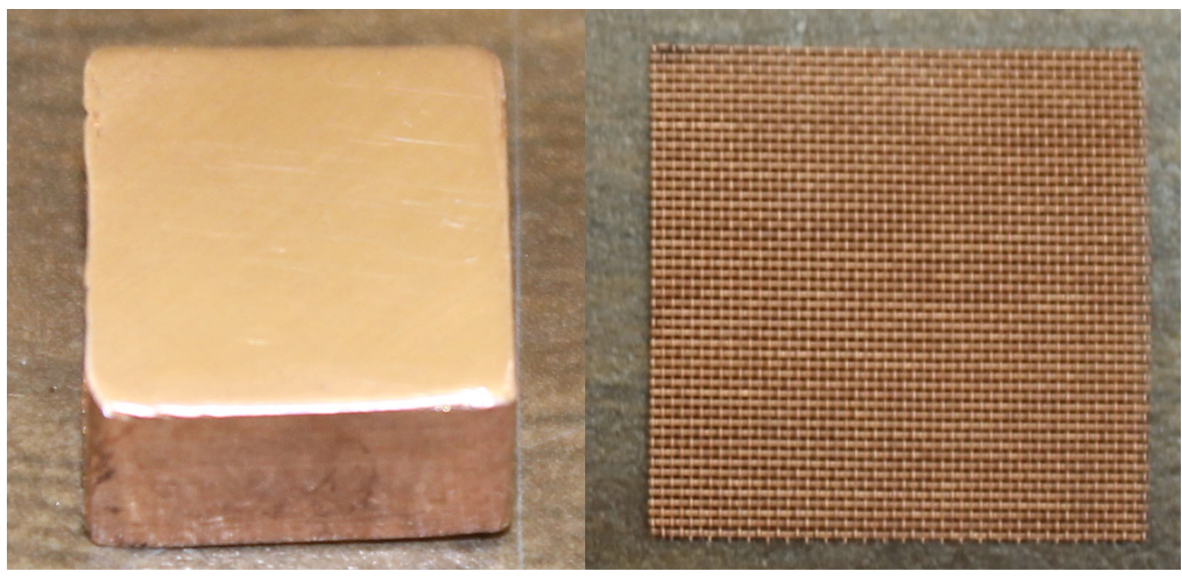

Figure 3.1: Image of the precisely machined and cleaned copper substrate (left), and the inter-woven copper mesh pieces cut to the required dimensions (right).

\subsubsection{Cu-Cu Diffusion Bonding}

A number of experimental trials were performed with varying sizes of copper substrates and copper meshes, varying levels of clamping forces, varying levels of vacuum to finally arrive at proper working conditions to obtain a clean, oxide-free, and durable bonding of the copper meshes to the copper substrate. The results of some of the trials are provided in Figure 3.2.
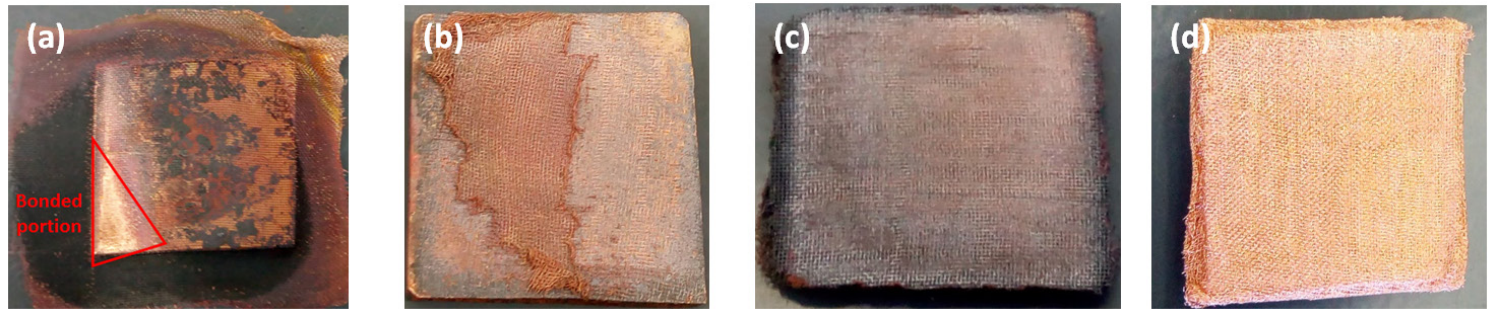

Figure 3.2: Progress of the experimental trials to arrive at a functional bonding of the copper meshes to the substrate: (a) beam clamped setup in partial vacuum with one mesh layer, (b) beam clamped setup in partial vacuum with 2 mesh layers, (c) bench vice clamped setup with 6 mesh layer in partial vacuum (oxidation), and (d) bench vice clamped setup in low vacuum with 6 mesh layers. 
The prepared copper meshes and substrate were placed such that the copper substrate forms the base followed by two large mesh pieces, two medium mesh pieces, three small mesh pieces, and finally one small mesh piece. The copper mesh setup was placed between two steel plates of $6 " \mathrm{x} 3 " \mathrm{x} 1 / 2 "$ and clamped in a bench vice. The bench vice was tightened to about $3500 \mathrm{lbs}$ of clamping force. The steel blocks were equipped with heaters. The heaters provided the necessary heat for the diffusion bonding. In addition, the steel block consisted of a hole in which a probe thermocouple is inserted to monitor the real-time temperature of the setup during the bonding process. The entire setup, with the copper substrate, meshes; steel blocks, heaters, thermocouple, and bench vice were placed in a vacuum chamber. Necessary electrical connections were made through thermocouple and electrical feedthrough inside the vacuum chamber. The setup was sealed and vacuumed using a vacuum pump. The temperature of the setup was slowly increased at the rate of around $5 \square \mathrm{C} / \mathrm{min}$ by increasing the voltage input to the heaters. Once the bonding was completed, the setup was cooled by cutting off the voltage to the heaters. The low pressure of the chamber was maintained during the cooling process to prevent copper oxidation. The chamber was then pressurized to atmospheric pressure. The process described above converged from a number of trials and results in a clean, oxide free, and highly durable diffusion bonding of the copper meshes to each other and the copper substrate. The resulting diffusion bonded copper substrate-mesh surface at the microscopic level is shown in Figure 3.3. 

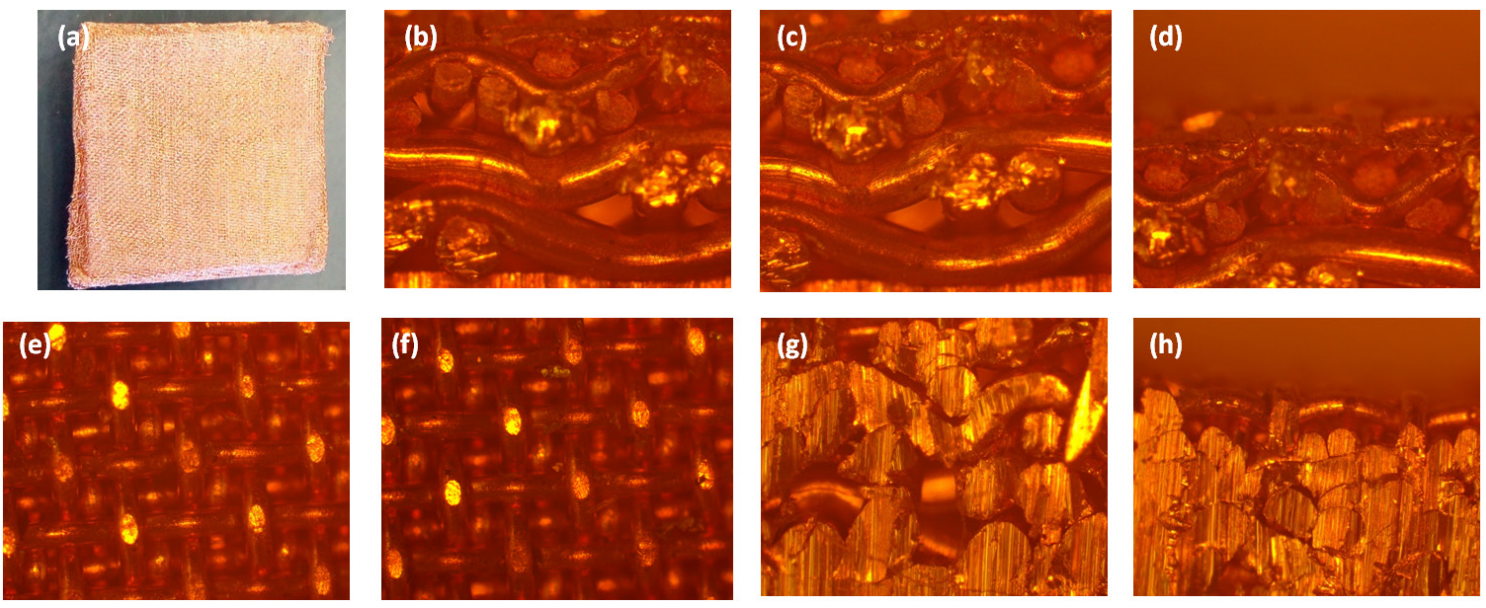

Figure 3.3: Diffusion bonded copper substrate-mesh surface: (a) overview of the substrate-mesh surface, (b, c) microscopic images of the large copper meshes bonded to the substrate at the free edges, (d) microscopic image of the small copper mesh at the top free edges, (e, f) microscopic image of top view, and (g, h) microscopic images of the machined channel side walls.

\subsubsection{Machining of Channels on the Copper Mesh Surface}

Since the initial copper mesh pieces were $25 \mathrm{~mm} \times 25 \mathrm{~mm}$, the extra projections of the copper mesh from the sides were cut out using a metal cutter tool so that the final surface was simply a $20 \mathrm{~mm}$ x $20 \mathrm{~mm}$ block. The total mesh layer thickness after diffusion bonding was measured to be $1.95 \mathrm{~mm}$ from the substrate surface. A CAD model of the required machined surface was generated using SolidWorks and the corresponding Gcode for the design, to be used in a CNC machine, was generated in NX. The required channels of $2.5 \mathrm{~mm}$ width and $1.95 \mathrm{~mm}$ deep were machined using a 1/16" end mill with a feed-rate of $0.2 \mathrm{~mm}$ depth per cut and the end mill spindle speed of $1800 \mathrm{rpm}$. A hole of $1.5 \mathrm{~mm}$ diameter and $10 \mathrm{~mm}$ depth was drilled at the mid of point of the thickness into the base of the copper substrate where a thermocouple could be inserted to measure the temperature of the top surface of the channel during condensation. The side of the bridges or the banks of the channels, after machining the required channels, would usually be partially closed due to the shearing of the copper mesh material. As this would prevent 
our surface from functioning as expected, the pores are thus re-opened. This is done by rinsing the machined surface in a solution of copper etchant (Ferric Chloride Copper Etchant) for intermittent periods of 30 seconds each followed by rinsing in DI water. The final working condensation surface is shown in Figure 3.4.
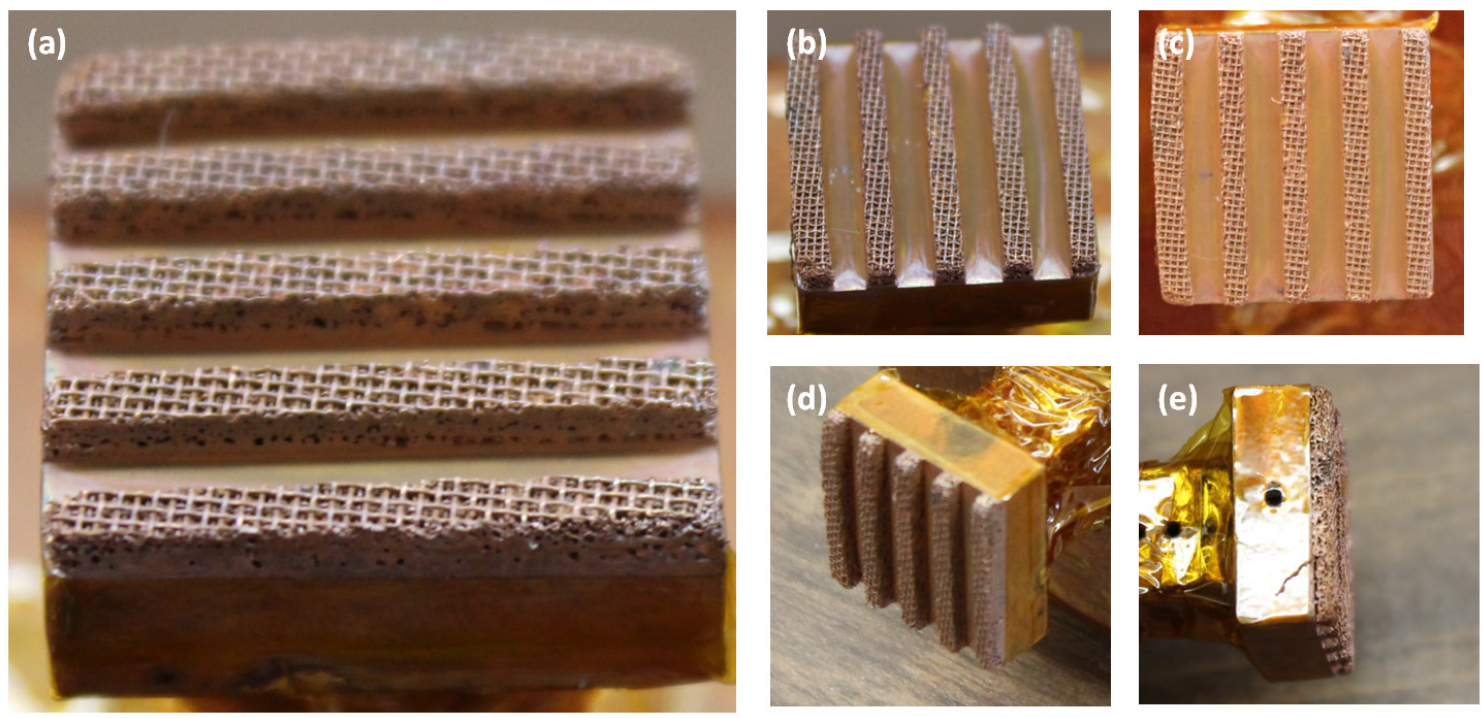

Figure 3.4: Final condensation surface: (a) side walls of the machined channels with pores opened-up after copper etchant rinsing, and (b-e) various orientations of the condensation surface.

\subsection{Condensation Surface with Cover Mesh}

The condensation surface with the cover mesh layer was fabricated with the exact same manufacturing process and steps as those described in Sections 3.1.1, 3.1.2 and 3.1.3. The mesh configuration for this layer comprised of two large pore meshes, two medium meshes and two small meshes, in this exact order, starting from the base substrate. All meshes are $25 \mathrm{~mm} \times 25 \mathrm{~mm}$ with configurations described in Table 3.1. The process for bonding these meshes to the copper substrate was the same process as described in Sections 3.1.1 and 3.1.2. The bonded copper mesh substrate was machined with the same process as described in Section 3.1.3, but with channel widths of $1 \mathrm{~mm}$. Since the initial 
bonded mesh layer was $1.3 \mathrm{~mm}$ in thickness, the channels were machined only up to a depth of $1.3 \mathrm{~mm}$. The mesh surface was rinsed with copper etchant as described previously to open up the pores on the sidewalls of the capillary bridges. Now, a second diffusion bonding was performed to bond a small pore size cover mesh layer onto the tips of the capillary bridges with the same procedure as described in Section 3.1.2. The total mesh thickness after the second bonding was determined to be $1.75 \mathrm{~mm}$. The final working condensation surface with cover mesh is shown in Figure 3.5.

Table 3.1: Specifications of the inter-woven copper meshes bonded to the copper substrate in the case of the surface with cover mesh layer

\begin{tabular}{|c|c|c|c|c|}
\hline Layer & $\begin{array}{c}\text { Opening } \\
(\mathbf{m m})\end{array}$ & Wire Dia (mm) & No. of Layers & $\begin{array}{c}\text { Mesh } \\
\text { Thickness } \\
\text { (mm) }\end{array}$ \\
\hline Base - Large Pore & 0.5334 & 0.3048 & 2 & 1.2192 \\
\hline Mid - Medium Pore & 0.2794 & 0.2286 & 2 & 0.9144 \\
\hline Top - Small Pore & 0.1778 & 0.1397 & 2 & 0.5588 \\
\hline Cover - Small Pore & 0.1778 & 0.1397 & 1 & 0.2794 \\
\hline \multicolumn{2}{|l}{ Total Expected Mesh Thickness (Base + Mid + Top + Cover) } & 2.9718 \\
\hline \multicolumn{6}{|l}{ Final Mesh Thickness Resulting from Bonding and Compression } & 1.75 \\
\hline
\end{tabular}



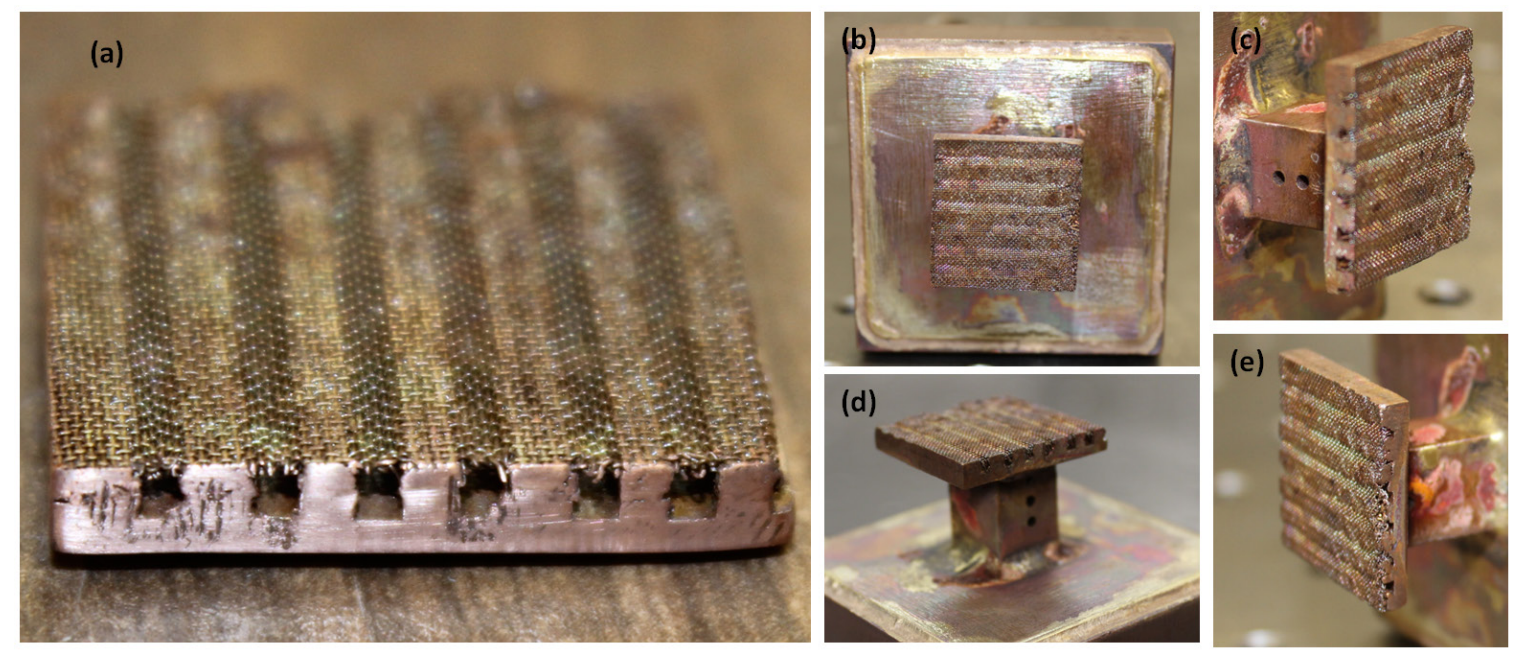

Figure 3.5: Final condensation surface with cover mesh: (a) condensation surface with the cover mesh layer bonded, and (b-e) various orientations of the condensation surface with cover mesh.

\subsection{Heat Exchanger}

The heat exchanger designed for our condensation surface was fabricated by a three step manufacturing process including the machining of individual parts, brazing to seal the parts, and assembly to the liquid feedthrough of the vacuum chamber.

\subsubsection{Machining of Individual Parts}

A copper stock block of 2" x 2" x 1" was machined to the required size of $50.8 \mathrm{~mm} \times$ $50.8 \mathrm{~mm} \times 19.05 \mathrm{~mm}$. Channels of $5.08 \mathrm{~mm}$ width and $11.68 \mathrm{~mm}$ depth with banks of $1.02 \mathrm{~mm}$ width were machined on this block to provide a serpentine path for the flow of the cooling liquid. This design resulted in seven channels along the length of the heat exchanger with a serpentine channel flow path increasing the total flow length of the cooling fluid and also increasing the surface area for heat transfer on either sides of the banks effectively enhancing the performance of the cooling block. The walls of the heat 
exchanger were $4.57 \mathrm{~mm}$ thick. The CAD model of the heat exchanger main body along with all the dimensions is as shown in Figure 3.6.
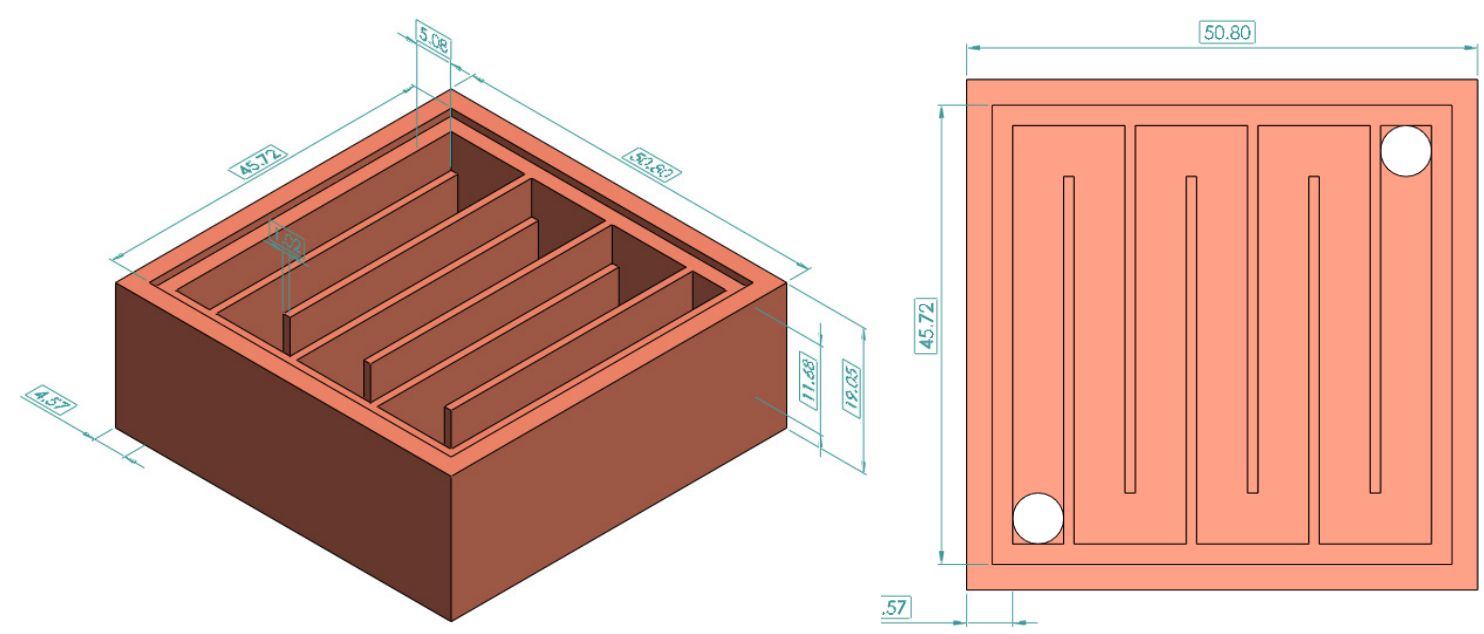

Figure 3.6: CAD model of the main body of the heat exchanger

The top surface of the heat exchanger was enclosed by a machined cover plate of size $45.72 \mathrm{~mm} \times 45.72 \mathrm{~mm} \times 2.03 \mathrm{~mm}$. To accurately measure the heat added to the condensation surface during condensation, a 1D-heat transfer column of dimensions of 10 $\mathrm{mm} \times 10 \mathrm{~mm} \times 28.7 \mathrm{~mm}$ was fabricated. Three equidistant holes of $1.5 \mathrm{~mm}$ diameter and $5 \mathrm{~mm}$ depth were drilled into the center of the 1D column along the height of the column. Three thermocouples were inserted into these three equidistant holes to monitor the temperatures at these positions in real-time. Since the width of the 1D column was less compared to its height, the lateral heat transfer can be neglected and assumed that heat conduction happens only along the height of the column. By measuring the temperature differences between these three points, the heat flux along the height of the column and hence the condensation surface can be accurately measured. The CAD model of the cover plate and 1D column are shown in Figure 3.7. 

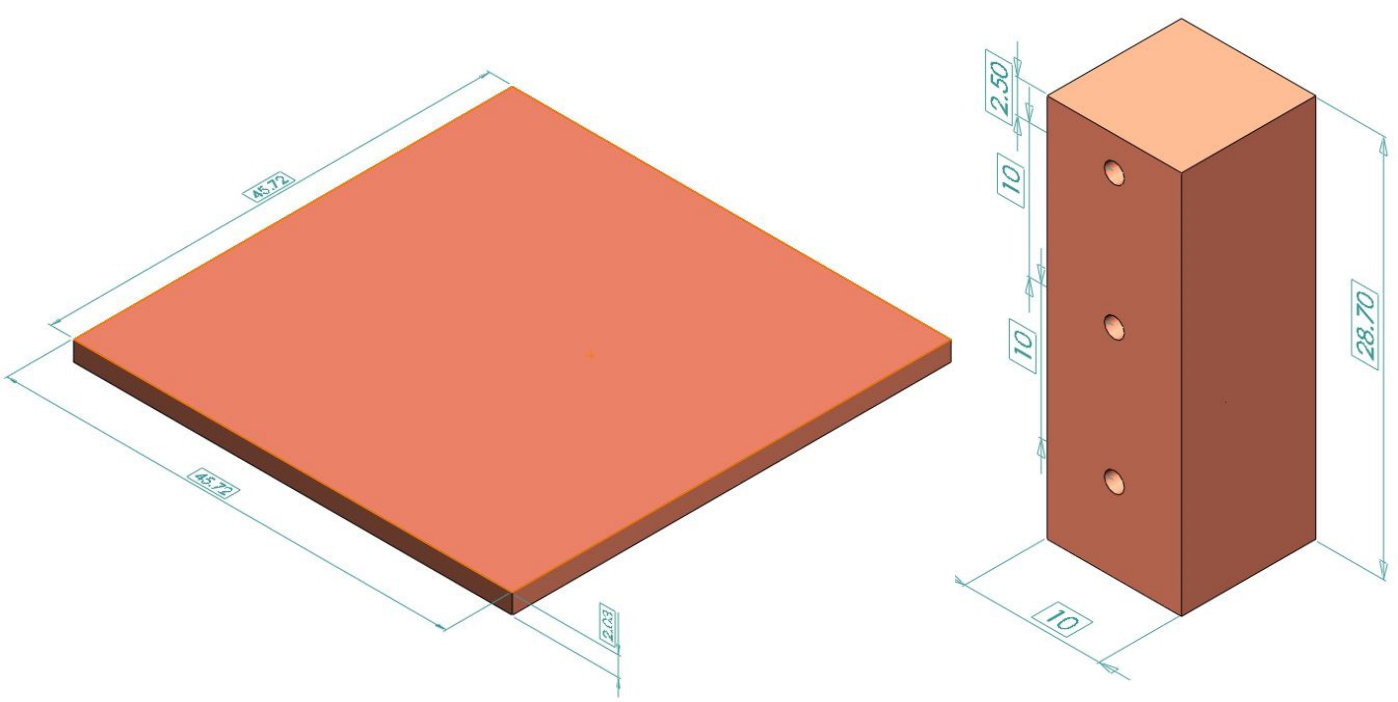

Figure 3.7: CAD model of the cover plate (left) and the 1D column (right).

\subsubsection{Assembly of Heat Exchanger}

Since 1D column, cover plate, and steel pipes have to be individually brazed to the heat exchanger main body, the brazing process was carried out in three stages to assemble the heat exchange module.

The cover plate of the heat exchanger was attached to the main body by a high temperature brazing process to make an airtight seal along the top surface perimeter of the block as shown in Figure 3.9. The cover plate was centrally placed on top of the heat exchanger main body and the setup is heated to about $870 \square \mathrm{C}$ and maintained at that temperature. At this point, a high melting point cadmium rod enclosed with the flux material was applied along the perimeter of the block at the junction of the cover plate and main body. The cadmium rod continuously melts as it is being applied at the junction, forms a neat fillet at the junction, and hence seals the cover plate to the main body. 
The main body of the heat exchanger had 2 holes drilled at the left bottom corner and the right top corner coinciding with the inlet and the outlet of serpentine channel flow path of the cooling liquid inside the body of the block (as shown in Figure 3.8). Two steel pipes of $1 / 4$ " diameter and 7" length were brazed to the inlet and outlet holes of the heat exchanger using the same brazing process as above but by using a low melting point cadmium rod where the setup was heated to about $610 \square \mathrm{C}$. This was done so that the setup does not reach $870 \square \mathrm{C}$; otherwise, there was a good chance that the previously brazed cover plate and main body could detach. Similarly, the fabricated 1D column was brazed to the cover plate at the center using the same low temperature brazing process as before. Since only the top surface of the cover plate was carefully heated to about $610 \square \mathrm{C}$, the temperature at the bottom of the main body was slightly lesser than $610 \square \mathrm{C}$. This ensured that only the cadmium material at the junction of the 1D column and cover plate melted to form a neat fillet while the previously brazed steel pipe and main body junction remained intact. Thus, the heat exchanger module was assembled using a three stage brazing process. The CAD model of the designed heat exchanger is shown in Figure 3.8. The schematic of the final assembled heat exchanger with the designed dimensions is shown in Figure 3.9. The fabricated, brazed, and assembled heat exchanger module is shown in Figure 3.10. 


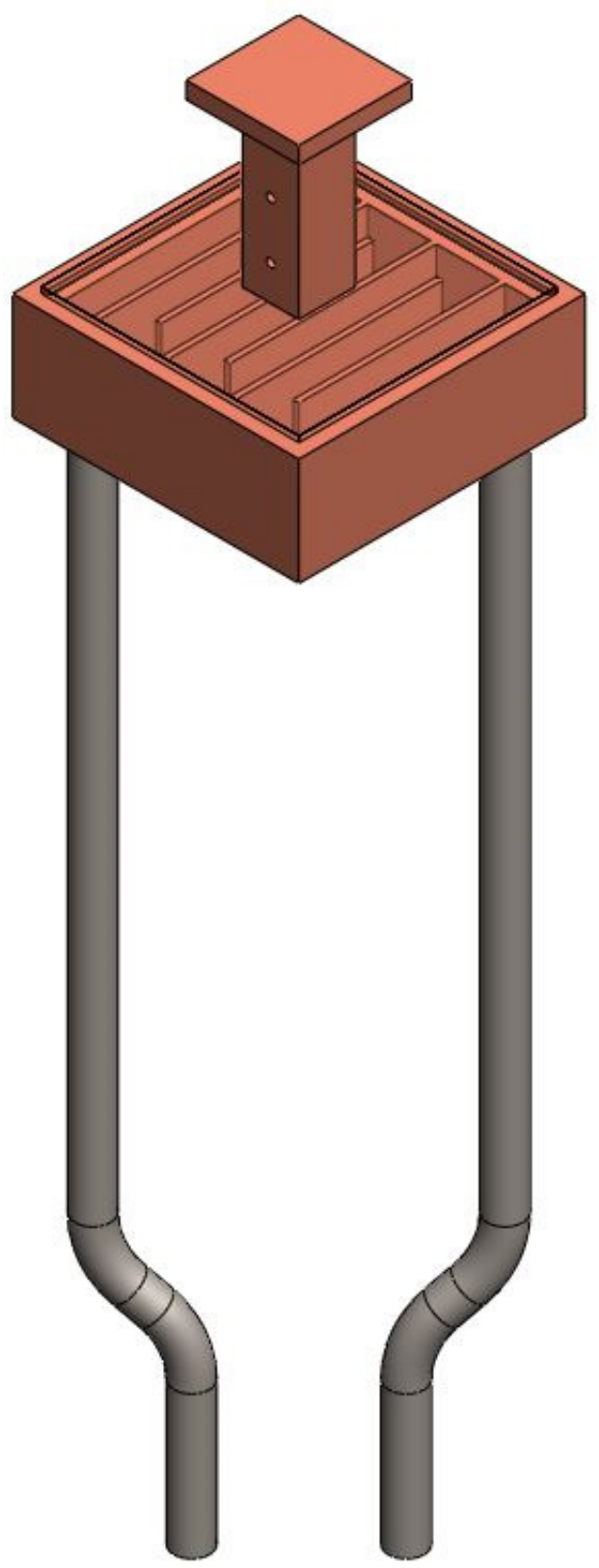

Figure 3.8: CAD model of the designed heat exchanger assembly. 


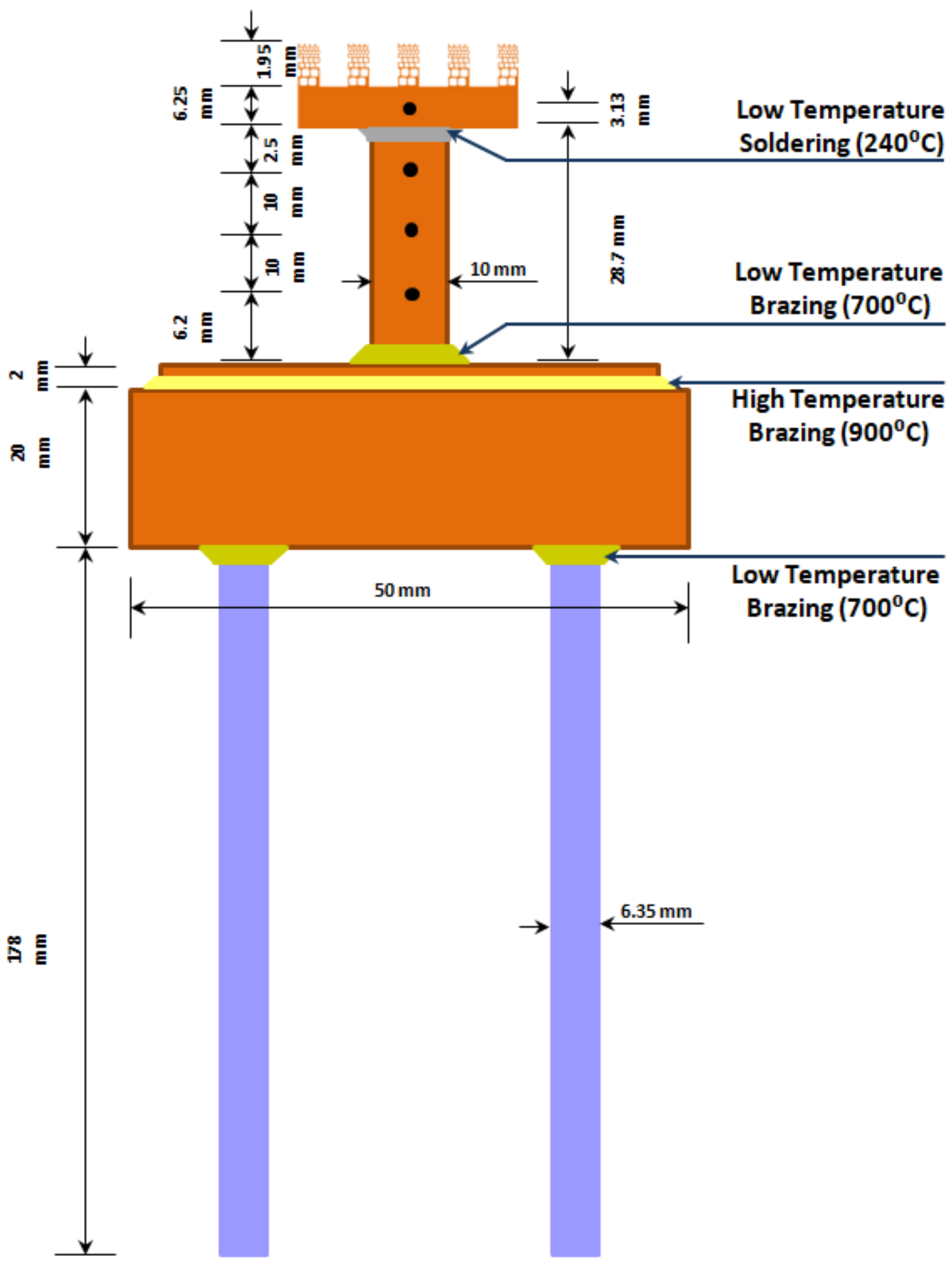

Figure 3.9: Schematic of the assembled heat exchanger module with dimensions. 

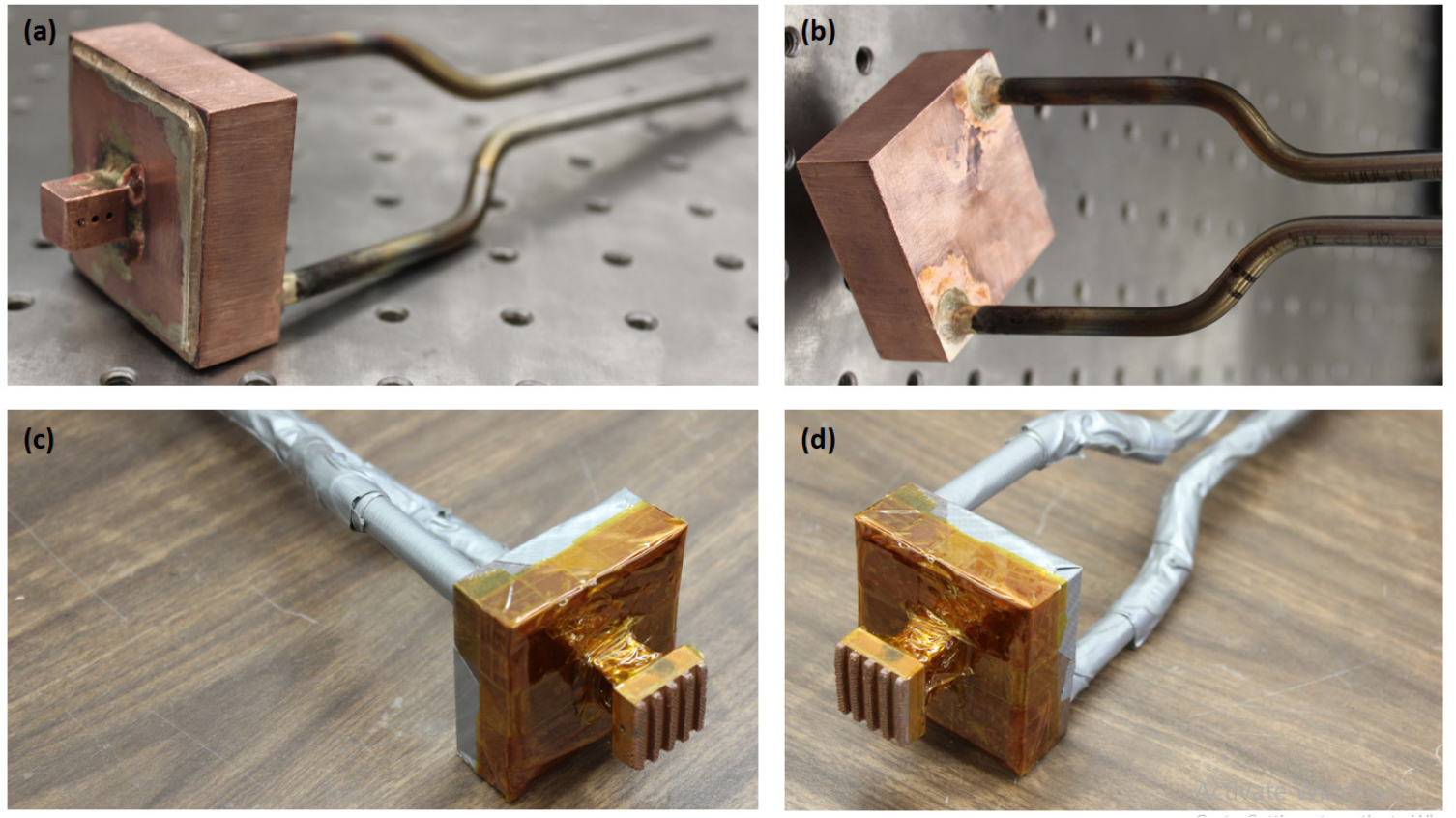

Figure 3.10: Fabricated, brazed, and assembled heat exchanger module: $(a, b)$ heat exchanger with the brazed main body, cover plate, 1D column and feed pipes, and (c, d) heat exchanger with the condensation surface soldered and covered with the first stage of insulation (kapton tape and duct-tape).

The fabricated condensation surface was attached to the top of the $1 \mathrm{D}$ column using a simple low temperature soldering process. A low temperature solder material with a melting point of $240 \square \mathrm{C}$ is placed between the top surface of the 1D column and bottom surface of the condensation surface and the setup is heated. This results in an air gap free soldering of the condensation surface to the $1 \mathrm{D}$ column. This represents an easy mechanism for detaching and attaching of various condensation surfaces to the 1D column.

\subsubsection{Fixing the Heat Exchanger to the Liquid Feedthrough}

The liquid feedthrough of the vacuum chamber consisted of four 1/4" pipes with attached 1/4" Swagelok connectors. The steel pipes of the heat exchangers were double bent to coincide with two pipes of the liquid feedthrough, inserted into the Swagelok connectors, 
and tightened to form airtight seals. The liquid feedthrough was connected to the vacuum chamber through KF40 connections. The entire assembly thus resulted in a separate, tightly sealed loop for the cooling fluid isolated from the rest of the chamber. 


\section{Experimental Setup and Operation}

Considering the extensive research that has been carried out over the past few decades on phase change heat transfer, a major hurdle and stumbling block for the progress of this research has been the validation of the results, repeatability of the results, and nonconforming of the results carried out by various research groups for the same experimental conditions. The reason for such a discrepancy of the results has been the non-uniform methods of measurement employed in collecting the data. One of the major factors affecting the experimental results has been the effect of presence of noncondensable gases close to the condensing surface, which provides an effective thermal barrier for condensation.

Colburn et al. [104] were among some of the early researchers who worked on understanding the effect of non-condensable gases on condensation. Rose et al. [14] and Citakoglu et al. [117] studied the errors in measurement resulting from the presence of non-condensable gases at the condensation surface and showed that the results were hugely affected by the presence of even very small quantities of non-condensable gases at the interface. In the studies conducted by Sparrow et al. [118] on laminar film condensation, very small quantities of non-condensable gases showed significant reduction in heat transfer. Denny et al. [119] investigated analytically the effect of various species of mixtures containing non-condensable gases. Condensation in enclosures represents situations where the concentration of non-condensable gases increases at the condensing surface and hence has greater significance on heat transfer as showed by Wang et al. [120]. Similarly Kageyama et al. [121] provided resistance 
network models to correlate the experimental data. As the condensation proceeds, the vapor containing the non-condensable gases is brought closer to the surface. As a result, the concentration of these gases at the condensing surface increases. Due to concentration gradient established, the gases diffuse away from the surface into the vapor in the immediate vicinity. The condensing surface is therefore deprived of vapor and hence the rate of condensation decreases greatly. To further understand this phenomenon, Thiel et al. [122] studied the effect of high concentrations of non-condensable gases at the condensing surface. A number of other research groups have also actively pursued the understanding of the effect of varying concentrations and species of non-condensable gases on various geometries [123-130]. Most of the research indicates that the true performance of a surface in phase change heat transfer can be gauged uniformly only in the absence of these non-condensable gases.

Hence, the condensation experimentation was carried out in vacuum to remove the effect of any non-condensable gases and maintain the consistency of the measured data. To accurately measure the heat flux through the $1 \mathrm{D}$ column, one critical criteria is to prevent any external heat addition to the $1 \mathrm{D}$ column through its side faces. By ensuring heat conduction through the $1 \mathrm{D}$ column occurs only due to its interactions between the cover plate and the condensation surface and not its lateral faces, we can conclude that temperatures differences between the three thermocouples along the 1D column are caused only due the heat addition from the condensation surface, which directly reflects the rate of condensation. In addition, to effectively utilize the cooling effect of the coolant only for the condensation surface, we have to ensure there is no external heat addition to 
the heat exchanger from elsewhere and that condensation does not occur anywhere on the heat exchanger. Both of the above-described effects can be achieved by providing a very good insulation around the heat exchanger, especially around the 1D column. The heat exchanger surfaces and the $1 \mathrm{D}$ column were covered by three layers of kapton tape to serve as the first stage of insulation. For the second stage, we used thick layers of stone wool with a thermal conductivity of $0.03 \mathrm{~W} / \mathrm{m} . \mathrm{K}$. A one-inch-thick layer of stone wool was wrapped around all the surfaces of the heat exchanger and packed tightly around the 1D column. The stone wool was held in place by wrapping seven to eight layers of ducttape around the stone wool, which serves as the third stage of insulation. The lateral and bottom surfaces of the condensation surface were also covered to prevent condensation on these faces.

\subsection{Condensation Test Setup Components}

The condensation test setup consisted of a vacuum chamber, the insulated heatexchanger, and condensation surface assembly, Novec 7100 / Water (working fluid), thermocouples, pressure transducer, piping for cooling water flow, data acquisition system for measuring real-time temperature, multimeter to measure the voltage from the pressure transducer, copper heating block with cartridge heaters and an insulation brick on which the entire test setup is placed.

\subsubsection{Vacuum Chamber}

The vacuum chamber used for the condensation experiment was a stainless steel structure that resembles a $4 "$ diameter cross-junction pipe. The chamber was 10" in length, 6" in 
width, and 10" in height. It consisted of four ISO100 type connections and a KF25 type connection. An ISO100 type glass viewport was fixed to the ISO100 junction closest to the condensation surface. A stainless steel cross-junction pipe with four KF40 type connections, a stainless steel T-junction pipe with three KF40 type connections, and an ISO100 to KF40 adapter were employed in conjunction with the vacuum chamber to attach the other required parts and assemble a functional setup. All components to be attached to vacuum chamber were such that they have KF40 connections, which can be securely connected using KF40 O-rings and KF40 clamps and seal them airtight. The vacuum chamber is shown in Figure 4.1.
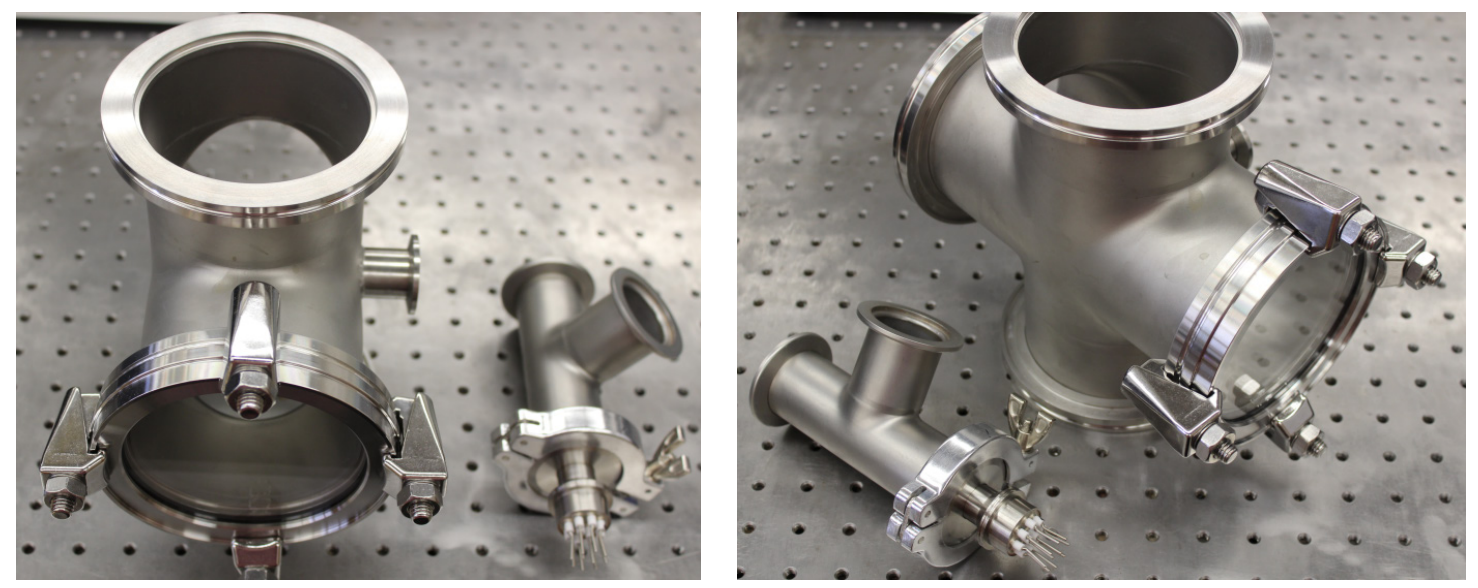

Figure 4.1: Vacuum chamber with the viewport and KF40 T-junction.

\subsubsection{Thermocouples and Data Acquisition System}

Five thermocouple probes were used to measure working temperatures of the test setup. The thermocouple were calibrated by a constant temperature bath to an accuracy of \pm 0.2 $\mathrm{K}$ before the experiments. Three thermocouples were inserted into the three pre-drilled holes in the $1 \mathrm{D}$ column. One thermocouple was inserted into the hole drilled in the condensation surface to measure the surface temperature of the condensation surface. 
One thermocouple was placed in the Novec 7100 fluid to measure temperature of the liquid during the experiment. Two more thermocouples were inserted into 1/4" pipes of the heat exchanger module to measure the inlet and outlet cooling water temperatures. The five thermocouples inside the vacuum chamber were connected internally to a ten-pin thermocouple feedthrough. The pins on the atmospheric side of the thermocouple feedthrough and the two thermocouples inserted in the heat exchanger were all connected to an Agilent/HP 34972A LXI Data Acquisition Switch Unit, which displays and records the real-time temperatures of all the thermocouples. The thermocouples and the data acquisition system used are shown in Figure 4.2.
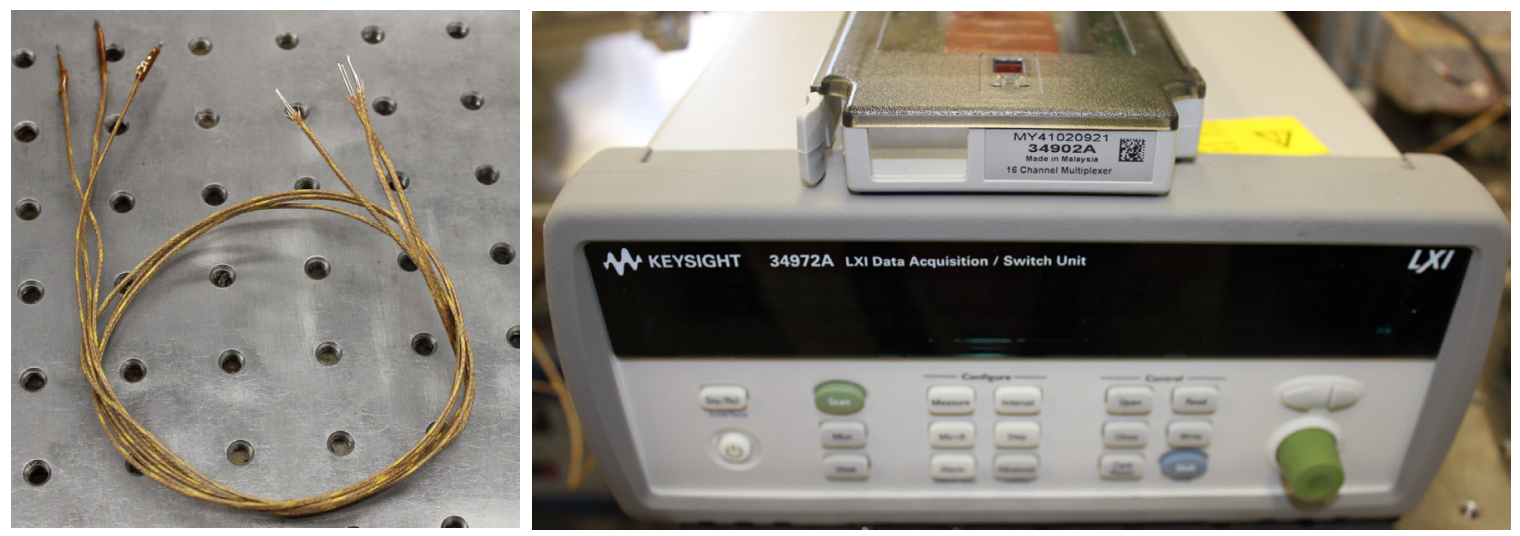

Figure 4.2: Thermocouples (left), and the data acquisition system (right) used in the experiment.

\subsubsection{Pressure Transducer, DC Power Source, and Multimeter}

A high accuracy silicon pressure transducer with a steel diaphragm was mounted on one of the free pipes in the liquid feedthrough to measure the saturation pressure of the fluid during the experiment. The absolute pressure transducer used was an Omega PX309 model with pressure measuring range of $0 \mathrm{kPa}$ to $101.325 \mathrm{kPa}$ ( 0 to $15 \mathrm{psi})$. The sensor takes an excitation voltage of $10 \mathrm{~V}$ and provides an output voltage of $0 \mathrm{mV}$ to $100 \mathrm{mV}$ 
corresponding to a pressure of $0 \mathrm{kPa}$ to $101.325 \mathrm{kPa}$ respectively. The pressure transducer comes with a 1/4" 18 - MNPT connection and hence a Swagelok junction with a $1 / 4 " 18$ - FNPT connection at one end, was used to mount the pressure transducer vertically on the liquid feedthrough pipe. A DC power source device was used to provide the excitation voltage and a Keithley 2700 Multimeter/Data Acquisition System was utilized to measure the output voltage of the pressure transducer. The combination of the high accuracy multimeter and pressure give precise values of the saturation pressure of the fluid in real-time. The effect of the condensate on the measuring diaphragm was negligible as the pressure readings were consistent with prolonged usage and varying stages of condensation. The pressure transducer, dc source and multimeter used to measure the pressure are shown in Figure 4.3.
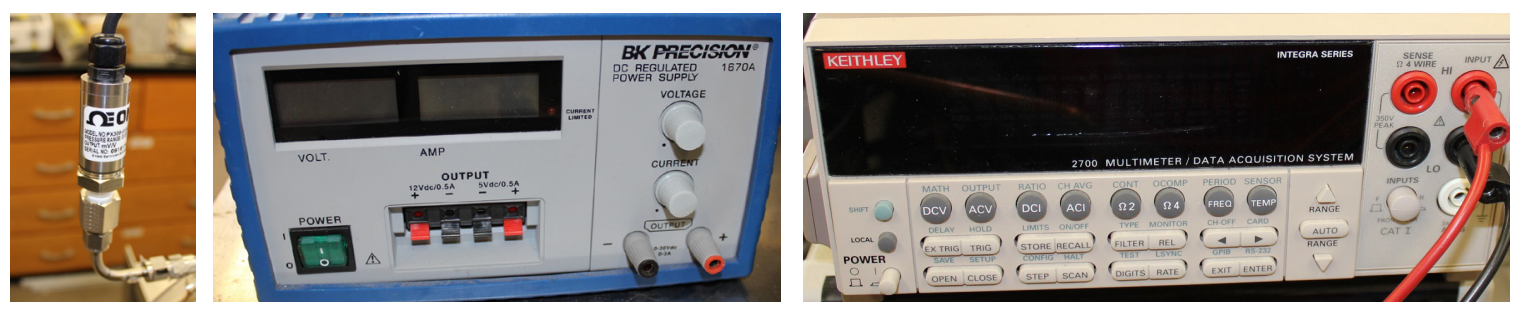

Figure 4.3: Pressure transducer - PX309-015AV model (left) with the DC power source (mid) and the Keithley 2700 multimeter (right).

\subsubsection{Heating Block and Cooling Water}

A copper block with holes drilled to house two $250 \mathrm{~W}$ cartridge heaters was used to heat the Novec 7100 and Water fluids to generate vapor during the experiment. The copper heating block was placed on an insulation brick to avoid loss of heat and effectively utilize the heat output of the block. The vacuum chamber was placed on the copper heating block to ensure close contact of the block with the setup. The inlet and outlet 
pipes of the liquid feedthrough were connected to a constant temperature water supply, which functions as the coolant. As a result, the inside of the heat exchanger with the liquid feedthrough pipes form a separate, isolated, cooling loop which was always at atmospheric pressure irrespective of the pressure inside the vacuum chamber.

\subsubsection{Novec 7100 Dielectric Fluid}

Novec 7100 dielectric fluid was used as the low surface tension working fluid in this experimentation. The fluid has a low surface tension of $13.6 \mathrm{mN} / \mathrm{m}$ and serves as an ideal fluid to display the effectiveness of the fabricated condensation surface due to its extreme wetting characteristics. About $250 \mathrm{ml}$ of the fluid is filled in the vacuum chamber for the experimentation. Salient properties of Novec 7100 are provided in Table 4.1.

Table 4.1: Specifications Properties of Novec 7100 Dielectric Fluid

\begin{tabular}{|c|c|c|}
\hline Property & Unit & Value \\
\hline Boiling Point & ${ }^{\circ} \mathrm{C}$ & 61 \\
\hline Vapor Pressure & $\mathrm{kPa}$ & 27 \\
\hline Heat of Vaporization & $\mathrm{kJ} / \mathrm{kg}$ & 112 \\
\hline Liquid Density & $\mathrm{Kg} / \mathrm{m}^{3}$ & 1510 \\
\hline Vapor Density & $\begin{array}{c}8.6 \times 1.225 \\
\mathrm{~kg} / \mathrm{m}^{3}(\mathrm{air})\end{array}$ & 10.535 \\
\hline Kinematic Viscosity & $\mathrm{cSt}$ & 0.38 \\
\hline Absolute Viscosity & $\mathrm{cP}$ & 0.58 \\
\hline Specific Heat & $\mathrm{J} / \mathrm{kg}-\mathrm{K}$ & 1183 \\
\hline Thermal Conductivity & $\mathrm{W} / \mathrm{m}-\mathrm{K}$ & 0.069 \\
\hline Surface Tension & $\mathrm{mN} / \mathrm{m}$ & 13.6 \\
\hline
\end{tabular}




\subsection{Assembly of the Experimental Setup}

Vacuum chamber formed the main body of the experimental setup to which all other components were attached. The schematic and actual assembled condensation experimental setups are shown in Figure 4.4 and Figure 4.5, respectively. The left limb ISO100 connection was fixed with a glass viewport to visualize the surface during condensation. Novec 7100 fluid was filled in the bottom limb of the vacuum chamber as shown (Water is filled in case of testing with water). The top and bottom ISO100 connection were closed with ISO100 steel caps and O-rings to seal them airtight. The right lib of the chamber was connected to an ISO100 to KF40 adaptor. The KF40 junction of the adaptor was connected to a KF40 cross-junction pipe on the right. The liquid feedthrough was fixed through the KF40 cross-junction as shown in the figure. One of the remaining KF40 ends of the cross-junction was connected to the thermocouple feedthrough. The pressure transducer was mounted on a free pipe of the liquid feedthrough. The inlet and outlet pipes of the feedthrough were connected to a constant temperature water supply and sink respectively. The entire setup was placed on the copper heating block. The cartridges heaters in the heating block were connected to a variac. The thermocouple feedthrough pins were connected to the Agilent data acquisition system using the same thermocouple wire material as the one used inside the chamber. The pressure transducer was connected to the DC power source and Keithley multimeter to complete the assembly of the condensation experimental setup. 


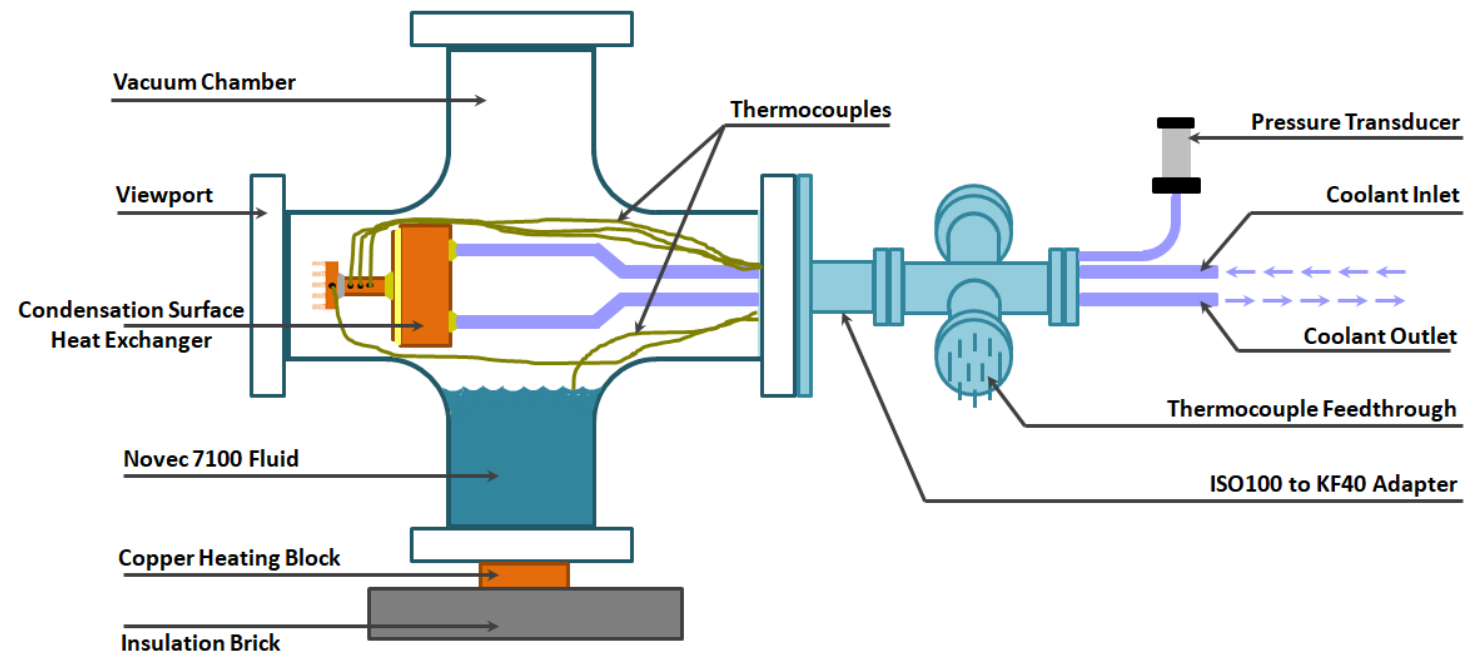

Figure 4.4: Schematic of Condensation Experimental Setup.
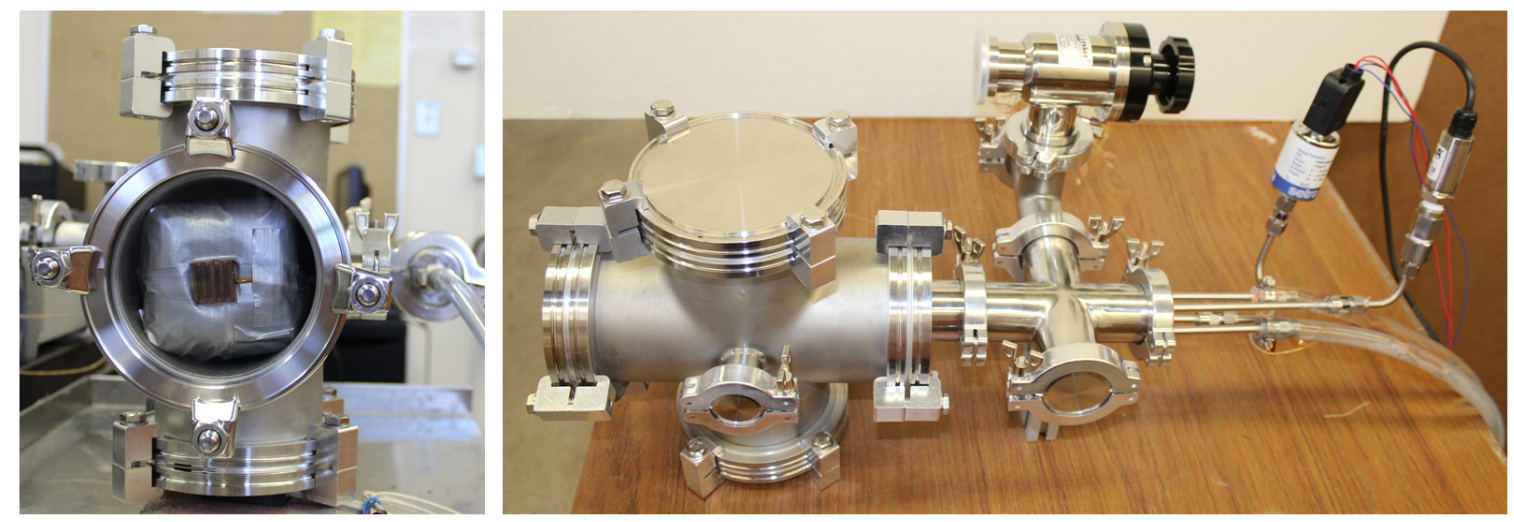

Figure 4.5: Assembled condensation test setup.

\subsection{Operation}

Once the test setup was assembled, the chamber was vacuumed to well below the saturation pressure of the liquid calculated from the liquid temperature readings. This was typically around $20 \mathrm{kPa}$ for a temperature of about $23 \square \mathrm{C}$ for the Novec 7100 Fluid (around $2.81 \mathrm{kPa}$ for a temperature of about $23 \square \mathrm{C}$ for water). Then, the pressure was reduced even further, for example, to a value of $15 \mathrm{kPa}$ for Novec ( $1 \mathrm{kPa}$ for Water), to remove any non-condensable gases to the maximum extent possible. The loss of the evaporated fluid due to lower pressures was considered during the initial charging 
process. The temperature and pressure measurement devices were activated to obtain real-time temperature and pressure readings of the setup. Initially, due to low pressures inside the chamber, the temperature of the fluid dropped to match the saturation temperature corresponding to the pressure inside the chamber. The evaporation continuously increased inside the chamber as external heat was added to the chamber to bring the chamber close to room temperature. The cooling water supply was turned on and a voltage of about $20 \mathrm{~V}$ is supplied to the heating block. The entire setup reaches an equilibrium with the constant temperatures being displayed for all the thermocouples connected. This initial process takes about 1.5 hours. The thermocouples in the 1D column showed a constant difference in temperature between them indicating the heat flux that is being added to the condensation surface during condensation. The cooling water inlet and outlet temperatures also showed a constant difference indicated the rate of heat addition to the heat exchanger is also constant. The temperature and pressure readings and the flowrate of the cooling fluid were recorded at this equilibrium state. The voltage of the heating block was further increased by $10 \mathrm{~V}$ keeping all other parameters constant. As a result of this, the rate of evaporation increases due to the increased heat added from the heating block. The temperature of the cooling water would remain the same with negligible variation in temperature. After a while, a new equilibrium state was established. The setup takes about 0.5 to $0.75 \mathrm{hrs}$ to reach the new equilibrium state. Temperatures and pressure are recorded at this state, the voltage of the heating block was further increased by $10 \mathrm{~V}$, and the process continued. Recordings showed that with increase in the heat addition, the temperature difference in the $1 \mathrm{D}$ column and thus the rate of condensation increased. 


\subsection{Uncertainty Analysis}

Uncertainty analysis is performed to determine the possible error ranges, for all the measured and calculated values, depending on the accuracies of the all the measuring devices. The final results in the following sections are reported by incorporating the results of the uncertainty analysis, in the form of error bars, so as to account for possible uncertainties in the temperatures measured and subsequent calculations of heat fluxes, heat transfer coefficients and equivalent film thicknesses. The formulae used for the uncertainty analyses are as shown below.

The uncertainty in the measurements provided by the thermocouples is taken as $\delta T=$ $\pm 0.2 \mathrm{~K}$ and the accuracy in the dimensions of the precision-machined parts, such as the fabricated condensation surface, 1D column, heat exchanger assembly etc. are taken as $\delta t= \pm 0.00015 m$.

The uncertainty in the calculation of heat flux values is performed as

$$
\frac{\delta q^{\prime \prime}}{q^{\prime \prime}}=\sqrt{\left(\frac{\delta\left(\Delta T_{c}\right)}{\Delta T_{c}}\right)^{2}+\left(\frac{\delta t_{c}}{t_{c}}\right)^{2}}
$$

The uncertainty in the calculation of heat transfer coefficient values is performed as

$$
\frac{\delta h}{h}=\sqrt{\left(\frac{\delta q^{\prime \prime}}{q^{\prime \prime}}\right)^{2}+\left(\frac{\delta(\Delta T)}{\Delta T}\right)^{2}}
$$

The uncertainty in the calculation of equivalent film thickness values is performed as

$$
\frac{\delta t_{f}}{t_{f}}=\sqrt{\left(\frac{\delta q^{\prime \prime}}{q^{\prime \prime}}\right)^{2}+\left(\frac{\delta(\Delta T)}{\Delta T}\right)^{2}}
$$




\section{Results and Discussion}

The condensation experiment was performed for three surfaces; a plain copper substrate without the copper meshes (dimensions were the same as those shown in Figure 2.2, but, without the copper meshes); the condensation surface fabricated with capillary bridges exactly as shown in Figure 2.2; and finally the condensation surface with capillary bridges and the additional top cover mesh layer as shown in Figure 2.5. All three surfaces were tested with Novec 7100 Fluid and Water giving a total of six test case results. The temperature and pressure readings along with the cooling water flow rates were recorded during each experiment. The condensation performance for each test case was measured by calculating the respective heat flux through the condensation surface for various temperature driving potentials, i.e., the difference in the saturated temperature and the surface temperature.

The critical parameter of heat flux was calculated through two methods. The first method was the conventional method of determining the inlet and outlet temperatures of the cooling water through the heat exchanger and determining the flow rate of the cooling water. A separate dry test (i.e., without condensing vapor) determined heat loss at each surface temperature. The rate of heat removal by the cooling water thus gives a measure of the rate of latent heat added to the condensation surface and hence the heat flux of the surface can be calculated using the below formula:

$$
q^{\prime \prime}=\frac{\dot{m} \times C_{p} \times\left(T_{\text {out }}-T_{\text {in }}\right)-q_{\text {loss }}}{\text { Surface Area }}=\frac{\dot{m} \times C_{p} \times\left(T_{\text {out }}-T_{\text {in }}\right)-q_{\text {loss }}}{A}
$$


The surface temperature of the condensation surface was obtained by extrapolation of the temperature reading of thermocouple at the center of condensation surface. The saturation temperature of the working fluid was calculated from the saturation pressure reading.

The second method of determining the heat flux was based on the temperature differences in the 1D column. The rate of heat conduction through the copper 1D column gives a more accurate measure of the rate of latent heat of condensation added to the surface during the process. The heat flux of the surface can be calculated using the 1Dcolumn temperatures using the below formula:

$q^{\prime \prime}=k \frac{\Delta T_{c}}{L}$

We have observed that heat flux calculated based on the above methods are close and hence either of the methods is suitable for the heat flux calculations.

The results of the six test cases are provided in the following sections. In the following, the condensation surface initially fabricated without the covering top mesh is referred to as 'surface 1' and the surface fabricated with the additional cover mesh layer is referred to as 'surface 2 '.

\subsection{Performance Comparison of Water}

Figure 5.1 shows the heat flux of the plain surface and surface 1 at different subcooling temperatures (i.e., $\mathrm{T}_{\text {sat }}-\mathrm{T}_{\text {surface }}$ ) for condensate water vapor. The results indicate a linear trend where the heat flux, and hence, the rate of condensation increase at higher subcooling temperature potential for both surfaces. It can be also seen that the surface 1 
has a better heat flux compared to the plain surface. For instance, the heat flux of the surface 1 is increased by around $47 \%$ compared to the plain surface at a subcooling temperature of $4^{\circ} \mathrm{C}$. The increase in the condensation heat flux is believed to be due to the induced capillary assisted effect combined with the gravitationally driven flow of the condensate vapor along with the added surface area for condensation process through the bonded copper meshes. However, the present capillary assisted condensation surfaces were particularly designed for low surface tension liquids, and not for water. The capillary length of water is $\sim 2.7 \mathrm{~mm}$, which is higher than the distance between the capillary bridges. This results the condensate water vapor to remain filled in the channels between the capillary bridges. Therefore, the present capillary assisted condensation surfaces probably underperform compared to a capillary assisted condensation surface optimized for water.

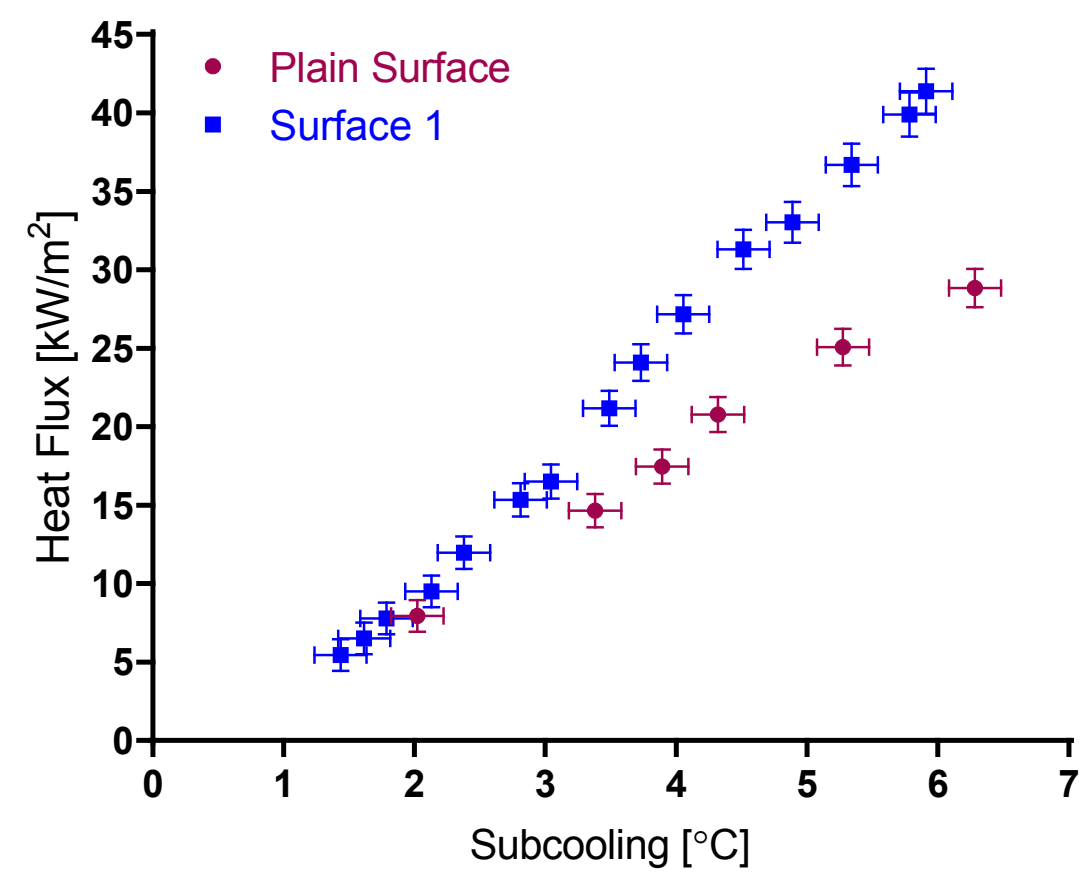


Figure 5.1: Heat flux of the plain surface and the capillary assisted condensation surface 1 at different subcooling temperatures for condensate water vapor.

The capillary assisted condensation surface 2 fabricated with an additional top cover layer compared to surface 1 is also observed to perform better than the plain surface as shown in Figure 5.2. Here, a similar linear trend of increasing heat flux with subcooling temperature is observed. Although not specifically designed for water, both the fabricated surfaces showed an improved condensation performance compared to a plain surface. Surface 2 has a higher heat flux of around $82 \%$ when compared to the plain surface at a subcooling temperature of $4^{\circ} \mathrm{C}$. A higher condensation heat transfer of surface 2 compared to surface 1 is attributed to the additional condensation area available through the top cover layer mesh. Although both of these surfaces ultimately result in filmwise condensation at high subcooling temperatures, the presence of the cover layer and a lower distance between the capillary bridges seem to significantly improve the performance of surface 2 . The heat fluxes observed in surface 2 are greater than those observed in surface 1 by a factor of 1.75 , at a subcooling temperature of $4^{\circ} \mathrm{C}$. The comparison of heat fluxes for all the surfaces are provided in Figure 5.2. 


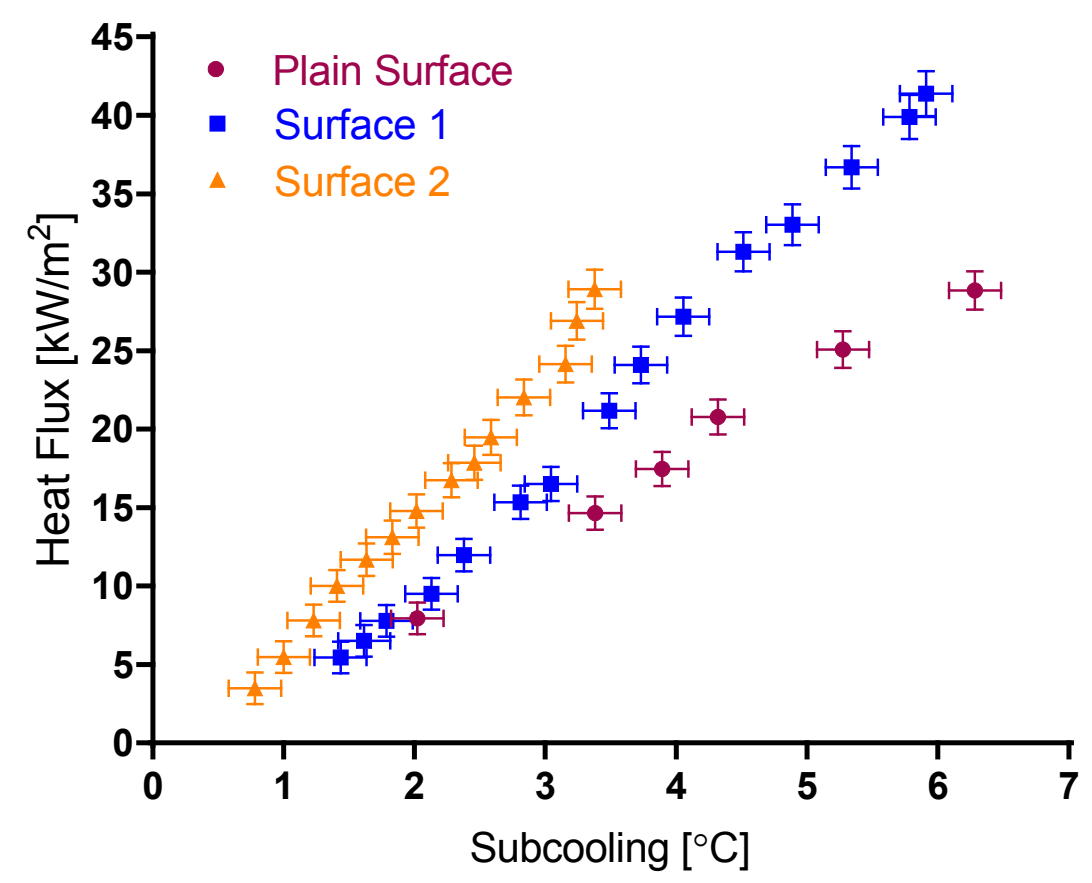

Figure 5.2: Heat flux of the plain surface and the capillary assisted condensation surface 1 and 2 at different subcooling temperatures for condensate water vapor.

Heat transfer coefficient for both the working fluids and all three surfaces can be calculated from the below formula:

Heat transfer coefficient $\left[\frac{W}{m^{2}-K}\right]=\frac{\text { Heat Flux }\left[\frac{W}{m^{2}}\right]}{\text { Subcooling }[K]} \rightarrow h\left[\frac{W}{m^{2}-K}\right]=\frac{q^{\prime \prime}\left[\frac{W}{m^{2}}\right]}{\Delta T[K]}$

The heat transfer coefficients of surface 1 and surface 2 in comparison to the plain surface are provided in Figure 5.3. It can be observed that the heat transfer coefficients of all three surfaces are typical of filmwise condensation. Although, not specifically designed for water, we can observe that heat transfer coefficients of both surface 1 and 2 are higher compared to the plain surface. This increase can be attributed to the increased surface area and also wicking of the condensate into the capillary bridges. At a 
subcooling of $4^{\circ} \mathrm{C}$, we can clearly see that the heat transfer coefficient of plain surface is around $4000 \mathrm{~W} / \mathrm{m}^{2}-\mathrm{K}$ while surfaces 1 and 2 show higher coefficients of around 6000 $\mathrm{W} / \mathrm{m}^{2}-\mathrm{K}$ and $8500 \mathrm{~W} / \mathrm{m}^{2}-\mathrm{K}$ respectively, with a performance increase of $50 \%$ for surface 1 and an increase of more than $100 \%$ for surface 2 .

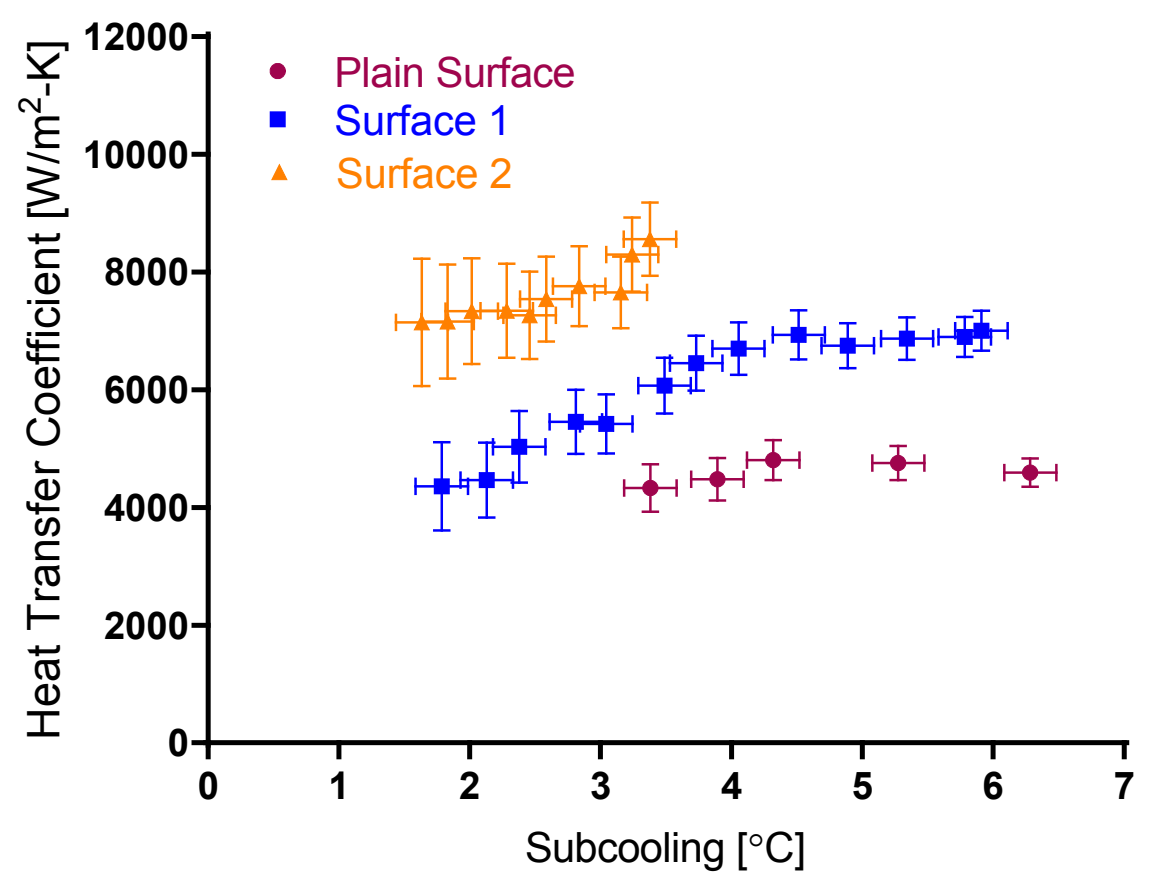

Figure 5.3: Heat transfer coefficient comparison of plain surface with surface 1 and surface 2 (water).

The equivalent liquid film thickness for both the working fluids and all three surfaces can be calculated from the below formula:

Equivalent liquid film thickness $[\mathrm{m}]$

$$
=\frac{\text { Thermal conductivity of fluid }\left[\frac{W}{m-K}\right] \times \text { Subcooling }[K]}{\text { Heat Flux }\left[\frac{W}{m^{2}}\right]}
$$


$t_{f}[\mu m]=\frac{k\left[\frac{W}{m-K}\right] \times \Delta T[K]}{q^{\prime \prime}\left[\frac{W}{m^{2}}\right] \times 1000000}$

The equivalent liquid film thickness during condensation of water vapor on all investigated surfaces is shown in Figure 5.4. The equivalent liquid film thickness provides a general understanding on the thickness range of liquid films present during the condensation process. It is evident that the average equivalent film thicknesses are lower for both surfaces 1 and 2 compared to the plain surface. At a subcooling of $4^{\circ} \mathrm{C}$, we can observe that the equivalent falling film thickness is 140 microns for plain surface, which subsequently decreases to around 90 microns, and 60 microns for surfaces 1 and 2, respectively.

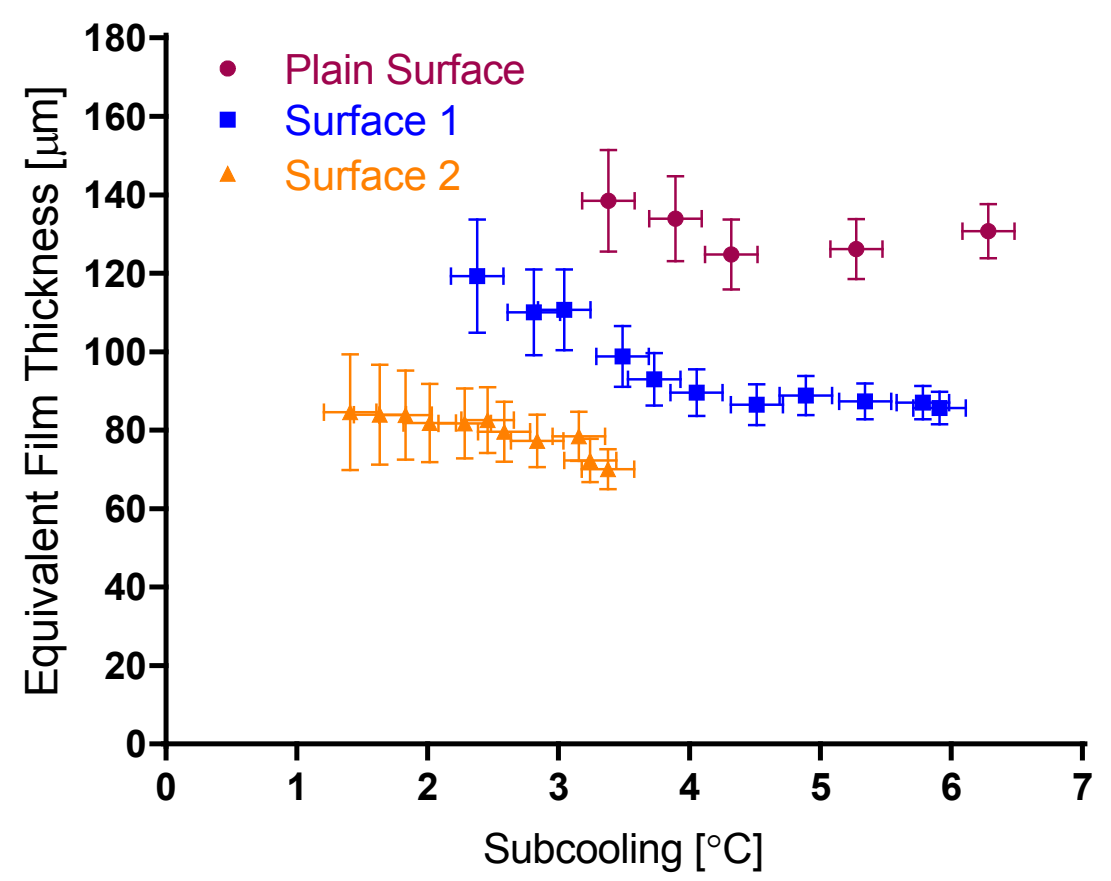

Figure 5.4: Equivalent liquid film thickness for plain surface, surface 1, and surface 2 (water). 


\subsection{Performance Comparison of Novec 7100 Fluid}

Novec 7100 fluid has a capillary length of $0.96 \mathrm{~mm}$ (Appendix A.1). Both the fabricated surfaces are designed such that the channel widths are greater than this value of capillary length to ensure that the liquid does not remain pinned in the channels. The heat flux comparison of plain surface with surface 1 for Novec 7100 is provided in Figure 5.5. The results indicate a linear trend of increasing heat flux with increasing subcooling temperature. The heat fluxes obtained from the plain surface were in the expected range as these values are in good agreement with the experimental condensation data available in literature for low surface tension liquids such as FC-72 (which has physical properties very similar to Novec 7100). It can be observed that the heat fluxes for surface 1 are significantly greater than the plain surface by a factor of around 3 at a subcooling temperature of $8^{\circ} \mathrm{C}$. Therefore, the condensation heat transfer rate is improved by around $200 \%$. The condensation heat transfer performance of surface 1 is significantly higher than the plain surface due to the increased surface area, and the induced capillary effect coming into play to effectively remove the condensate. 


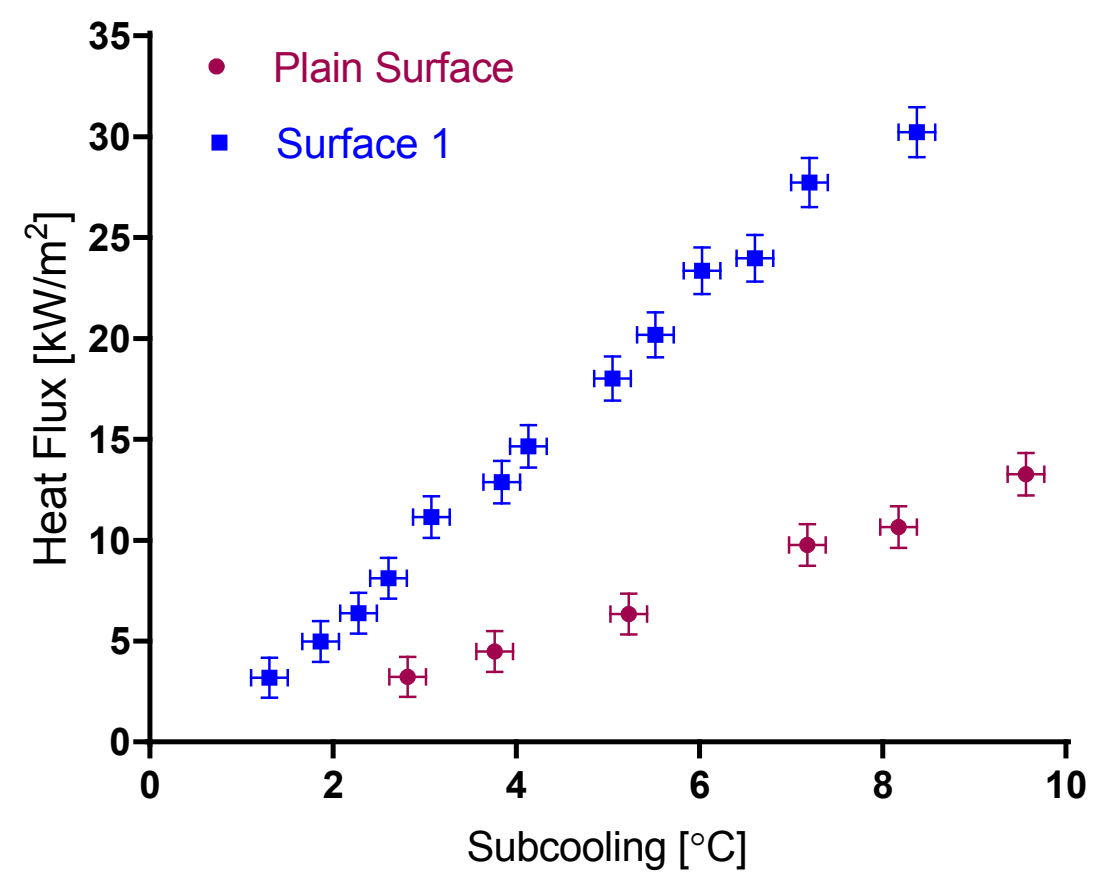

Figure 5.5: Heat flux of the plain surface and the capillary assisted condensation surface 1 at different subcooling temperatures for condensate Novec 7100 vapor.

Surface 2 with an additional cover mesh layer and a decreased channel width further enhances the rate of condensation of Novec 7100 fluid as can be observed from the results in Figure 5.6. The condensation performance for surface 2 is increased by more than $350 \%$ compared to a plain surface at a subcooling temperature of $7^{\circ} \mathrm{C}$. This increase can be owed to general increase in the surface area due to the copper meshes, and the additional surface area provided by the cover mesh layer. Hence, surface 2 proved to be the best surface to enhance the condensation performance of Novec 7100 fluid with increased performances of greater than $350 \%$ and more than 4.5 times increase in heat flux values. Surface 2 out performs surface 1 by a factor of 1.4 at a subcooling temperature of $7^{\circ} \mathrm{C}$. The maximum heat flux measured was around $45 \mathrm{~kW} / \mathrm{m}^{2}$ for a temperature difference of $7^{\circ} \mathrm{C}$, for surface 2 . Hence, we were able to obtain significantly 
higher heat fluxes and thus enhanced condensation performances for both our fabricated surfaces by employing a cost effective and simple to manufacture the capillary assisted condensate removal method.

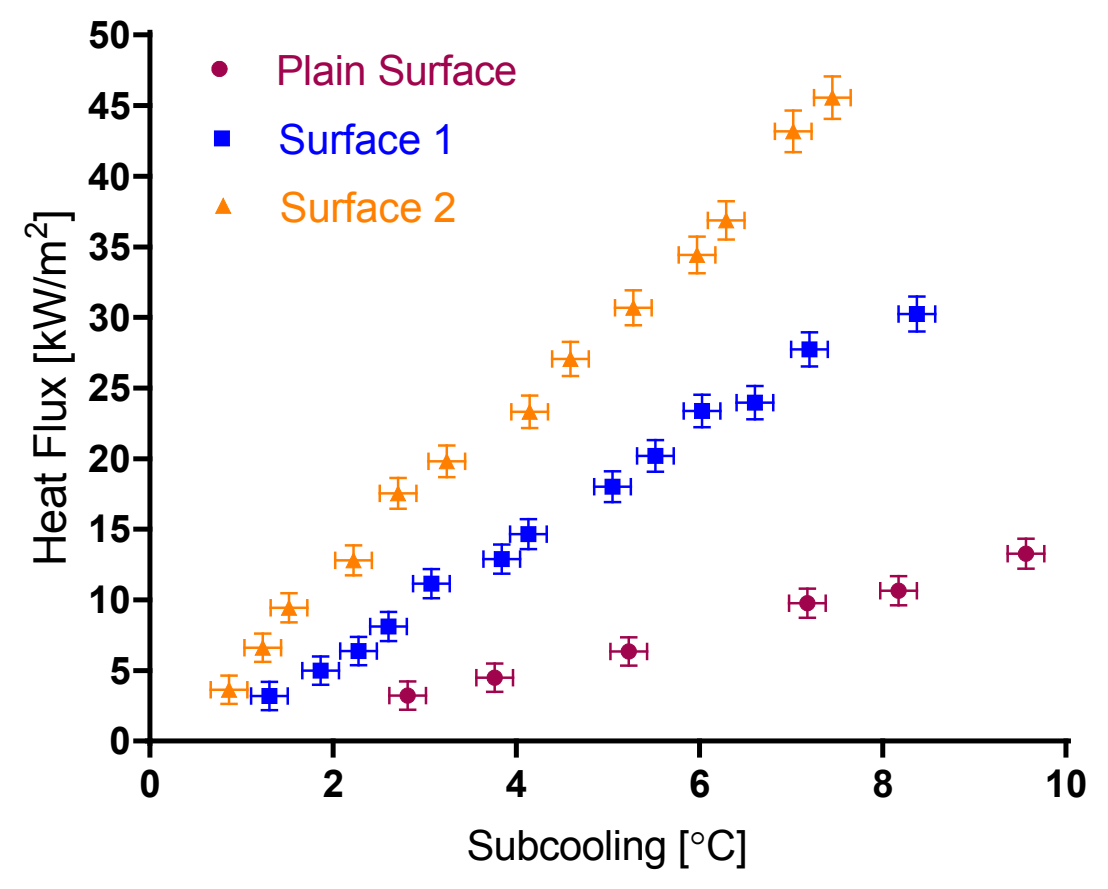

Figure 5.6: Heat flux of the plain surface and the capillary assisted condensation surface 1 and 2 at different subcooling temperatures for condensate Novec 7100 vapor.

There is a significant increase in the heat transfer coefficient due to the presence of capillary bridges and the cover layer as can be observed from Figure 5.7. For subcooling of around $7^{\circ} \mathrm{C}$, the heat transfer coefficient increases 4 times for surface 1 at $4000 \mathrm{~W} / \mathrm{m}^{2}$ $\mathrm{K}$ and 6 times for surface 2 with the cover layer at $6000 \mathrm{~W} / \mathrm{m}^{2}-\mathrm{K}$, compared to a plain surface which is at $1300 \mathrm{~W} / \mathrm{m}^{2}-\mathrm{K}$ for the same subcooling. The wicking effect of the capillary bridges and the additional cover layer effectively assist in increasing the condensation rate as well as the condensate removal rate, and thus the significant increase in the heat transfer coefficient is observed. 


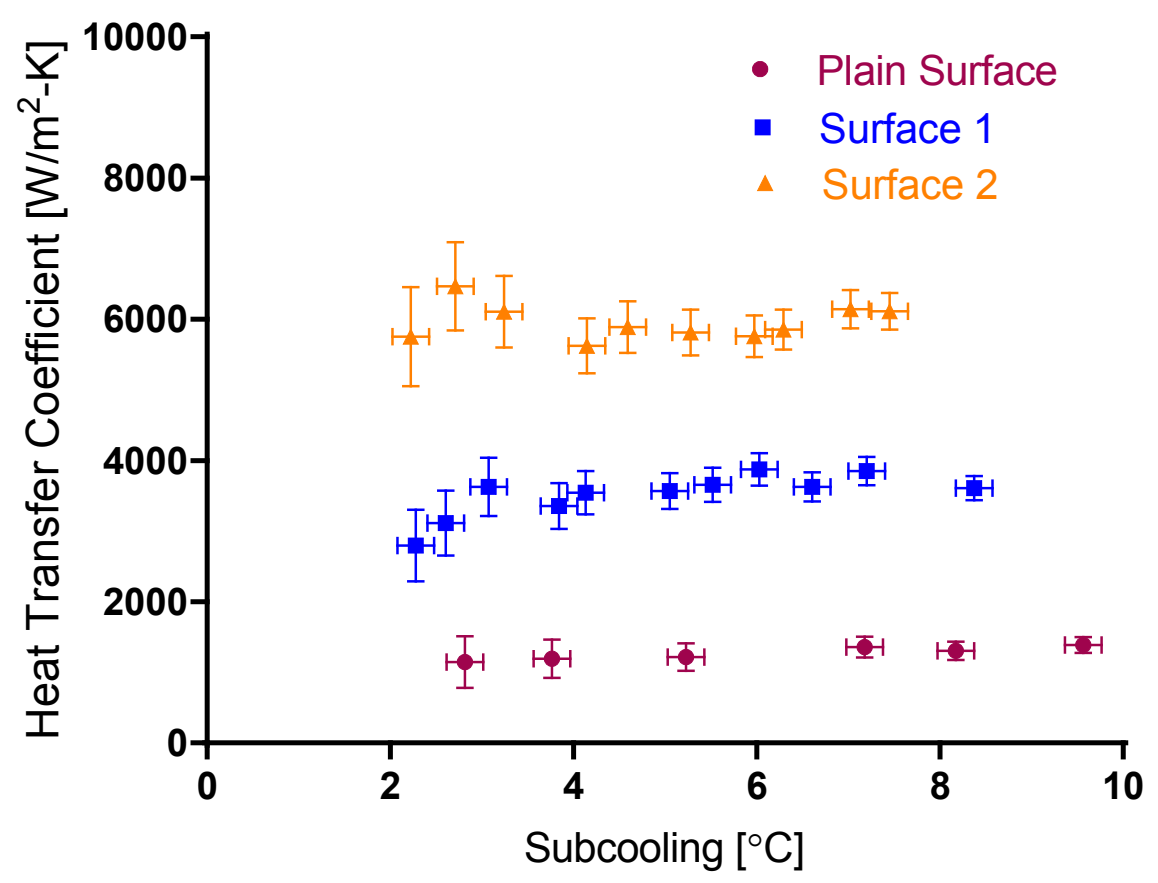

Figure 5.7: Heat transfer coefficient comparison of plain surface with surface 1 and surface 2 (Novec).

It is clearly evident from Figure 5.8, that due to the high wickability of the designed capillary bridges, the condensate is continuously removed from the condensing surfaces and hence a significant reduction in the equivalent liquid film thickness of the condensate is observed. As a result, the thermal barrier for condensation, which is majorly due to the high thickness of the falling film, is reduced by almost 5 times, and the overall condensation heat transfer of the surface is enhanced. For subcooling of around $7^{\circ} \mathrm{C}$, the plain surface shows a thickness of around 55 microns while the equivalent film thickness of surface 1 and 2 are around 20 microns and 10 microns, respectively. 


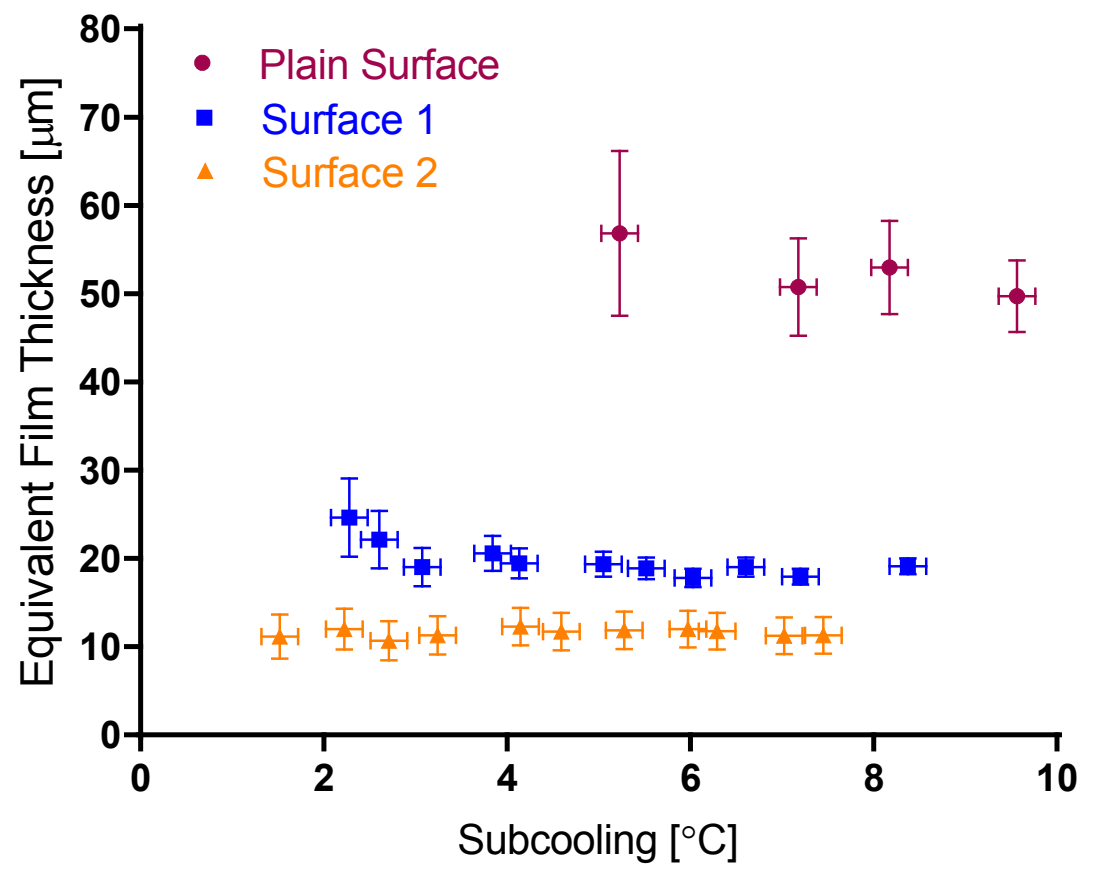

Figure 5.8: Equivalent film thickness for plain surface, surface 1, and surface 2 (Novec). 


\section{Future Scope}

The experiments conducted under this thesis proved that the capillary assisted condensation heat transfer concept could significantly enhance the condensation rate of low surface tension liquids. We are far from fully understanding the behavior of various parameters in enhancing the condensation performance. The potential of such surfaces can be fully realized by thorough optimizing of the surface for a particular liquid. Further fabrication and test are required to characterize the effect of each parameter on the condensation performance. The experimentation could be continued by fabricating surfaces with varying pore sizes of the mesh layers, the number of mesh layers, the width

of the channels, the number of cover layers, the order of mesh layers, the working fluid, and the substrate and mesh material. 


\section{Conclusion}

Condensation of low surface tension liquids typically occurs in the filmwise mode with gravity only the viable means of condensate removal from the surface. With our approach, we have fabricated robust, industrially scalable surfaces to employ an induced capillary pressure combined with the gravitational removal to substantially enhance the condensation heat transfer rate of low surface tension liquids. The new surface effectively decouples the condensation surface and condensate removal paths. We have observed condensation rate improvement by a factor of 3 , at a subcooling of $8^{\circ} \mathrm{C}$, compared to a plain surface, for low surface tension liquids such as Novec 7100. By adding a cover layer and decreasing the channel widths of the condensing surface, we have obtained further enhancement in the condensation rates with a factor of 4.5 , at a subcooling of $7^{\circ} \mathrm{C}$, compared to plain surface for Novec 7100 fluid. Although surfaces particularly fabricated in this thesis were not designed for water, they still provide an improvement in condensation compared to a plain surface. Simple machining processes and diffusion bonding processes were used to manufacture all the surfaces and heat exchangers used for experiments. Thus, we have explored the concept of employing a capillary assisted method to enhance condensation performance of low surface tension liquids and presented, in this thesis, a very simple, cost effect, and scalable approach to fabricate these surfaces. 


\section{Reference List}

1. Hao, Chonglei et al. 2016. "Bioinspired Interfacial Materials with Enhanced Drop Mobility: From Fundamentals to Multifunctional Applications." Small 12(14):1825-39. Retrieved February 28, 2018 (http://doi.wiley.com/10.1002/smll.201503060).

2. Huang, Zhiwei, Yunho Hwang, and Reinhard Radermacher. 2017. "Review of Nature-Inspired Heat Exchanger Technology." International Journal of Refrigeration 78:1-17. Retrieved (http://www.sciencedirect.com/science/article/pii/S0140700717301019).

3. Cho, H.Jeremy, Daniel J. Preston, Yangying Zhu, and Evelyn N. Wang. 2016. "Nanoengineered Materials for Liquid-vapour Phase-Change Heat Transfer." Nature Reviews Materials 2:16092. Retrieved (http://dx.doi.org/10.1038/natrevmats.2016.92).

4. Parker, Andrew R. and Chris R. Lawrence. 2001. "Water Capture by a Desert Beetle." Nature 414:33. Retrieved (http://dx.doi.org/10.1038/35102108).

5. Zheng, Yongmei et al. 2010. "Directional Water Collection on Wetted Spider Silk." Nature 463:640. Retrieved (http://dx.doi.org/10.1038/nature08729).

6. Rolf Kehlhofer, Bert Rukes, Frank Hannemann, Franz Stirnimann, (PennWell, 2009), "Combined-Cycle Gas and Steam Turbine Power Plants", 3rd Edition

7. Beér, János M. 2007. "High Efficiency Electric Power Generation: The Environmental Role." Progress in Energy and Combustion Science 33(2):107-34. Retrieved (http://www.sciencedirect.com/science/article/pii/S0360128506000347).

8. Kandlikar, S. G., Garimella, S., Li, D., Colin, S. \& King, M. R., 2006, "Heat Transfer and Fluid flow in Minichannels and Microchannels." (Elsevier, 2006)

9. Tanasawa, I., 1991, "Advances in Heat Transfer." (Academic Press, 1991)

10. Hung, T. C., T. Y. Shai, and S. K. Wang. 1997. "A Review of Organic Rankine Cycles (ORCs) for the Recovery of Low-Grade Waste Heat.” Energy 22(7):66167. Retrieved (http://www.sciencedirect.com/science/article/pii/S036054429600165X).

11. Luijten, C. C. M., R. G. P. van Hooy, J. W. F. Janssen, and M. E. H. van Dongen. 1998. "Multicomponent Nucleation and Droplet Growth in Natural Gas." The Journal of Chemical Physics 109(9):3553-58. Retrieved (https://doi.org/10.1063/1.476950).

12. Castle, W. F. 2002. "Air Separation and Liquefaction: Recent Developments and Prospects for the Beginning of the New Millennium." International Journal of Refrigeration 25(1):158-72. Retrieved (http://www.sciencedirect.com/science/article/pii/S0140700701000032). 
13. Rufford, T. E. et al. 2012. "The Removal of $\mathrm{CO} 2$ and N2 from Natural Gas: A Review of Conventional and Emerging Process Technologies." Journal of Petroleum Science and Engineering 94-95:123-54. Retrieved (http://www.sciencedirect.com/science/article/pii/S0920410512001581).

14. Rose, J. W. 2002. "Dropwise Condensation Theory and Experiment: A Review." Proceedings of the Institution of Mechanical Engineers, Part A: Journal of Power and Energy 216(2):115-28. Retrieved (https://doi.org/10.1243/09576500260049034).

15. Schmidt, E., W. Schurig, and W. Sellschopp. 1930. "Versuche Über Die Kondensation von Wasserdampf in Film- Und Tropfenform." Technische Mechanik Und Thermodynamik 1(2):53-63. Retrieved (https://doi.org/10.1007/BF02641051).

16. Mikic, B. B. 1969. "On Mechanism of Dropwise Condensation.” International Journal of Heat and Mass Transfer 12(10):1311-23. Retrieved (http://www.sciencedirect.com/science/article/pii/0017931069901744).

17. Hiroaki, Tanaka and Tsuruta Takaharu. 1984. "A Microscopic Study of Dropwise Condensation.” International Journal of Heat and Mass Transfer 27(3):327-35. Retrieved (http://www.sciencedirect.com/science/article/pii/0017931084902801).

18. Rausch, M. H., A. Leipertz, and A. P. Fröba. 2010. "Dropwise Condensation of Steam on Ion Implanted Titanium Surfaces." International Journal of Heat and Mass Transfer 53(1):423-30. Retrieved (http://www.sciencedirect.com/science/article/pii/S0017931009004955).

19. Dietz, C., K. Rykaczewski, A. G. Fedorov, and Y. Joshi. 2010. "Visualization of Droplet Departure on a Superhydrophobic Surface and Implications to Heat Transfer Enhancement during Dropwise Condensation." Applied Physics Letters 97(3):33104. Retrieved (https://doi.org/10.1063/1.3460275).

20. Anand, Sushant, Adam T. Paxson, Rajeev Dhiman, J.David Smith, and Kripa K. Varanasi. 2012. "Enhanced Condensation on Lubricant-Impregnated Nanotextured Surfaces." ACS Nano 6(11):10122-29. Retrieved (https://doi.org/10.1021/nn303867y).

21. Azimi, Gisele, Rajeev Dhiman, Hyuk-Min Kwon, Adam T. Paxson, and Kripa K. Varanasi. 2013. "Hydrophobicity of Rare-Earth Oxide Ceramics." Nature Materials 12:315. Retrieved (http://dx.doi.org/10.1038/nmat3545).

22. T., Paxson Adam, Yagüe Jose L., Gleason Karen K., and Varanasi Kripa K. 2013. "Stable Dropwise Condensation for Enhancing Heat Transfer via the Initiated Chemical Vapor Deposition (iCVD) of Grafted Polymer Films." Advanced Materials 26(3):418-23. Retrieved (https://doi.org/10.1002/adma.201303065).

23. Anderson, David M. et al. 2012. "Using Amphiphilic Nanostructures To Enable Long-Range Ensemble Coalescence and Surface Rejuvenation in Dropwise 
Condensation." ACS Nano 6(4):3262-68. Retrieved

(https://doi.org/10.1021/nn300183d).

24. Torresin, Daniele, Manish K. Tiwari, Davide Del Col, and Dimos Poulikakos. 2013. "Flow Condensation on Copper-Based Nanotextured Superhydrophobic Surfaces." Langmuir 29(2):840-48. Retrieved (https://doi.org/10.1021/1a304389s).

25. Bejan, A.; Kestin, J., 1983, "Entropy Generation Through Heat and Fluid Flow", Journal of Applied Mechanics, vol. 50, issue 2, p. 475, DOI: 10.1115/1.3167072

26. Preston, Daniel J., Daniela L. Mafra, Nenad Miljkovic, Jing Kong, and Evelyn N. Wang. 2015. "Scalable Graphene Coatings for Enhanced Condensation Heat Transfer." Nano Letters 15(5):2902-9. Retrieved (https://doi.org/10.1021/n1504628s).

27. Enright, Ryan, Nenad Miljkovic, Ahmed Al-Obeidi, Carl V Thompson, and Evelyn N. Wang. 2012. "Condensation on Superhydrophobic Surfaces: The Role of Local Energy Barriers and Structure Length Scale." Langmuir 28(40):1442432. Retrieved (https://doi.org/10.1021/la302599n).

28. Wang, T.Humplik and J.Lee and S. C.O'Hern and B. A.Fellman and M. A.Baig and S. F.Hassan and M. A.Atieh and F.Rahman and T.Laoui and R.Karnik and E. N. 2011. "Nanostructured Materials for Water Desalination." Nanotechnology 22(29):292001. Retrieved (http://stacks.iop.org/0957-4484/22/i=29/a=292001).

29. Reifert, V. G., A. I. Sardak, S. V Grigorenko, and V. L. Podbereznyj. 1989. "Heat Exchange at Dropwise Condensation in Heat Exchangers of Desalination Plants." Desalination 74:373-82. Retrieved (http://www.sciencedirect.com/science/article/pii/0011916489850647).

30. Caruso, Gianfranco, Damiano Vitale Di Maio, and Antonio Naviglio. 2013. "Condensation Heat Transfer Coefficient with Noncondensable Gases inside near Horizontal Tubes." Desalination 309:247-53. Retrieved (http://www.sciencedirect.com/science/article/pii/S0011916412005838).

31. Preston, Daniel J., Daniela L. Mafra, Nenad Miljkovic, Jing Kong, and Evelyn N. Wang. 2015. "Scalable Graphene Coatings for Enhanced Condensation Heat Transfer." Nano Letters 15(5):2902-9. Retrieved (https://doi.org/10.1021/n1504628s).

32. D. A. McNeil G. Cuthbertson, B. M.Burnside. 2000. "Dropwise Condensation of Steam on a Small Tube Bundle at Turbine Condenser Conditions." Experimental Heat Transfer 13(2):89-105. Retrieved (https://doi.org/10.1080/089161500269481).

33. Liu, Liping and Jacobi, Anthony M., "The Effects of Hydrophilicity on Water Drainage and Condensate Retention on Air-Conditioning Evaporators" (2006). International Refrigeration and Air Conditioning Conference. Paper 847. http://docs.lib.purdue.edu/iracc/847 
34. Lee, Jaesang, Shaily Mahendra, and Pedro J. J. Alvarez. 2010. "Nanomaterials in the Construction Industry: A Review of Their Applications and Environmental Health and Safety Considerations." ACS Nano 4(7):3580-90. Retrieved (https://doi.org/10.1021/nn100866w).

35. Zhang, F. Y., Yang, X. G., \& Wang, C. Y. (2006). Liquid Water Removal from a Polymer Electrolyte Fuel Cell. Journal of The Electrochemical Society, 153 (2 ), A225-A232. https://doi.org/10.1149/1.2138675

36. Peters, T. B. et al. 2012. "Design of an Integrated Loop Heat Pipe Air-Cooled Heat Exchanger for High Performance Electronics." IEEE Transactions on Components, Packaging and Manufacturing Technology 2(10):1637-48.

37. Park, Kyoo-Chul, Shreerang S. Chhatre, Siddarth Srinivasan, Robert E. Cohen, and Gareth H. McKinley. 2013. "Optimal Design of Permeable Fiber Network Structures for Fog Harvesting." Langmuir 29(43):13269-77. Retrieved (https://doi.org/10.1021/la402409f).

38. Kim, Hyunho et al. 2017. "Water Harvesting from Air with Metal-Organic Frameworks Powered by Natural Sunlight.” Science 356(6336):430 LP-434. Retrieved (http://science.sciencemag.org/content/356/6336/430.abstract).

39. Yadav, Mahesh Kumar, Sameer Khandekar, and Pavan K. Sharma. 2016. "An Integrated Approach to Steam Condensation Studies inside Reactor Containments: A Review." Nuclear Engineering and Design 300:181-209. Retrieved (http://www.sciencedirect.com/science/article/pii/S0029549316000145).

40. Kim, Hyungdae, Tae-Soon Kwon, and Dong Eok Kim. 2016. "Experimental Study of Air-Cooled Water Condensation in Slightly Inclined Circular Tube Using Infrared Temperature Measurement Technique." Nuclear Engineering and Design 308:38-50. Retrieved (http://www.sciencedirect.com/science/article/pii/S0029549316302710).

41. Kashchiev, D. (2000). "Nucleation: Basic theory with applications". Oxford: Butterworth Heinemann.

42. O'neill, Gary A. and J. W. Westwater. 1984. "Dropwise Condensation of Steam on Electroplated Silver Surfaces." International Journal of Heat and Mass Transfer 27(9):1539-49. Retrieved (http://www.sciencedirect.com/science/article/pii/0017931084902667).

43. Detz, Clifford M. and Robert J. Vermesh. 1976. "Nucleation Effects in the Dropwise Condensation of Steam on Electroplated Gold Surfaces." AIChE Journal 22(1):87-93. Retrieved (http://dx.doi.org/10.1002/aic.690220110).

44. Erb, R. and Thelen, E., 1965. Promoting permanent dropwise condensation. Industrial \& Engineering Chemistry, 57(10), pp.49-52. 
45. Wilkins, David G., Leroy A. Bromley, and Stanley M. Read. 1973. "Dropwise and Filmwise Condensation of Water Vapor on Gold." AIChE Journal 19(1):11923. Retrieved (http://dx.doi.org/10.1002/aic.690190117).

46. Woodruff, David W. and J. W. Westwater. 1979. "Steam Condensation on Electroplated Gold: Effect of Plating Thickness." International Journal of Heat and Mass Transfer 22(4):629-32. Retrieved (http://www.sciencedirect.com/science/article/pii/0017931079900668).

47. Marto, P.J., Looney, D.J., Rose, J.W. and Wanniarachchi, A.S., 1986. Evaluation of organic coatings for the promotion of dropwise condensation of steam. International journal of heat and mass transfer, 29(8), pp.1109-1117.

48. Bonner Richard W., I. I. I. 2010. "Dropwise Condensation Life Testing of Self Assembled Monolayers." (49378):221-26. Retrieved (http://dx.doi.org/10.1115/IHTC14-22936).

49. Vemuri, S., K. J. Kim, B. D. Wood, S. Govindaraju, and T. W. Bell. 2006. "Long Term Testing for Dropwise Condensation Using Self-Assembled Monolayer Coatings of N-Octadecyl Mercaptan." Applied Thermal Engineering 26(4):42129. Retrieved (http://www.sciencedirect.com/science/article/pii/S1359431105001985).

50. Vemuri, S. and K. J. Kim. 2006. "An Experimental and Theoretical Study on the Concept of Dropwise Condensation." International Journal of Heat and Mass Transfer 49(3):649-57. Retrieved (http://www.sciencedirect.com/science/article/pii/S0017931005005399).

51. Das, A.K., Kilty, H.P., Marto, P.J., Andeen, G.B. and Kumar, A., 2000. The use of an organic self-assembled monolayer coating to promote dropwise condensation of steam on horizontal tubes. Journal of heat transfer, 122(2), pp.278-286.

52. Beysens, Daniel. 2006. "Dew Nucleation and Growth." Comptes Rendus Physique 7(9):1082-1100. Retrieved (http://www.sciencedirect.com/science/article/pii/S1631070506002325).

53. FEVRE, LE and E. J. 1966. "A Theory of Heat Transfer by Dropwise Condensation." 3rd International Heat Transfer Conference, 1966 2:362-75. Retrieved March 5, 2018 (http://ci.nii.ac.jp/naid/10030920523/en/).

54. Tanaka, Hiroaki. 1975. "A Theoretical Study of Dropwise Condensation." Journal of Heat Transfer 97(1):72-78. Retrieved (http://dx.doi.org/10.1115/1.3450291).

55. Kim, Sunwoo and Kwang J. Kim. 2011. "Dropwise Condensation Modeling Suitable for Superhydrophobic Surfaces." Journal of Heat Transfer 133(8):81502-8. Retrieved (http://dx.doi.org/10.1115/1.4003742). 
56. Miljkovic, Nenad, Ryan Enright, and Evelyn N. Wang. 2013. "Modeling and Optimization of Superhydrophobic Condensation." Journal of Heat Transfer 135(11):111004-14. Retrieved (http://dx.doi.org/10.1115/1.4024597).

57. Beysens, D., A. Steyer, P. Guenoun, D. Fritter, and C. M. Knobler. 1991. "How Does Dew Form?" Phase Transitions 31(1-4):219-46. Retrieved (https://doi.org/10.1080/01411599108206932).

58. Fritter, Daniela, Charles M. Knobler, and Daniel A. Beysens. 1991. "Experiments and Simulation of the Growth of Droplets on a Surface (Breath Figures)." Physical Review A 43(6):2858-69. Retrieved (https://link.aps.org/doi/10.1103/PhysRevA.43.2858).

59. Rose, J. W. 1967. “On the Mechanism of Dropwise Condensation.” International Journal of Heat and Mass Transfer 10(6):755-62. Retrieved (http://www.sciencedirect.com/science/article/pii/0017931067901354).

60. Rose, J. W. 1976. "Further Aspects of Dropwise Condensation Theory." International Journal of Heat and Mass Transfer 19(12):1363-70. Retrieved (http://www.sciencedirect.com/science/article/pii/0017931076900648).

61. Rose, J. W. 1981. "Dropwise Condensation Theory." International Journal of Heat and Mass Transfer 24(2):191-94. Retrieved (http://www.sciencedirect.com/science/article/pii/0017931081900260).

62. Merte, Herman. 1973. “Condensation Heat Transfer.” Pp. 181-272 in, vol. 9, edited by T. F. Irvine and J. P. B. T.-A. in H. T. Hartnett. Elsevier. Retrieved (http://www.sciencedirect.com/science/article/pii/S0065271708700637).

63. Ma, X., Zhou, X.D., Lan, Z., Song, T.Y. and Ji, J., 2007. Experimental investigation of enhancement of dropwise condensation heat transfer of steam-air mixture: falling droplet effect. Journal of enhanced heat transfer, 14(4).

64. Ma, Xue-hu. 2003. “CONDENSATION HEAT TRANSFER OF STEAM ON VERTICAL DROPWISE AND FILMWISE COEXISTING SURFACES WITH A THICK ORGANIC FILM PROMOTING DROPWISE MODE." Experimental Heat Transfer 16(4):239-53. Retrieved (https://www.tandfonline.com/doi/abs/10.1080/08916150390223065).

65. 马学虎, 陈嘉宾, 徐敦颀 and 林纪方, 2001. Heat transfer characteristics of dropwise condensation of steam on vertical polymer coated plates. 中国化学工程学报: 英文版, 9(1), pp.17-21.

66. Tanner, D. W., D. Pope, C. J. Potter, and D. West. 1968. "Heat Transfer in Dropwise Condensation at Low Steam Pressures in the Absence and Presence of Non-Condensable Gas." International Journal of Heat and Mass Transfer 11(2):181-90. Retrieved (http://www.sciencedirect.com/science/article/pii/0017931068901488).

67. Stylianou, S. A. and J. W. Rose. 1983. "Drop-to-Filmwise Condensation Transition: Heat Transfer Measurements for Ethanediol." International Journal of 
Heat and Mass Transfer 26(5):747-60. Retrieved (http://www.sciencedirect.com/science/article/pii/0017931083900261).

68. Kim, Ho-Young, Heon Ju Lee, and Byung Ha Kang. 2002. "Sliding of Liquid Drops Down an Inclined Solid Surface." Journal of Colloid and Interface Science 247(2):372-80. Retrieved (http://www.sciencedirect.com/science/article/pii/S0021979701981561).

69. DIMITRAKOPOULOS, P. and J. J. L. HIGDON. 1999. “On the Gravitational Displacement of Three-Dimensional Fluid Droplets from Inclined Solid Surfaces." Journal of Fluid Mechanics 395:181-209. Retrieved (https://www.cambridge.org/core/article/on-the-gravitational-displacement-ofthreedimensional-fluid-droplets-from-inclined-solidsurfaces/51643A858BBD07EF84C58213D174B8D5).

70. Sikarwar, Basant Singh, Sameer Khandekar, Smita Agrawal, Sumeet Kumar, and K. Muralidhar. 2012. "Dropwise Condensation Studies on Multiple Scales." Heat Transfer Engineering 33(4-5):301-41. Retrieved (https://doi.org/10.1080/01457632.2012.611463).

71. Holden, K. M., A. S. Wanniarachchi, P. J. Marto, D. H. Boone, and J. W. Rose. 1987. "The Use of Organic Coatings to Promote Dropwise Condensation of Steam." Journal of Heat Transfer 109(3):768-74. Retrieved (http://dx.doi.org/10.1115/1.3248156).

72. Ma, Xuehu, John W. Rose, Dunqi Xu, Jifang Lin, and Buxuan Wang. 2000. "Advances in Dropwise Condensation Heat Transfer: Chinese Research." Chemical Engineering Journal 78(2):87-93. Retrieved (http://www.sciencedirect.com/science/article/pii/S1385894700001558).

73. Cassie, A. B. D. and S. Baxter. 1944. "Wettability of Porous Surfaces." Transactions of the Faraday Society 40(0):546-51. Retrieved (http://dx.doi.org/10.1039/TF9444000546).

74. Narhe, R. D. and D. A. Beysens. 2004. "Nucleation and Growth on a Superhydrophobic Grooved Surface." Phys. Rev. Lett. 93(7):76103. Retrieved (https://link.aps.org/doi/10.1103/PhysRevLett.93.076103).

75. Beysens, R. D.Narhe and D. A. 2006. "Water Condensation on a SuperHydrophobic Spike Surface." EPL (Europhysics Letters) 75(1):98. Retrieved (http://stacks.iop.org/0295-5075/75/i=1/a=098).

76. Narhe, R. D. and D. A. Beysens. 2007. "Growth Dynamics of Water Drops on a Square-Pattern Rough Hydrophobic Surface.” Langmuir 23(12):6486-89. Retrieved (https://doi.org/10.1021/la062021y).

77. Varanasi, Kripa K., Ming Hsu, Nitin Bhate, Wensha Yang, and Tao Deng. 2009. "Spatial Control in the Heterogeneous Nucleation of Water." Applied Physics Letters 95(9):94101. Retrieved (https://doi.org/10.1063/1.3200951). 
78. Wenzel, R.N., 1936. Resistance of solid surfaces to wetting by water. Industrial \& Engineering Chemistry, 28(8), pp.988-994.

79. Dorrer, Christian and Jürgen Rühe. 2007. "Condensation and Wetting Transitions on Microstructured Ultrahydrophobic Surfaces." Langmuir 23(7):3820-24. Retrieved (https://doi.org/10.1021/la063130f).

80. Chen, Chuan-Hua et al. 2007. "Dropwise Condensation on Superhydrophobic Surfaces with Two-Tier Roughness." Applied Physics Letters 90(17):173108. Retrieved (https://doi.org/10.1063/1.2731434).

81. Wen, Rongfu et al. 2017. "Hydrophobic Copper Nanowires for Enhancing Condensation Heat Transfer." Nano Energy 33:177-83. Retrieved (http://www.sciencedirect.com/science/article/pii/S2211285517300186).

82. Mouterde, Timothée et al. 2017. "Antifogging Abilities of Model Nanotextures." Nature Materials 16:658. Retrieved (http://dx.doi.org/10.1038/nmat4868).

83. Mandsberg, Nikolaj Kofoed and Rafael Taboryski. 2017. "Spatial Control of Condensation on Chemically Homogeneous Pillar-Built Surfaces." Langmuir 33(21):5197-5203. Retrieved (https://doi.org/10.1021/acs.langmuir.7b01159).

84. Xie, Jian, Jinliang Xu, Xiaotian He, and Qi Liu. 2017. "Large Scale Generation of Micro-Droplet Array by Vapor Condensation on Mesh Screen Piece." Scientific Reports 7:39932. Retrieved (http://dx.doi.org/10.1038/srep39932).

85. Nam, Youngsuk and Y.Sungtaek Ju. 2008. "Comparative Study of Copper Oxidation Schemes and Their Effects on Surface Wettability." (48715):1833-38. Retrieved (http://dx.doi.org/10.1115/IMECE2008-67492).

86. Varanasi, Kripa K., Ming Hsu, Nitin Bhate, Wensha Yang, and Tao Deng. 2009. "Spatial Control in the Heterogeneous Nucleation of Water." Applied Physics Letters 95(9):94101. Retrieved (https://doi.org/10.1063/1.3200951).

87. Jun Lee, Seung, Sanghyun Lee, and Kwan Hyoung Kang. 2012. "Droplet Jumping by Electrowetting and Its Application to the Three-Dimensional Digital Microfluidics." Applied Physics Letters 100(8):81604. Retrieved (https://doi.org/10.1063/1.3688487).

88. Boreyko, Jonathan B. and Chuan-Hua Chen. 2009. "Self-Propelled Dropwise Condensate on Superhydrophobic Surfaces." Physical Review Letters 103(18):184501. Retrieved (https://link.aps.org/doi/10.1103/PhysRevLett.103.184501).

89. Dietz, C., K. Rykaczewski, A. G. Fedorov, and Y. Joshi. 2010. "Visualization of Droplet Departure on a Superhydrophobic Surface and Implications to Heat Transfer Enhancement during Dropwise Condensation." Applied Physics Letters 97(3):33104. Retrieved (https://doi.org/10.1063/1.3460275).

90. Enright, Ryan, Nenad Miljkovic, Jorge L. Alvarado, Kwang Kim, and John W. Rose. 2014. "Dropwise Condensation on Micro- and Nanostructured Surfaces." 
Nanoscale and Microscale Thermophysical Engineering 18(3):223-50. Retrieved (https://doi.org/10.1080/15567265.2013.862889).

91. Enright, Ryan, Nenad Miljkovic, Nicholas Dou, Youngsuk Nam, and Evelyn N. Wang. 2013. "Condensation on Superhydrophobic Copper Oxide Nanostructures." Journal of Heat Transfer 135(9):91304-12. Retrieved (http://dx.doi.org/10.1115/1.4024424).

92. Miljkovic, Nenad et al. 2013. "Jumping-Droplet-Enhanced Condensation on Scalable Superhydrophobic Nanostructured Surfaces." Nano Letters 13(1):179_ 87. Retrieved (https://doi.org/10.1021/nl303835d).

93. Miljkovic, N., Enright, R., \& Wang, E. N. (2012). Effect of Droplet Morphology on Growth Dynamics and Heat Transfer during Condensation on Superhydrophobic Nanostructured Surfaces. ACS Nano, 6(2), 1776-1785. https://doi.org/10.1021/nn205052a

94. Rykaczewski, Konrad et al. 2013. "Multimode Multidrop Serial Coalescence Effects during Condensation on Hierarchical Superhydrophobic Surfaces." Langmuir 29(3):881-91. Retrieved (https://doi.org/10.1021/1a304264g).

95. Feng, Jie, Zhaoqian Qin, and Shuhuai Yao. 2012. "Factors Affecting the Spontaneous Motion of Condensate Drops on Superhydrophobic Copper Surfaces." Langmuir 28(14):6067-75. Retrieved (https://doi.org/10.1021/la300609f).

96. Wisdom, Katrina M. et al. 2013. "Self-Cleaning of Superhydrophobic Surfaces by Self-Propelled Jumping Condensate." Proceedings of the National Academy of Sciences 110(20):7992 LP-7997. Retrieved (http://www.pnas.org/content/110/20/7992.abstract).

97. Chen, Xuemei et al. 2011. "Nanograssed Micropyramidal Architectures for Continuous Dropwise Condensation." Advanced Functional Materials 21(24):4617-23. Retrieved (http://dx.doi.org/10.1002/adfm.201101302).

98. Miljkovic, Nenad, Daniel J. Preston, Ryan Enright, and Evelyn N. Wang. 2014. "Jumping-Droplet Electrostatic Energy Harvesting." Applied Physics Letters 105(1):13111. Retrieved (https://doi.org/10.1063/1.4886798).

99. Miljkovic, Nenad, Daniel J. Preston, Ryan Enright, and Evelyn N. Wang. 2013. "Electric-Field-Enhanced Condensation on Superhydrophobic Nanostructured Surfaces." ACS Nano 7(12):11043-54. Retrieved (https://doi.org/10.1021/nn404707j).

100. Boreyko, Jonathan B., Yuejun Zhao, and Chuan-Hua Chen. 2011. "Planar Jumping-Drop Thermal Diodes.” Applied Physics Letters 99(23):234105. Retrieved (https://doi.org/10.1063/1.3666818).

101. Boreyko, Jonathan B. and C.Patrick Collier. 2013. "Delayed Frost Growth on Jumping-Drop Superhydrophobic Surfaces." ACS Nano 7(2):1618-27. Retrieved (https://doi.org/10.1021/nn3055048). 
102. Chen, Xuemei et al. 2013. "Activating the Microscale Edge Effect in a Hierarchical Surface for Frosting Suppression and Defrosting Promotion."

Scientific Reports 3:2515. Retrieved (http://dx.doi.org/10.1038/srep02515).

103. Zhang, Q., He, M., Chen, J., Wang, J., Song, Y. and Jiang, L., 2013. "Anti-icing surfaces based on enhanced self-propelled jumping of condensed water microdroplets." Chemical communications, 49(40), pp.4516-4518.

104. Colburn, A. P., \& Hougen, O. A. (1934). "Design of cooler condensers for mixtures of vapors with noncondensing gases." Industrial \& Engineering Chemistry, 26(11), 1178-1182.

105. Allen, D. T.; Shonnard, D. R.Green, (2001), "Engineering:

Environmentally Conscious Design of Chemical Processes", 1st ed.; Pearson Education: NJ

106. Dincer, I, 2017, "Refrigeration Systems and Applications", 3rd ed.; John Wiley \& Sons: West Sussex, U.K.

107. Lim, Wonsub, Kwangho Choi, and Il Moon. 2013. "Current Status and Perspectives of Liquefied Natural Gas (LNG) Plant Design.” Industrial \&

Engineering Chemistry Research 52(9):3065-88. Retrieved (https://doi.org/10.1021/ie302877g).

108. Chen, Jianyong and Jianlin Yu. 2008. "Performance of a New Refrigeration Cycle Using Refrigerant Mixture R32/R134a for Residential AirConditioner Applications." Energy and Buildings 40(11):2022-27. Retrieved (http://www.sciencedirect.com/science/article/pii/S037877880800114X).

109. Park, Ki-Jung, Taebeom Seo, and Dongsoo Jung. 2007. "Performance of Alternative Refrigerants for Residential Air-Conditioning Applications." Applied Energy 84(10):985-91. Retrieved (http://www.sciencedirect.com/science/article/pii/S0306261907000566).

110. Wong, Tak-Sing et al. 2011. "Bioinspired Self-Repairing Slippery Surfaces with Pressure-Stable Omniphobicity." Nature 477:443. Retrieved (http://dx.doi.org/10.1038/nature10447).

111. Lafuma, A.; Quéré, D., 2011, "Slippery Pre-suffused Surfaces", Europhys. Lett. 2011, 965600110.1209/0295-5075/96/56001

112. Smith, J. D.; Dhiman, R.; Anand, S.; Reza-Garduno, E.; Cohen, R. E.; McKinley, G. H.; Varanasi, K. K., 2013, "Droplet Mobility on Lubricantimpregnated Surfaces", Soft Matter, 2013, 9, 1772-178010.1039/C2SM27032C

113. Solomon, B. R.; Subramanyam, S. B.; Farnham, T. A.; Khalil, K. S.; Anand, S.; Varanasi, K. K., 2016, "Non-wettable Surfaces"; Royal Society of Chemistry: UK, 2016; Chapter 10, pp 285-318a

114. Weisensee, Patricia B. et al. 2017. "Condensate Droplet Size Distribution on Lubricant-Infused Surfaces." International Journal of Heat and Mass Transfer 
109:187-99. Retrieved

(http://www.sciencedirect.com/science/article/pii/S0017931016334925).

115. Rykaczewski, Konrad et al. 2014. "Dropwise Condensation of Low Surface Tension Fluids on Omniphobic Surfaces." Scientific Reports 4:4158. Retrieved (http://dx.doi.org/10.1038/srep04158).

116. Sett, Soumyadip, Xiao Yan, George Barac, Leslie W. Bolton, and Nenad Miljkovic. 2017. "Lubricant-Infused Surfaces for Low-Surface-Tension Fluids: Promise versus Reality." ACS Applied Materials \& Interfaces 9(41):36400-408. Retrieved (https://doi.org/10.1021/acsami.7b10756).

117. Citakoglu, E. and J. W. Rose. 1968. "Dropwise Condensation-some Factors Influencing the Validity of Heat-Transfer Measurements." International Journal of Heat and Mass Transfer 11(3):523-37. Retrieved (http://www.sciencedirect.com/science/article/pii/001793106890094X).

118. Sparrow, E. M. and E. R. G. Eckert. 1961. "Effects of Superheated Vapor and Noncondensable Gases on Laminar Film Condensation." AIChE Journal 7(3):473-77. Retrieved (http://dx.doi.org/10.1002/aic.690070326).

119. Denny, V. E., A. F. Mills, and V. J. Jusionis. 1971. "Laminar Film Condensation From a Steam-Air Mixture Undergoing Forced Flow Down a Vertical Surface." Journal of Heat Transfer 93(3):297-304. Retrieved (http://dx.doi.org/10.1115/1.3449814).

120. Wang, Chad-Yang and Chuan-Jing Tu. 1988. "Effects of NonCondensable Gas on Laminar Film Condensation in a Vertical Tube." International Journal of Heat and Mass Transfer 31(11):2339-45. Retrieved (http://www.sciencedirect.com/science/article/pii/0017931088901652).

121. Kageyama, T., P. F. Peterson, and V. E. Schrock. 1993. "Diffusion Layer Modeling for Condensation in Vertical Tubes with Noncondensable Gases." Nuclear Engineering and Design 141(1):289-302. Retrieved (http://www.sciencedirect.com/science/article/pii/002954939390107K).

122. Thiel, Gregory P. and John H. Lienhard. 2012. "Entropy Generation in Condensation in the Presence of High Concentrations of Noncondensable Gases." International Journal of Heat and Mass Transfer 55(19):5133-47. Retrieved (http://www.sciencedirect.com/science/article/pii/S0017931012003274).

123. Taitel, Yehuda and Abraham Tamir. 1969. "Condensation in the Presence of a Noncondensable Gas in Direct Contact." International Journal of Heat and Mass Transfer 12(9):1157-69. Retrieved (http://www.sciencedirect.com/science/article/pii/0017931069901227).

124. Tamir, Abraham and Yehuda Taitel. 1970. "Condensation of Steam in a Channel Flow in the Presence of Noncondensable Gases with Surface Resistance." Desalination 8(3):293-306. Retrieved (http://www.sciencedirect.com/science/article/pii/S0011916400802350). 
125. Chang, Ki. I. and Donald L. Spencer. 1971. "Effect of Regularly Spaced Surface Ridges on Film Condensation Heat Transfer Coefficients for Condensation in the Presence of Noncondensable Gas." International Journal of Heat and Mass Transfer 14(3):502-5. Retrieved (http://www.sciencedirect.com/science/article/pii/0017931071901700).

126. Denny, V. E. and V. J. Jusionis. 1972. "Effects of Noncondensable Gas and Forced Flow on Laminar Film Condensation." International Journal of Heat and Mass Transfer 15(2):315-26. Retrieved (http://www.sciencedirect.com/science/article/pii/0017931072900774).

127. Yasuo, Mori and Hijikata kunio. 1973. "Free Convective Condensation Heat Transfer with Noncondensable Gas on a Vertical Surface." International Journal of Heat and Mass Transfer 16(12):2229-40. Retrieved (http://www.sciencedirect.com/science/article/pii/0017931073900094).

128. Saddy, M. and F. V Del Pozo. 1974. "Enhancement of Condensation Heat Transfer in the Presence of Noncondensable by Viscous Dissipation." International Journal of Heat and Mass Transfer 17(8):933-43. Retrieved (http://www.sciencedirect.com/science/article/pii/0017931074901604).

129. Corradini, Michael L. 1984. "Turbulent Condensation on a Cold Wall in the Presence of a Noncondensable Gas." Nuclear Technology 64(2):186-95. Retrieved (https://doi.org/10.13182/NT84-A33341).

130. Peterson, P. F., V. E. Schrock, and T. Kageyama. 1993. "Diffusion Layer Theory for Turbulent Vapor Condensation With Noncondensable Gases." Journal of Heat Transfer 115(4):998-1003. Retrieved (http://dx.doi.org/10.1115/1.2911397). 


\section{A Calculations}

The calculations used for various parameters in this document are provided in the sections below.

\section{A.1 Calculation of Capillary Length for Novec 7100}

The major factors for determining the width of the channels for the condensation surface has been the capillary length of the working fluid. The width of the channels is designed such that it is always greater than the capillary length of the fluid, such that the fluid will not tend to remain in the channels and will flow down due to gravity. Both the condensation surfaces fabricated have been designed for Novec 7100 fluid. The calculation of the capillary length for Novec 7100 fluid is as shown below.

$$
L_{c}=\sqrt{\frac{\sigma}{\left(\rho_{l}-\rho_{v}\right) \times g}}=\sqrt{\frac{0.0136}{(1510-10.535) \times 9.81}}=0.000961539 \mathrm{~m}
$$

Hence the capillary length of Novec 7100 fluid is determined to be $0.9615 \mathrm{~mm}$..

\section{A.2 Calculation of Meniscus Profile for Novec 7100}

Another factor affecting the behavior of the working fluid in the channels of the condensation surface is the meniscus formed by the fluid in the channels. Since no literature is available to determine the meniscus profile of a liquid in a vertical channel with porous walls in the presence of gravity, we have used a conventional formula to determine the meniscus profile of Novec 7100 fluid in a horizontal channel with solid 
walls, to at least obtain a general idea of the meniscus dimensions. The equation used to determine the meniscus is shown below:

$\frac{y}{L_{c}}=\cosh ^{-1}\left(\frac{2 L_{c}}{z}\right)-\cosh ^{-1}\left(\frac{2 L_{c}}{z_{0}}\right)+\left(4+\frac{z_{0}^{2}}{L_{c}{ }^{2}}\right)^{\frac{1}{2}}-\left(4+\frac{z^{2}}{L_{c}{ }^{2}}\right)^{\frac{1}{2}}$

By solving this nonlinear O.D.E., we obtain the shape of the interface as shown in Figure 2.1. 


\section{B Copyright documentation}

All images in the Introduction Section have been used in this thesis after obtaining official permissions from the respective journals. All copyrighted images have been provided with appropriate citations to credit the respective journals and authors.

Figure 1.1, Narhe, R. D. and D. A. Beysens. 2007. "Growth Dynamics of Water Drops on a Square-Pattern Rough Hydrophobic Surface." Langmuir 23(12):6486-89. Retrieved (https://doi.org/10.1021/la062021y). Reprinted (adapted) with permission from (Mandsberg, Nikolaj Kofoed and Rafael Taboryski. 2017. "Narhe, R. D. and D. A. Beysens. 2007. "Growth Dynamics of Water Drops on a Square-Pattern Rough Hydrophobic Surface." Langmuir 23(12):6486-89. Retrieved (https://doi.org/10.1021/la062021y)). Copyright (2007) American Chemical Society."

Figure 1.2, Figure 1.3, Chen, Chuan-Hua et al. 2007. "Dropwise Condensation on Superhydrophobic Surfaces with Two-Tier Roughness." Applied Physics Letters 90(17):173108. Retrieved (https://doi.org/10.1063/1.2731434). Permission purchase order number: 4313910309149

Figure 1.4, Figure 1.5, Wen, Rongfu et al. 2017. "Hydrophobic Copper Nanowires for Enhancing Condensation Heat Transfer." Nano Energy 33:177-83. Retrieved (http://www.sciencedirect.com/science/article/pii/S2211285517300186). Permission purchase order number: 4313910799672

Figure 1.6, Mouterde, Timothée et al. 2017. "Antifogging Abilities of Model Nanotextures." Nature Materials 16:658. Retrieved (http://dx.doi.org/10.1038/nmat4868). Permission purchase order number: 4313911009760

Figure 1.7, Mandsberg, Nikolaj Kofoed and Rafael Taboryski. 2017. "Spatial Control of Condensation on Chemically Homogeneous Pillar-Built Surfaces." Langmuir 33(21):5197-5203. Retrieved (https://doi.org/10.1021/acs.langmuir.7b01159). Reprinted (adapted) with permission from (Mandsberg, Nikolaj Kofoed and Rafael Taboryski. 2017. "Spatial Control of Condensation on Chemically Homogeneous Pillar-Built Surfaces." Langmuir 33(21):5197-5203. (https://doi.org/10.1021/acs.langmuir.7b01159)). Copyright (2017) American Chemical Society."

Figure 1.8, Figure 1.9, Figure 1.10, Xie, Jian, Jinliang Xu, Xiaotian He, and Qi Liu. 2017. "Large Scale Generation of Micro-Droplet Array by Vapor Condensation on Mesh Screen Piece." Scientific Reports 7:39932. Retrieved (http://dx.doi.org/10.1038/srep39932). Only citation required. 
Figure 1.11, Varanasi, Kripa K., Ming Hsu, Nitin Bhate, Wensha Yang, and Tao Deng. 2009. "Spatial Control in the Heterogeneous Nucleation of Water." Applied Physics Letters 95(9):94101. Retrieved (https://doi.org/10.1063/1.3200951). Permission purchase order number: 4313911361003

Figure 1.12, Jun Lee, Seung, Sanghyun Lee, and Kwan Hyoung Kang. 2012. "Droplet Jumping by Electrowetting and Its Application to the Three-Dimensional Digital Microfluidics." Applied Physics Letters 100(8):81604. Retrieved (https://doi.org/10.1063/1.3688487). Permission purchase order number: 4313920075817

Figure 1.13, Figure 1.14, Boreyko, Jonathan B. and Chuan-Hua Chen. 2009. "SelfPropelled Dropwise Condensate on Superhydrophobic Surfaces." Physical Review Letters 103(18):184501. Retrieved (https://link.aps.org/doi/10.1103/PhysRevLett.103.184501). Permission request number: RNP/18/MAR/002597

Figure 1.15, Figure 1.16, Figure 1.17, Miljkovic, Nenad et al. 2013. "Jumping-DropletEnhanced Condensation on Scalable Superhydrophobic Nanostructured Surfaces." Nano Letters 13(1):179-87. Retrieved (https://doi.org/10.1021/nl303835d). Reprinted (adapted) with permission from (Miljkovic, Nenad et al. 2013. "Jumping-Droplet-Enhanced Condensation on Scalable Superhydrophobic Nanostructured Surfaces." Nano Letters 13(1):179-87. Retrieved (https://doi.org/10.1021/nl303835d)). Copyright (2013) American Chemical Society."

Figure 1.18, Miljkovic, N., Enright, R., \& Wang, E. N. (2012). Effect of Droplet Morphology on Growth Dynamics and Heat Transfer during Condensation on Superhydrophobic Nanostructured Surfaces. ACS Nano, 6(2), 1776-1785. https://doi.org/10.1021/nn205052a. Reprinted (adapted) with permission from (Miljkovic, N., Enright, R., \& Wang, E. N. (2012). Effect of Droplet Morphology on Growth Dynamics and Heat Transfer during Condensation on Superhydrophobic Nanostructured Surfaces. ACS Nano, 6(2), 1776-1785. https://doi.org/10.1021/nn205052a). Copyright (2012) American Chemical Society."

Figure 1.19, Figure 1.20, Feng, Jie, Zhaoqian Qin, and Shuhuai Yao. 2012. "Factors Affecting the Spontaneous Motion of Condensate Drops on Superhydrophobic Copper Surfaces." Langmuir 28(14):6067-75. Retrieved (https://doi.org/10.1021/la300609f). Reprinted (adapted) with permission from (Feng, Jie, Zhaoqian Qin, and Shuhuai Yao. 2012. "Factors Affecting the Spontaneous Motion of Condensate Drops on Superhydrophobic Copper Surfaces." Langmuir 28(14):6067-75. Retrieved (https://doi.org/10.1021/la300609f)). Copyright (2012) American Chemical Society."

Figure 1.21, Figure 1.22, Wisdom, Katrina M. et al. 2013. "Self-Cleaning of Superhydrophobic Surfaces by Self-Propelled Jumping Condensate." Proceedings of the National Academy of Sciences 110(20):7992 LP-7997. Retrieved (http://www.pnas.org/content/110/20/7992.abstract). Citation Provided 
Figure 1.23, Figure 1.24, Figure 1.25, Chen, Xuemei et al. 2011. "Nanograssed Micropyramidal Architectures for Continuous Dropwise Condensation." Advanced Functional Materials 21(24):4617-23. $\quad$ Retrieved (http://dx.doi.org/10.1002/adfm.201101302). Permission purchase order number: 4316370911762

Figure 1.26, Boreyko, Jonathan B., Yuejun Zhao, and Chuan-Hua Chen. 2011. "Planar Jumping-Drop Thermal Diodes." Applied Physics Letters 99(23):234105. Retrieved (https://doi.org/10.1063/1.3666818). Permission purchase order number: 4316371049743

Figure 1.27, Boreyko, Jonathan B. and C.Patrick Collier. 2013. "Delayed Frost Growth on Jumping-Drop Superhydrophobic Surfaces." ACS Nano 7(2):1618-27. Retrieved (https://doi.org/10.1021/nn3055048). Reprinted (adapted) with permission from (Boreyko, Jonathan B. and C.Patrick Collier. 2013. "Delayed Frost Growth on JumpingDrop Superhydrophobic Surfaces." ACS Nano 7(2):1618-27. Retrieved (https://doi.org/10.1021/nn3055048)). Copyright (2013) American Chemical Society."

Figure 1.28, Chen, Xuemei et al. 2013. "Activating the Microscale Edge Effect in a Hierarchical Surface for Frosting Suppression and Defrosting Promotion." Scientific Reports 3:2515. Retrieved (http://dx.doi.org/10.1038/srep02515). Only citation required.

Figure 1.29, Rykaczewski, Konrad et al. 2014. "Dropwise Condensation of Low Surface Tension Fluids on Omniphobic Surfaces." Scientific Reports 4:4158. Retrieved (http://dx.doi.org/10.1038/srep04158). Only citation required

Figure 1.30, Figure 1.31, Sett, Soumyadip, Xiao Yan, George Barac, Leslie W. Bolton, and Nenad Miljkovic. 2017. "Lubricant-Infused Surfaces for Low-Surface-Tension Fluids: Promise versus Reality." ACS Applied Materials \& Interfaces 9(41):36400-408. Retrieved (https://doi.org/10.1021/acsami.7b10756). Reprinted (adapted) with permission from (Sett, Soumyadip, Xiao Yan, George Barac, Leslie W. Bolton, and Nenad Miljkovic. 2017. "Lubricant-Infused Surfaces for Low-Surface-Tension Fluids: Promise versus Reality." ACS Applied Materials \& Interfaces 9(41):36400-408. Retrieved (https://doi.org/10.1021/acsami.7b10756)). Copyright (2017) American Chemical Society." 